Celso Olivete Júnior

\title{
Estimativa da Idade Óssea Através da Análise Carpal Baseada na Simplificação do Método de Eklof \& Ringertz
}

Dissertação apresentada à Escola de Engenharia de São Carlos da Universidade de São Paulo, como parte dos requisitos para a obtenção do titulo de Mestre em Engenharia Elétrica.

Orientador: Prof. Dr. Evandro Luis Linhari Rodrigues

São Carlos

2005 


\section{"Sonho que se sonha só \\ É só um sonho que se sonha só \\ Mas sonho que se sonha junto é \\ Realidade"}

(Raul Seixas)

\section{Dedico este trabalho}

Aos meus pais Celso Olivete e Cidnea Carro Olivete, que com luta, mas principalmente com muita dedicação e amor, me deram a educação sem a qual eu não teria chegado a lugar algum. "Vocês dois são o meu grande orgulho e eu quero que tudo o que eu faça em toda a minha vida sejam provas de que o pouco que vocês acham que fizeram por mim, na verdade foi muito mais do que qualquer filho no mundo poderia querer. Vocês me deram simplesmente tudo e vão estar eternamente em tudo o que eu fizer".

Aos meus irmãos Alexandre e André e à minha irmã Ana Luiza. 


\section{AGRADECIMENTOS}

Ao Prof. Dr. Evandro Luis Linhari Rodrigues, pela orientação precisa na realização dessa pesquisa, pela confiança depositada em minha pessoa, pela dedicação, colaboração e ensinamentos transmitidos, indispensáveis para a realização deste trabalho.

Ao Prof. Dr. Adilson Gonzaga pelo acompanhamento parcial do trabalho.

Ao médico Dr. Romeu Santini, do Instituto de Diagnóstico Romeu Santini, localizado na cidade de São Carlos, pelo fornecimento dos laudos das imagens radiográficas, materiais de pesquisa e acompanhamento do trabalho. Agradeço também a todos os funcionários do Instituto que de alguma forma contribuíram para a realização deste trabalho.

À todos os integrantes do LAVI, pelo companheirismo, apoio técnico e psicológico, esclarecimento de dúvidas e etc.

Ao Marcelo Zanchetta, pelo fornecimento de alguns dados referentes a radiografias e pelo esclarecimento de dúvidas.

Aos companheiros de república.

MUITO OBRIGADO A TODOS!! 


\section{RESUMO}

Olivete, J. C. (2005) Estimativa da Idade Óssea Através da Análise Carpal Baseada na Simplificação do Método de Eklof \& Ringertz. Dissertação (Mestrado) - Escola de Engenharia de São Carlos, Universidade de São Paulo, São Carlos, 2005.

Este trabalho apresenta uma metodologia semi-automática e simplificada para estimação da idade óssea baseada no método de Eklof \& Ringertz. Fundamenta-se no processamento e extração de informações de imagens radiográficas da mão, mostrando a real influência do efeito Heel nesse tipo de imagem. Apresenta resultados obtidos com a aplicação de algoritmos de thresholding, com e sem a correção do efeito Heel,e propõe uma metodologia para isolar os ossos do tecido da mão para obtenção de dimensões dos mesmos. Essas dimensões foram usadas como informações para a estimação da idade óssea de seres humanos em fase de crescimento, buscando uma simplificação do método de Eklof \& Ringertz.

Palavras - chave: Análise Carpal, Idade Óssea, Efeito Heel, Visão Computacional, Thresholding, Eklof \& Ringertz. 


\section{ABSTRACT}

Olivete, J. C. (2005), Estimative of the Skeletal Age Through of Carpal Analysis Based on the Simplification of Eklof \& Ringertz Method. M. Sc. Dissertation - Escola de Engenharia de São Carlos, Universidade de São Paulo, São Carlos, 2005.

This research presents a semi-automatic and simplified methodology to estimate skeletal age by using the Eklof \& Ringertz method. The method is based on processing and extraction of hand radiographic images information, showing the Heel effect real influence in this type of image. The results obtained with application of thresholding algorithms, with and without Heel effect correction are presented and a methodology to isolate bone from hand's tissue for dimension measurements is proposed. These dimensions were used as the information for skeletal age estimation of humans in the growth phase, on order to simplify the Eklof \& Ringertz method.

Word-Keys: Carpal Analysis, Skeletal Age, Heel Effect, Computer Vision, Thresholding, Eklof \& Ringertz. 


\section{LISTA DE FIGURAS}

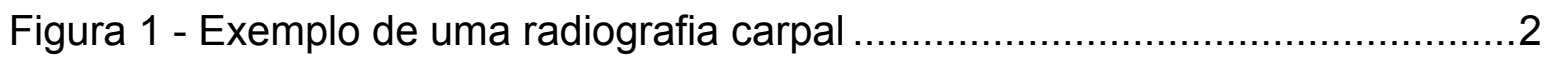

Figura 2 - Esquema anatômico dos ossos cárpicos e da mão...............................

Figura 3 - Centros de ossificação da mão e punho ..........................................10

Figura 4 - Exemplos de centros de ossificação do metacárpico I e da ulna...........11

Figura 5 - Índice de Eklof \& Ringertz, centros de ossificação utilizados ...............13

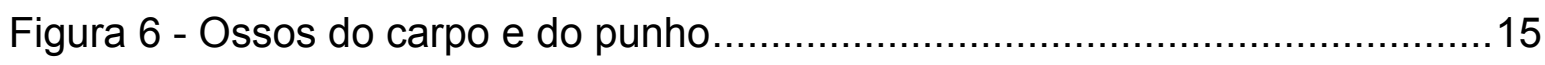

Figura 7 - Radiografia carpal ilustrando o efeito Heel ........................................16

Figura 8 - Distribuição da intensidade do feixe de raios-X ................................17

Figura 9 - Visão superficial de um tubo de raios-X ........................................18

Figura 10 - Esquema simplificado da ocorrência do efeito Heel ..........................19

Figura 11 - Projeção do ponto focal no centro e em outra posição do campo .......23

Figura 12 - Processo de emissão dos fótons pelo anodo ...................................24

Figura 13 - Divisões da matriz de fundo para determinação do eixo ânodo / cátodo .26

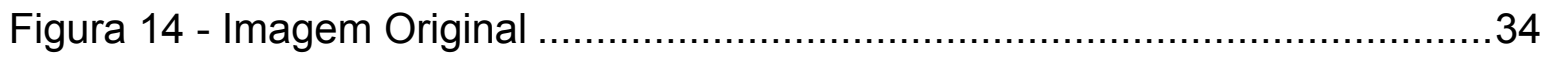

Figura 15(a,b,c,d) - Imagens processadas pelos métodos de thresholding sem a correção do efeito Heel: (a):Otsu. (b): Pun. (c): Niblack e (d): Rosenfeld ........35 Figura 16(a,b,c,d) - Imagens processadas pelos métodos de thresholding após a correção do efeito Heel: (a):Otsu. (b): Pun. (c): Niblack e (d): Rosenfeld ........37

Figura 17 - Tabelas do banco de dados. (a): mão . (b) metacárpico II...................40

Figura 18 - Centros de ossificação utilizados pelo método ...................................43

Figura 19 - Resultados obtidos utilizando os 10 centros de ossificação comparados com os laudos médicos. (a): imagens do sexo feminino . (b):

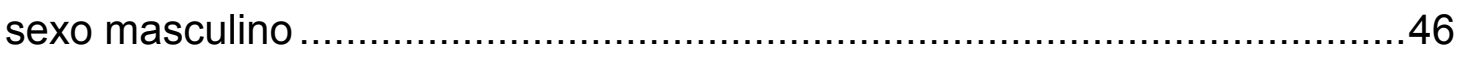

Figura 20 - Fantoma antropomórfico utilizado para realizar testes .....................47

Figura 21 - Imagem digitalizada do fantoma antropomórfico .............................48

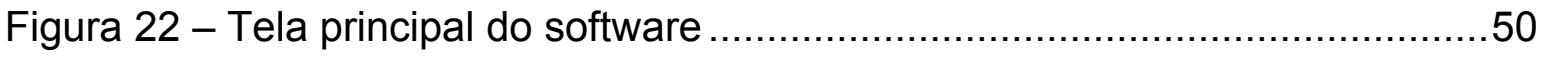

Figura 23 - (a): Imagem de entrada. (b): imagem suavizada. (c): imagem segmentada.... 
Figura 24 - Cadastro de imagens segmentadas no banco de dados .52

Figura 25 - Localizando uma imagem no banco de dados. .53

Figura 26 - (a): Marcações estimada dos centros de ossificação. (b): localização correta dos pontos utilizada por Eklof \& Ringertz .54

Figura 27 - Dimensões encontradas para os centros de ossificação .55

Figura 28 - Relatório da estimativa da idade óssea gerado pelo software 56

Figura 29 - Método completo X simplificação (5 centros de ossificação) para as imagens do sexo feminino .58

Figura 30 - Método completo X simplificação (5 centros de ossificação) para as imagens do sexo masculino. .59

Figura 31 - Gráfico das combinações em relação ao laudo médico. 61

Figura 32 - Gráfico com o somatório das combinações em todas as imagens do sexo feminino.

Figura 33 - Gráfico com o somatório das combinações em todas as imagens do sexo masculino .63

Figura 34 - Comparação entre método completo $X$ simplificação inicial ( 5 centros de ossificação) e simplificação final (3 centros) para as imagens do sexo feminino .64

Figura 35 - Comparação entre método completo $X$ simplificação inicial ( 5 centros de ossificação) e simplificação final (3 centros) para as imagens do sexo masculino.

Figura 36 - Resultados do software $X$ laudo médico para o conjunto de imagens do sexo feminino. 67

Figura 37 - Resultados do software $X$ laudo médico para o conjunto de imagens do sexo masculino .68

Figura 38 - Porcentagem de acertos do software $X$ laudo médico para o sexo masculino. 68

Figura 39 - Porcentagem de acertos do software $X$ laudo médico para o sexo feminino 
Figura 40 - (a): resultado do método completo. (b): resultado utilizando a simplificação para 5 centros de ossificação e (c): utilizando 3 centros de ossificação para as imagens do sexo feminino.

Figura 41 - (a): resultado do método completo. (b): resultado da simplificação utilizando 5 centros de ossificação e (c): utilizando 3 centros de ossificação para as imagens do sexo masculino.

Figura 42 - Linha de crescimento ósseo para os metacárpicos (II, III, IV) baseado

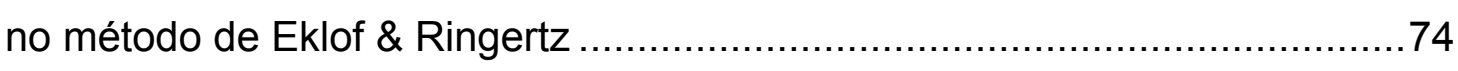

Figura 43 - Imagens carpais do sexo feminino utilizadas na Tabela $3 \ldots \ldots \ldots \ldots \ldots \ldots . . . .85$

Figura 44 - Imagens carpais do sexo masculino utilizadas na Tabela 3 ...............86

Figura 45 - Resultados obtidos por todas as combinações entre os centros de ossificação para a primeira imagem do sexo feminino ....................................89

Figura 46 - Resultados obtidos por todas as combinações entre os centros de ossificação para a segunda imagem do sexo feminino .................................90

Figura 47 - Resultados obtidos por todas as combinações entre os centros de ossificação para a terceira imagem do sexo feminino 91

Figura 48 - Resultados obtidos por todas as combinações entre os centros de ossificação para a quarta imagem do sexo feminino ...................................92

Figura 49 - Resultados obtidos por todas as combinações entre os centros de ossificação para a primeira imagem do sexo masculino.................................93

Figura 50 - Resultados obtidos por todas as combinações entre os centros de ossificação para a segunda imagem do sexo masculino ................................94

Figura 51 - Resultados obtidos por todas as combinações entre os centros de ossificação para a terceira imagem do sexo masculino...................................95

Figura 52 - Resultados obtidos por todas as combinações entre os centros de ossificação para a quarta imagem do sexo masculino .96 


\section{LISTA DE TABELAS}

Tabela 1 - Extensão para as medidas do índice de Eklof \& Ringertz, no sexo feminino

Tabela 2 - Extensão para as medidas do índice de Eklof \& Ringertz, no sexo masculino.

Tabela 3 - Idades obtidas pelo software utilizando a simplificação do método de Eklof \& Ringertz .84

Tabela 4 - Lista das combinações dos 5 centros de ossificação tomados 2 a 2 ...87 Tabela 5 - Lista das combinações dos 5 centros de ossificação tomados 3a 3 ....87

Tabela 6 - Lista das combinações dos 5 centros de ossificação tomados 4 a 4 ...88

Tabela 7 - Média obtida entre os 5 centros de ossificação ....................................88

Tabela 8 - Índice de Eklof \& Ringertz para o sexo feminino .................................97

Tabela 9 - Índice de Eklof \& Ringertz para o sexo masculino ...............................98

Tabela 10 - Pontos médios (medidas em $\mathrm{mm}$ ) e suas idades ósseas correspondentes para as medidas do índice de Eklof \& Ringertz, no sexo feminino

Tabela 11 - Pontos médios (medidas em $\mathrm{mm}$ ) e suas idades ósseas correspondentes para as medidas do índice de Eklof \& Ringertz, no sexo masculino 100 


\section{SUMÁRIO}

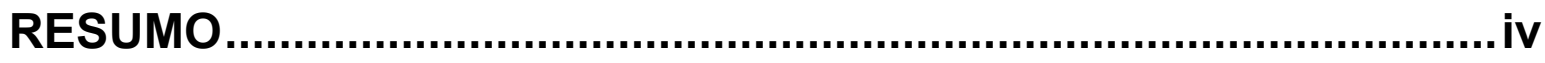

ABSTRACT ...........................................................................................

LISTA DE FIGURAS .................................................................... vi

LISTA DE TABELAS ..................................................................... ix

1 INTRODUÇÃO .....................................................................

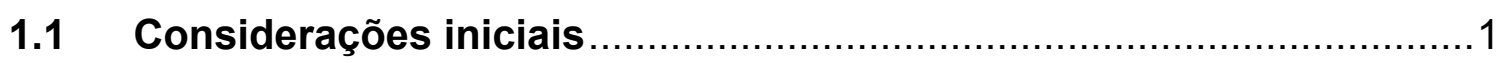

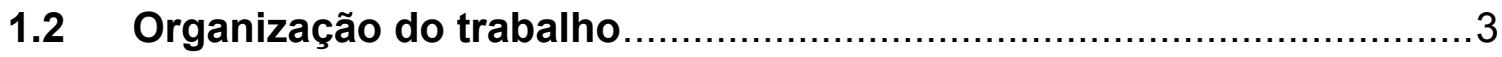

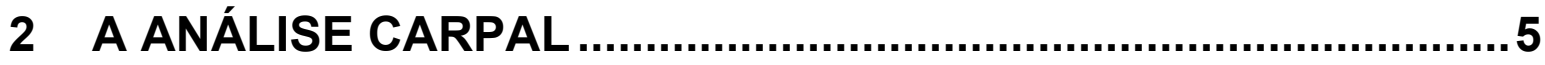

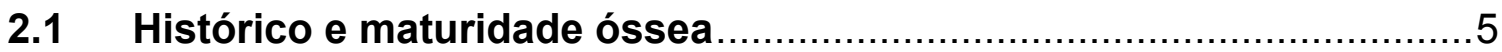

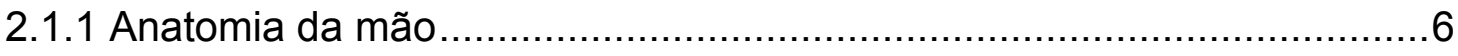

2.2 Métodos clássicos de avaliação da idade óssea ..............................

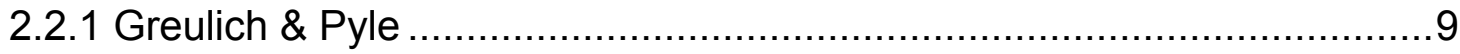

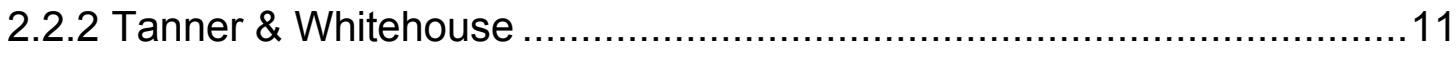

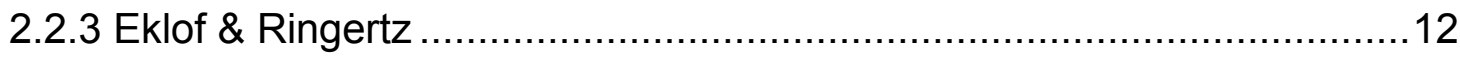

2.3 Escolha do Método de avaliação da idade óssea ............................14

3 A ANÁLISE DA RADIOGRAFIA DA MÃO ...............................15

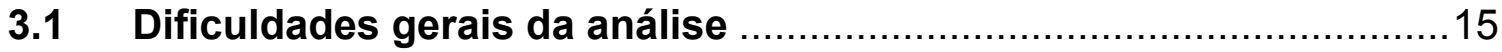

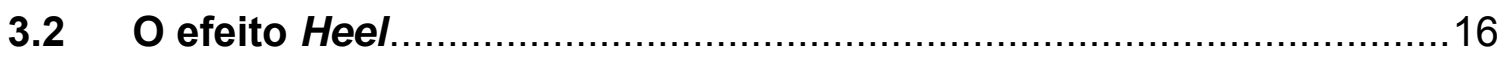

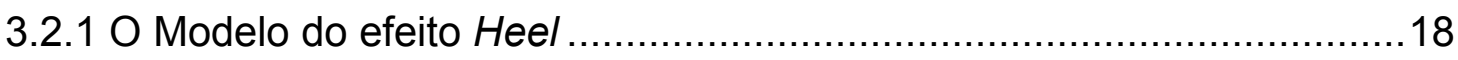

4 PROCESSAMENTO DE IMAGENS RADIOGRÁFICAS .............20

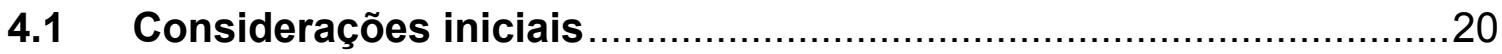

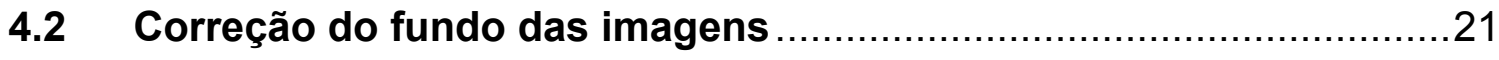

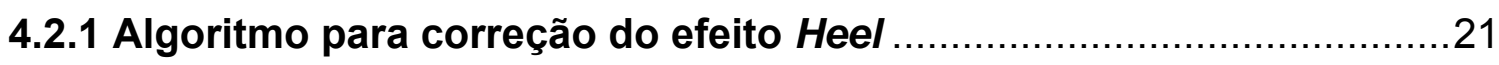

4.2.1.1 Cálculo das variações de densidades do fundo da imagem ...............22

4.2.1.2 Correção do efeito Heel na imagem ............................................25

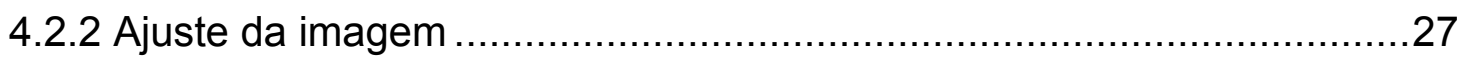

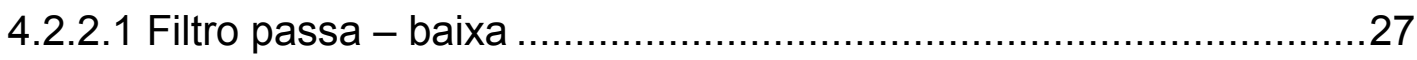

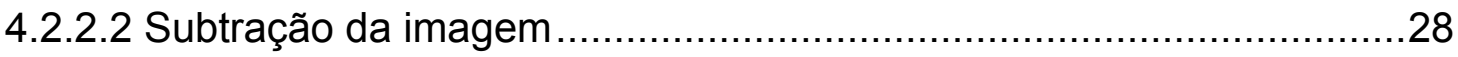




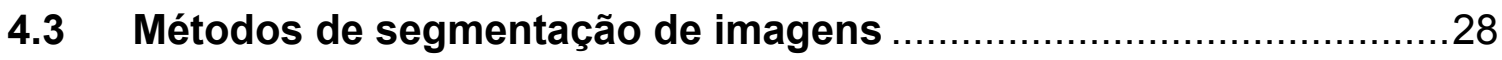

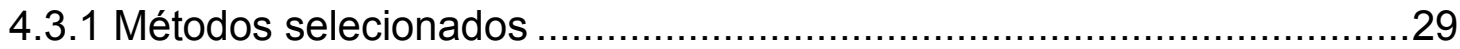

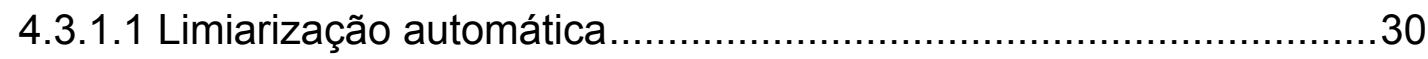

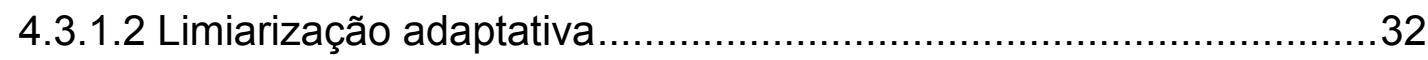

5 RESULTADOS DA SEGMENTAÇÃO ......................................... 34

5.1 Resultados sobre uma imagem sem a correção do efeito Heel............34

5.2 Resultados sobre uma Imagem após a correção do efeito Heel...........36

5.3 Conclusões sobre a segmentação................................................ 37

6 ESTIMATIVA DA IDADE ÓSSEA ..............................................40

6.1 Banco de dados de imagens e de medidas ...................................40

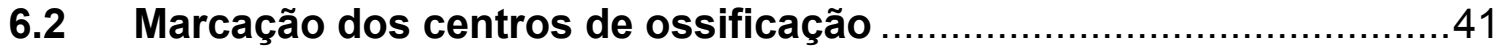

6.3 Obtenção das medidas e estimativa da idade óssea .......................44

6.4 Resultados obtidos utilizando a metodologia proposta por Eklof \&

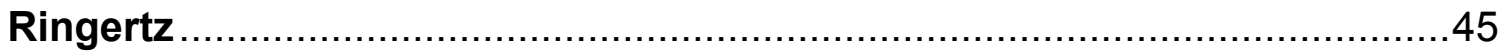

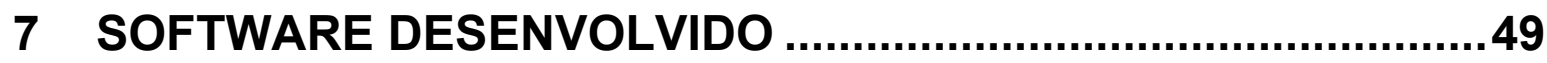

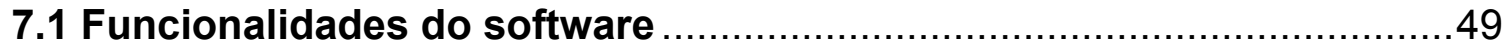

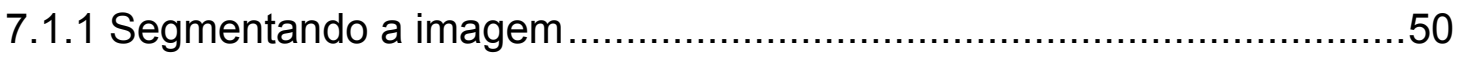

7.1.2 Cadastrando a imagem no banco de dados .......................................51

7.1.3 Localizando uma imagem no banco de dados.....................................52

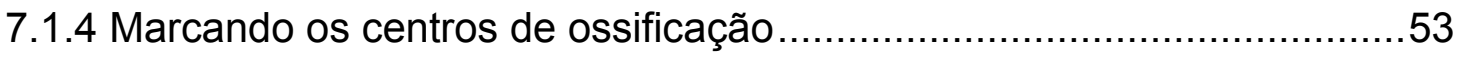

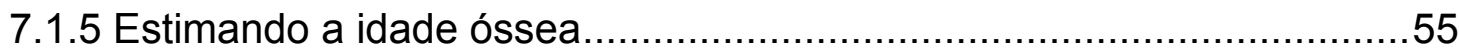

8 RESULTADOS DA SIMPLIFICAÇÃO DO MÉTODO DE EKLOF \&

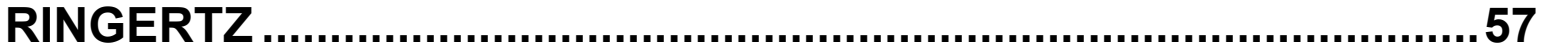

8.1 Método original $X$ simplificação proposta.........................................

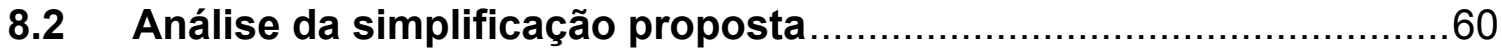

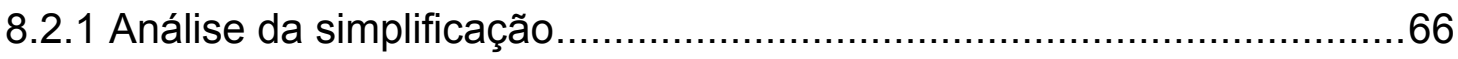

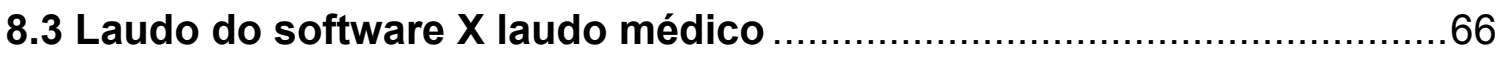

8.4 Comparações entre método original $X$ simplificações …......................70

8.5 Expandindo as medidas do método de Eklof \& Ringertz .....................73

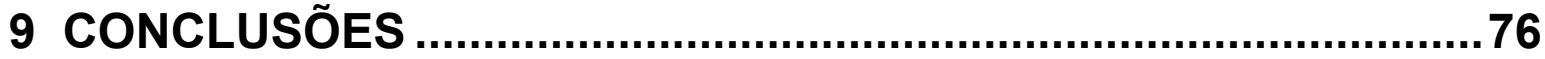


REFERÊNCIAS BIBLIOGRÁFICAS

APÊNDICE A - Lista de combinações entre os 5 centros de ossificação

APÊNDICE B - Gráficos gerados a partir das combinações para as imagens do sexo feminino 89 APÊNDICE C - Gráficos gerados a partir das combinações para as imagens do sexo masculino. 93

ANEXO A - Índices de Eklof \& Ringertz .......................................97 


\section{INTRODUÇÃO}

\subsection{Considerações iniciais}

O maior desafio na utilização de métodos de visão computacional para a obtenção de resultados satisfatórios na estimativa da idade óssea é a utilização de uma metodologia que seja capaz de obter diagnósticos computadorizados e análises quantitativas para estudos em grandes populações, com diferentes faixas etárias e contrastes. Teoricamente a estimativa da idade óssea pode ser obtida pela análise de qualquer osso do corpo humano, através de radiografias das regiões de interesse. A mão, é a região mais comumente utilizada pois trata-se de uma região de fácil acesso e também por não conter órgãos vitais, pode ser submetida a doses de radiação com mais freqüência. Utilizando imagens em nível de cinza, um dos processos mais simples para isolar os ossos do tecido da mão pode ser baseado nos níveis que os pixels das imagens apresentam. Porém, esse procedimento é comprometido pela distribuição irregular de intensidade dos raios$X$, o qual ocasiona uma iluminação não uniforme no fundo das imagens. Este efeito é conhecido por efeito Heel (BEHIELS et al., 2002).

A distribuição de intensidade depende do posicionamento relativo do dispositivo de gravação em relação à fonte dos raios- $X$, podendo variar não uniformemente entre $75 \%$ e $125 \%$ em relação ao centro de campo do aparelho de raio-X. Essas diferenças fazem com que algumas partes do filme sejam pouco sensibilizadas, enquanto outras sejam sensibilizadas em excesso, prejudicando o 
contraste necessário para a obtenção de uma boa imagem (GRATALE et al., 1990).

Atualmente existem vários métodos para a estimativa da idade óssea (TAVANO, 2001). Os métodos clássicos e mais importantes são: Greulich \& Pyle, Tanner \& Whitehouse e Eklof \& Ringertz. São os mais importantes e consistentes por apresentarem altos índices de correlação com a idade cronológica durante os estudos feitos usando crianças brasileiras. Os dois primeiros utilizam Atlas de padrões, isto é, são baseados na comparação entre as características da radiografia carpal e os padrões disponíveis no Atlas. Já o método de Eklof \& Ringertz utiliza-se de medidas de comprimento e largura de determinados centros d7e ossificação para estimar a idade óssea.

Este trabalho apresenta uma simplificação do método de Eklof \& Ringertz que será utilizada de forma semi-automática para a estimação da idade óssea. $\mathrm{O}$ método de Eklof \& Ringertz permite utilizar diretamente métodos computacionais não muito sofisticados, alcançando de uma forma simples, resultados importantes para o auxílio do acompanhamento do crescimento humano. Um outro critério importante é o fato deste método não se basear em uma análise inspecional e comparativa através do uso de Atlas. A Figura 1 ilustra uma radiografia carpal genérica.

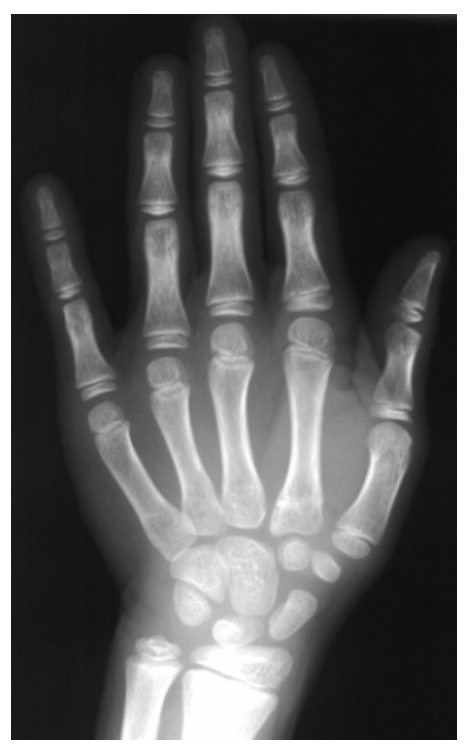

Figura 1 - Exemplo de uma radiografia carpal

Fonte: BEHIELS et al. (2002) 
Para a realização deste trabalho foram analisadas imagens de radiografias da mão esquerda (450 imagens de um banco que está sendo construído no Departamento de Engenharia Elétrica da USP - São Carlos), de pacientes do sexo masculino e feminino e com idades entre 6 e 18 anos. Essas radiografias foram obtidas em um aparelho convencional de raio-X, utilizando valores padrão para esse procedimento, ou seja, tensão de $45 \mathrm{Kv}$, corrente de $0.3 \mathrm{~mA}$ e distância focofilme de $1 \mathrm{~m}$, considerando ainda o feixe de raios- $X$ dirigido perpendicularmente ao centro do filme. Em todos os casos foi possível verificar que o fundo dessas imagens apresenta diferentes níveis de intensidade.

\subsection{Organização do trabalho}

O capítulo 2 deste trabalho apresenta os conceitos de análise carpal, anatomia da mão, maturidade óssea e os métodos clássicos de estimação da idade óssea.

No capítulo 3 são apresentadas as principais características de análise da radiografia carpal e as dificuldades gerais de análise. É apresentada uma descrição do fenômeno físico que provoca uma iluminação não uniforme nestas imagens radiográficas, conhecido por efeito Heel.

No capítulo 4 são descritas as técnicas de processamento de imagens carpais e os métodos de binarização utilizados para segmentá-las.

No capítulo 5 são apresentados os resultados da aplicação dos métodos de binarização sobre as imagens radiográficas da mão, mostrando a influência do efeito Heel.

O capítulo 6 mostra os passos utilizados pela metodologia para estimar a idade óssea, entre eles: modelo e estrutura do banco de dados, obtenção dos centros de ossificação e medidas de cada um deles e, a estimativa da idade óssea. 
O capítulo 7 é destinado para apresentar o software desenvolvido, bem como as suas funcionalidades.

Por fim, no capítulo 8 são apresentados os resultados finais utilizando a simplificação do método de Eklof \& Ringertz. 


\section{A ANÁLISE CARPAL}

\subsection{Histórico e maturidade óssea}

A análise de radiografias carpais tem sido muito utilizada para estimar a idade óssea de uma pessoa, obtendo o quanto o seu crescimento evoluiu em relação à sua maturidade óssea. A idade cronológica não é um bom critério para avaliar o desenvolvimento e o crescimento de uma pessoa, pois além de existirem as diferenças relacionadas ao sexo, existem outros fatores que podem ocorrer, como os fatores genéticos, ambientais e nutricionais.

Segundo Tanner, Whitehouse e Healvy (1959), durante a infância, o crescimento é intimamente relacionado com a idade cronológica, sofrendo um distúrbio no período da puberdade.

Uma outra maneira de se observar o crescimento e o desenvolvimento da pessoa é obtendo a idade morfológica, que consiste em comparar a altura e o peso da pessoa com tabelas e padrões existentes. Este não é um método eficaz, pois estas medidas podem variar de acordo com a raça e nacionalidade da pessoa. (BOSQUIERO et al., 2001).

Para Tavano (2001), a idade óssea tem sido o fator mais utilizado nos estudos de estimação de crescimento e desenvolvimento, obtendo resultados muito satisfatórios e, até certo ponto, seguros, quando comparados com a idade biológica. A determinação da idade óssea é obtida através da análise dos ossos da mão e do punho, onde os principais pontos de análise são: centros de ossificação, forma e fusão dos ossos. 
Segundo Tavano (2001), a maturidade óssea é determinada através da análise da radiografia da mão esquerda. Esta região tem sido muito utilizada devido à seqüência cronológica que a mesma apresenta. Os métodos utilizados são divididos em dois tipos: baseado em padrões, na qual a idade é obtida através de uma comparação visual com os padrões existentes em um Atlas como o de Todd(1937) e o método de escores, na qual cada centro de ossificação recebe um valor e no final da análise determina-se a idade comparando com uma escala de desenvolvimento.

Pode-se citar também o trabalho de Taffarel, Wangenhein e Silva(2003), que desenvolveram uma metodologia de estimação da idade óssea através da automatização do método de Tanner \& Whitehouse e o de Bosquiero et al. (2003), no qual realiza um estudo com o objetivo de verificar se os métodos de estimativa da idade óssea de Greulich \& Pyle e Tanner \& Whitehouse poderiam ser aplicados à população brasileira e qual destes métodos seria o mais confiável, quando comparados à idade cronológica do indivíduo.

Outro estudo importante foi o de Tavano (2001), em sua tese de doutorado, em 1976, na qual determinou a idade óssea de 590 crianças brasileiras, sendo 295 de cada sexo e na faixa etária de 3 a 17 anos, através dos índices de Greulich \& Pyle, Tanner \& Whitehouse (TW) e de Eklof \& Ringertz (ER), com a finalidade de verificar a possibilidade da utilização desses índices em nosso meio. Foram feitas simplificações em dois destes métodos. No método de TW, usou-se apenas os escores dos ossos cárpicos, eliminando os outros centros de ossificação. Já no ER foram modificadas as variações dimensionais de largura dos ossos utilizados. Foi provado também que estas modificações não afetaram os resultados finais.

\subsubsection{Anatomia da mão}

A mão é composta por vinte e sete ossos (Figura 2). Destes 27 ossos, 19 são alongados e localizam-se na palma da mão e nos dedos, os oito restantes são 
ossos curtos e formam o carpo, que articulados entre si, com os ossos do metacarpo, a ulna e o rádio correspondem ao punho.

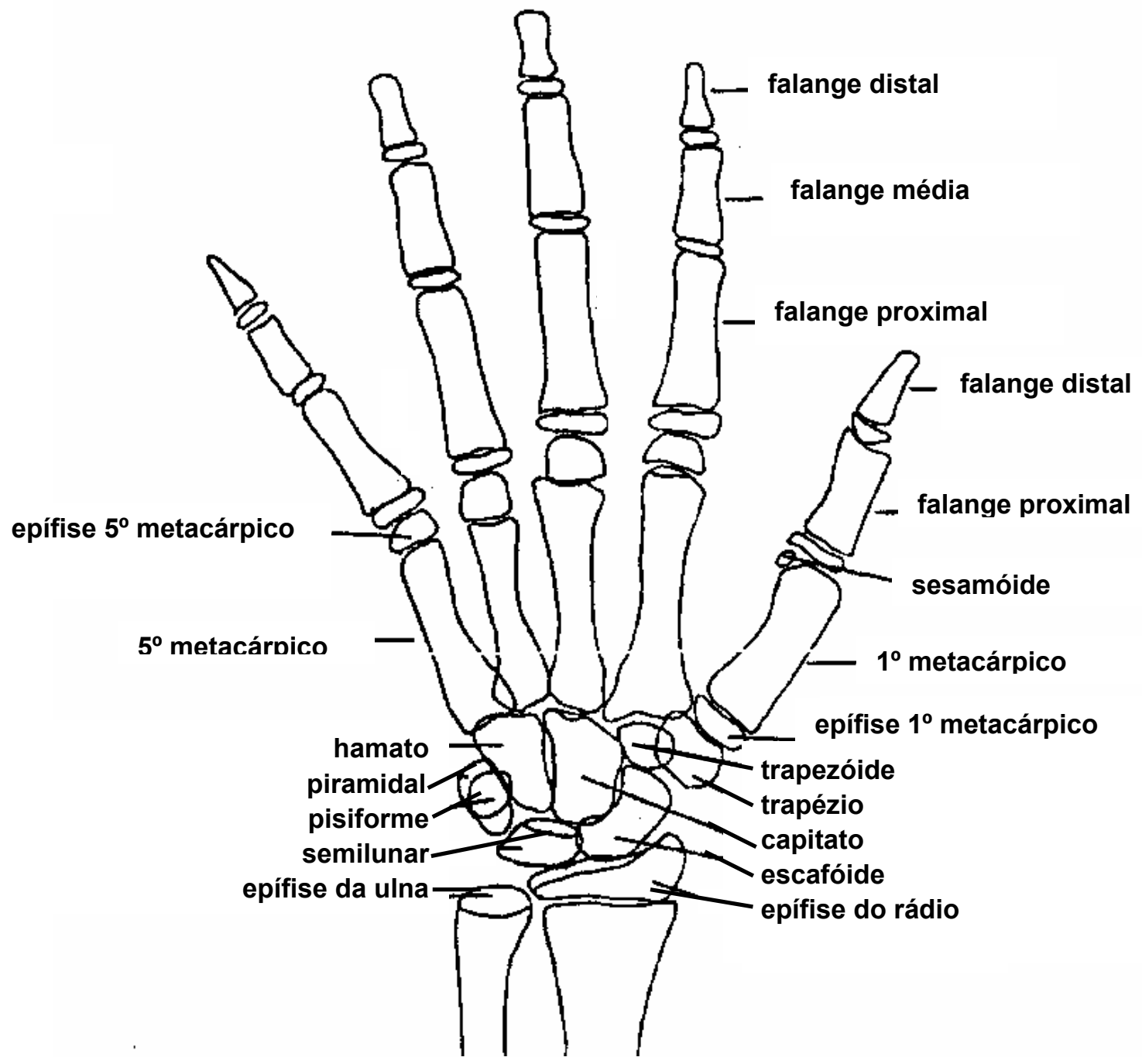

Figura 2 - Esquema anatômico dos ossos cárpicos e da mão Fonte: Tavano (2001)

O metacarpo é o conjunto de cinco ossos (do primeiro ao quinto Metacarpiano, contados a partir do polegar) que formam a palma da mão e estão ligados às falanges e aos ossos do carpo. Cada osso do metacarpo é formado por um corpo e por duas extremidades, que se articulam com as falanges proximais formando os nós do punho. O início da ossificação dos metacarpos se dá no terceiro mês antes do nascimento da criança (NETLER, 1990). 
As falanges são os ossos dos dedos, propriamente ditos, sendo que o polegar (ou primeiro dedo) é formado por duas falanges, a proximal e a distal, e os outros quatro dedos por: falanges proximal, média e distal. A falange proximal articula-se com o metacárpico, a distal é livre em sua extremidade distal e a média está colocada entre as duas. A ossificação das falanges ocorre durante o terceiro ou quarto mês antes do nascimento da criança (TAVANO, 2001).

O punho é formado pelos ossos do carpo, ilustrados na Figura 2, que são (do sentido do rádio para a ulna):

- Escafóide: é o osso de maior volume da fileira proximal e tem o formato de um barquinho.

- Semilunar: apresenta uma concavidade profunda na sua superfície inferior e têm o formato de uma meia lua.

- Trapézio: situa-se entre o Escafóide e a epífise do $1^{\circ}$ Metacárpico.

- Trapezóide: é o mais largo dorsal que ventralmente e articula-se com o Escafóide, o $2^{\circ}$ Metacárpico, o Trapézio e o Capitato.

- Capitato: é o maior dos ossos do carpo e é o primeiro a se ossificar.

- Hamato: têm um formato piramidal com a sua base fixada nos dois últimos metacárpicos.

- Pisiforme: é o menor osso do carpo, têm um formato arredondado e é o último a se ossificar.

- Piramidal: apresenta um formato de pirâmide com a sua base voltada para cima e para fora.

O início da ossificação do carpo geralmente ocorre após o nascimento da criança, entretanto têm ocorrido casos de nascimento com alguns ossos do carpo já ossificados. A palma é a frente da mão, de acordo com a posição anatômica relacionada ao braço (plano frontal), com a ulna voltada para dentro e o rádio para fora, delineando os limites da mão. O outro lado é chamado de dorso. No esqueleto da mão existem ossos ditos fixos, que são os da série distal do carpo e os metacarpianos centrais (segundo e terceiro metacarpos); e os móveis, que são os restantes e estão divididos principalmente em duas partes: as falanges, que 
dão forma aos dedos e os metacarpianos periféricos - o primeiro, o quarto e o quinto metacarpiano (BOSQUIERO et al., 2001).

\subsection{Métodos clássicos de avaliação da idade óssea}

Atualmente existem vários métodos para a estimação da idade óssea. Os métodos clássicos mais difundidos e mais utilizados no Brasil são: Greulich \& Pyle, Tanner \& Whitehouse e Eklof \& Ringertz. O primeiro utiliza um Atlas de padrões para fazer a avaliação inspecional dos ossos e assim estimar a idade óssea. A grande vantagem deste Atlas é que ele faz a distinção entre os sexos na apresentação dos padrões (HAITER, ALMEIDA e LEITE, 2000). O segundo utiliza escores. Já o método de Eklof \& Ringertz baseia-se nas medidas de comprimento e/ou largura de determinados centros de ossificação, com distinção entre sexos. Estes métodos são descritos a seguir.

\subsubsection{Greulich \& Pyle}

Este método baseia-se na comparação da radiografia carpal da criança e as radiografias contidas em um Atlas, "Atlas of Skeletal Maturation of the Hand", Todd (1937). Este Atlas é baseado em uma parte de dados coletados durante os estudos e apresentava diferentes padrões para cada sexo.

O método de Greulich \& Pyle envolve um grande número de comparações de todos os ossos da mão com as radiografias de diferentes idades disponibilizadas no Atlas, segundo o sexo, recebendo assim uma idade óssea igual àquela do padrão ao qual se assemelha. Um total de 28 pontos de ossificação precisam ser examinados durante a comparação (NIEMEIJER, 2002).

O Atlas apresenta 58 pranchas radiográficas com padrões que variam entre sexo e estão dispostos em intervalos de 3 meses de idade nos primeiros 18 meses, e a partir daí, até 5 anos, semianualmente e, daí pra frente, anualmente, 
exceto por alguns intervalos semestrais na puberdade. Cobre até a idade de 18 anos para o sexo feminino e 19 anos para o sexo masculino. Este Atlas também apresenta a idade esqueletal dos ossos individualmente e uma parte descritiva contendo as principais características de cada estágio de desenvolvimento, em quadros que se encontram junto a cada padrão para cada sexo (TAVANO, 2001).

A estimativa da idade óssea é obtida através de uma inspeção visual de 28 centros de ossificação, ilustrados pela Figura 3.

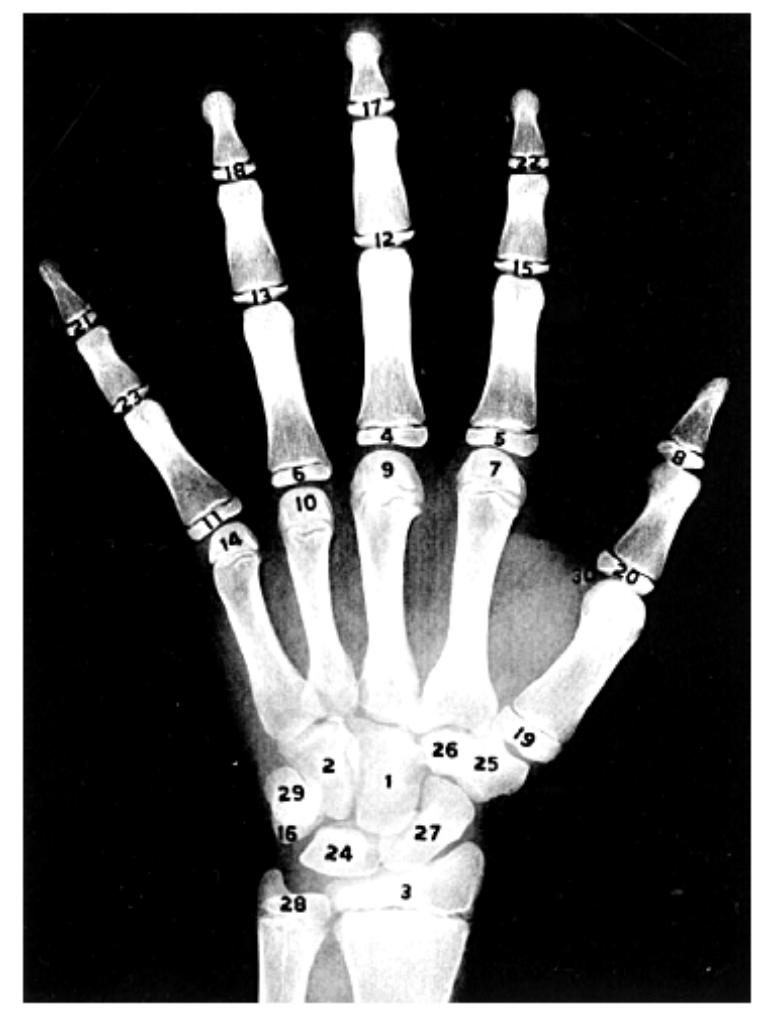

Figura 3 - Centros de ossificação da mão e punho

Fonte: Greulich e Pyle (1992).

Segundo Greulich \& Pyle (1992), estes centros deverão ser comparados com todos os padrões dispostos no Atlas até que se encontre um semelhante à radiografia que está sendo analisada. Estes padrões são formados por informações extraídas de radiografias carpais, obedecendo aos intervalos de idade. Na maioria dos casos analisados, nem sempre a fase em que a radiografia está coincide exatamente com algum padrão do Atlas. Quando isso ocorre, seleciona-se aquele que mais se aproxima da radiografia em análise. 


\subsubsection{Tanner \& Whitehouse}

O método de Tanner \& Whitehouse foi criado em 1969 e baseia-se em escores de Acheson, Vinicius e Fower (1966). São avaliados individualmente 20 centros de ossificação entre os ossos da mão e do punho. O segundo e o quarto dedos não são considerados porque a maturação dos metacárpicos e das falanges são geralmente intimamente ligados, prejudicando o isolamento preciso dessas áreas. A Figura 4 ilustra, respectivamente, os estágios do metacárpico I e da ulna.

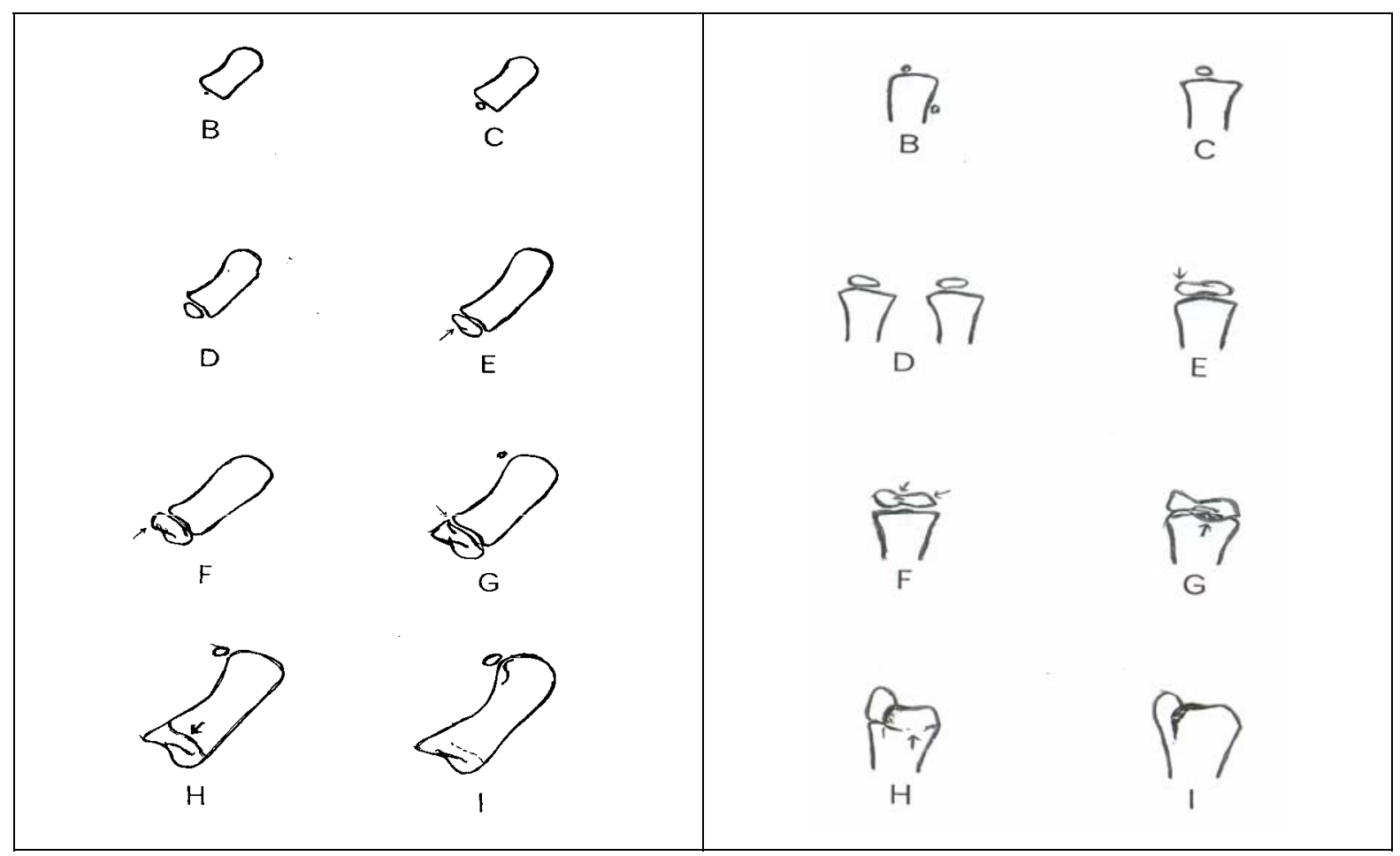

Figura 4 - Exemplos de centros de ossificação do metacárpico l e da ulna Fonte: Tanner, Whitehouse e Healvy (1969).

Como pode ser visto na Figura 4, foram escolhidos apenas os padrões dos centros de ossificação do metacárpico I e da ulna para exemplificar algumas fases 
de crescimento, excluindo-se os restantes, que poderão ser encontrados na bibliografia citada.

Este método baseia-se na atribuição de escores para cada um dos 20 ossos e, seguem a seguinte ordem: rádio, ulna, metacárpicos I, II e V; falanges proximais I, II e V; falanges médias III e V; falanges distais I, III e V; capitato, hamato, piramidal, semilunar, escafóide, trapézio e trapezóide.

Os ossos são avaliados em uma escala, de $\mathrm{A}$ até $\mathrm{I}$, exceto o rádio, que é avaliado de A - J. Se não existe sinal da presença de osso é dada a avaliação A. Estas avaliações são registradas comparando o osso em questão com os diagramas que existem no Atlas para cada ponto de ossificação. Isto está disposto em uma página com todos os estágios de cada osso, bem como as especificações de idades.

\subsubsection{Eklof \& Ringertz}

O método de Eklof \& Ringertz baseia-se nas medidas de comprimento e/ou largura de determinados centros de ossificação. Inicialmente foram realizados todos os testes possíveis com todos os ossos para determinar quais ossos proporcionavam resultados estatisticamente mais precisos na determinação da idade óssea em relação a laudos médicos. Após realizar estes testes, verificou-se que o crescimento de alguns ossos da mão e do pulso satisfaziam esta condição no intervalo de 1 a 15 anos de idade. Verificou-se também que as crianças com idade inferior a 1 ano e meio apresentavam uma regressão não linear entre idade cronológica e idade óssea e com isso concluiu-se que elas não poderiam ser incluídas nesta análise, pois apresentavam índices discrepantes de idade óssea (TAVANO, 2001). Para determinar os padrões normais, foram escolhidos 10 parâmetros (ossos) que possuíam os mais altos coeficientes de correlação $(0,922$ $-0,964)$ entre idades e medidas em questão. Estes parâmetros são apresentados na Figura 5. 


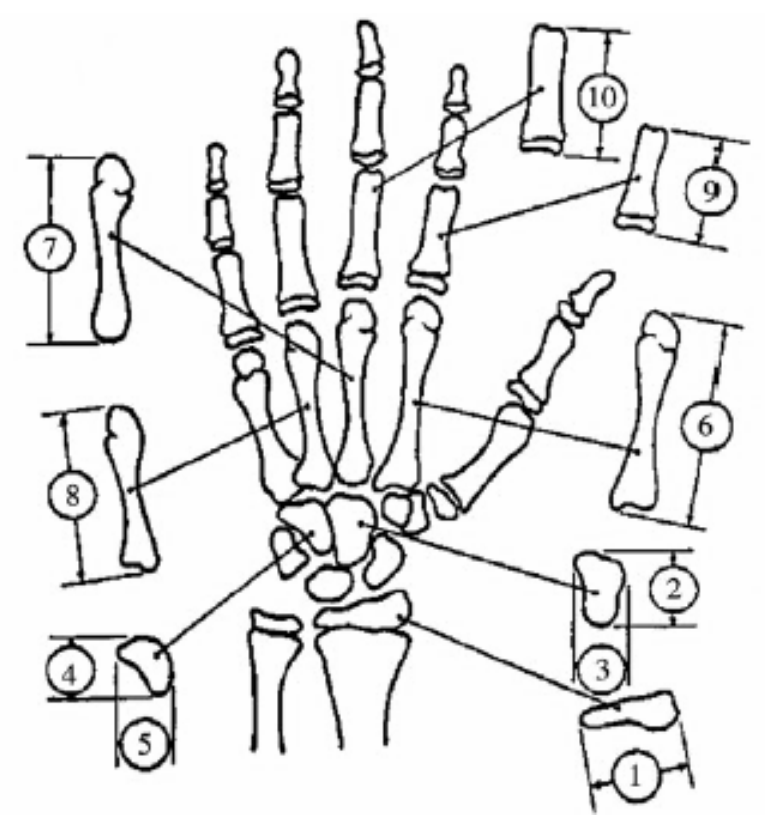

Figura 5 - Índice de Eklof \& Ringertz, centros de ossificação utilizados Fonte: Tanner, Whitehouse e Healvy (1959)

A estimativa da idade óssea é obtida através da análise dos centros de ossificação, formados pelas regiões ilustradas na Figura 5, onde: 1- largura da epífise distal do rádio, 2- comprimento do capitato, 3- largura do capitato, 4comprimento do hamato, 5- largura do hamato, 6- comprimento do metacárpico II, 7- comprimento do metacárpico III, 8- comprimento do metacárpico IV, 9comprimento da falange proximal II e 10- comprimento da falange proximal III.

Uma série de 1013 crianças foi estudada pelos autores, para estabelecer as variações normais. Usando cálculos estatísticos, eles apresentaram 2 tabelas, uma para cada sexo (Tabelas 8 e 9 do Anexo A), em que cada um dos 10 centros de ossificação tem um padrão mínimo e um máximo de medida (em milímetros). Estes parâmetros são apresentados para todas as idades, de 1 até 15 anos, com intervalos de 3 meses entre eles, representando um total de 56 parâmetros, para cada centro de ossificação. As Tabelas 10 e 11 do Anexo A representam os pontos médios (medidas em milímetros) e suas idades ósseas correspondentes para cada osso utilizado pelo índice de Eklof \& Ringertz. 
Atualmente, existem vários trabalhos que utilizam estes métodos para estimar a idade óssea. Um exemplo é o trabalho desenvolvido por Marques et al. (2001), no qual utiliza imagens carpais para estimar a idade óssea. Neste trabalho, todas as medidas objetivas dos ossos são obtidas, permitindo assim uma diferenciação da idade óssea nas diferentes fases de crescimento. Em seguida, foi construído um Atlas digital com todas as imagens e dados, refletindo o desenvolvimento ósseo da população estudada, que serve de base padrão para estimar as idades de outras pessoas.

Um outro trabalho importante foi o de França et al. (1998), que buscaram estabelecer cientificamente as idades ósseas e dentária utilizando radiografias da face, bacia, joelho, cotovelo, entre outros, que apresentam centros de ossificação. Inicialmente as imagens foram segmentadas utilizando técnicas de processamento de imagens e posteriormente foram analisadas utilizando o método de Tanner \& Whitehouse. Moraes et al. (2003), também realizaram um estudo com o intuito de comparar os métodos de Greulich \& Pyle e Eklof \& Ringertz para verificar a variabilidade, fidelidade, confiabilidade e a praticidade entre eles.

\subsection{Escolha do Método de avaliação da idade óssea}

O método escolhido para estimar a idade óssea neste trabalho foi o de Eklof \& Ringertz, o qual proporciona o uso de métodos computacionais simples, pois baseia-se na análise do comprimento e largura de 10 centros de ossificação. Um outro critério importante para esta escolha é o fato deste método não estar dependente de uma análise inspecional e comparativa através de Atlas (Greulich \& Pyle) e nem em escores (Tanner \& Whitehouse). Foram feitas algumas simplificações do método, utilizando-se alguns centros de ossificação para estimar a idade. Para validar os resultados da metodologia, as idades foram comparadas com os laudos médicos. 


\section{A ANÁLISE DA RADIOGRAFIA DA MÃO}

\subsection{Dificuldades gerais da análise}

Um dos principais problemas encontrados na estimativa da idade óssea através da análise das radiografias carpais está na análise dos ossos do punho, que são formados pelos ossos do carpo. Segundo Tavano (2001), estes ossos a partir de uma determinada idade cronológica (aproximadamente 10 anos) apresentam áreas sobrepostas. A Figura 6 ilustra parte de uma radiografia carpal de uma pessoa com idade cronológica de 15 anos.

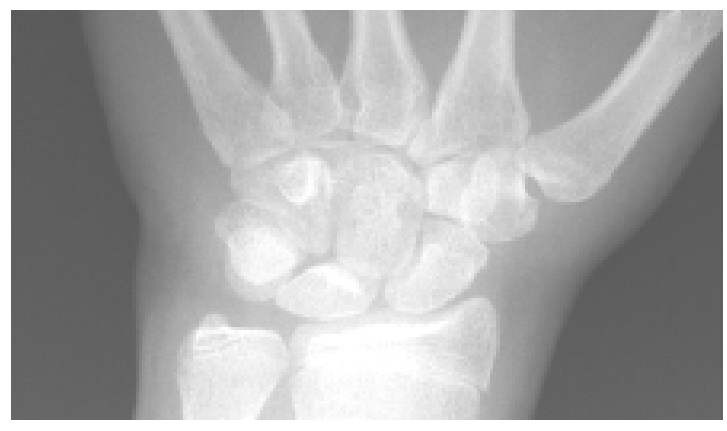

Figura 6 - Ossos do carpo e do punho Fonte:Tavano (2001)

Como pode ser visto na Figura 6, alguns ossos do carpo estão sobrepostos, não sendo possível determinar as áreas de cada osso, tornando impossível a precisão da estimativa da idade óssea. Outros problemas que dificultam a análise estão relacionados com a qualidade do filme, processo de formação da imagem, 
ruídos e, aquele inerente ao processo de radiografia, denominado efeito Heel (descrito no próximo item). Algum dos ossos pertencentes a esta região sobreposta (Figura 6) fazem parte da análise de Eklof \& Ringertz. Para solucionar este problema o método será implementado de uma maneira semi-automática e simplificada, excluindo estas áreas sobrepostas para a estimação da idade.

\section{$3.2 \mathrm{O}$ efeito Heel}

Segundo Fritz e Livingston (1985), um dos grandes problemas encontrados nas radiografias carpais está diretamente relacionado com a distribuição de intensidade dos raios- $X$, que causa uma iluminação não uniforme em algumas partes da imagem. Este fenômeno é conhecido como efeito Heel e é ilustrado pela Figura 7.

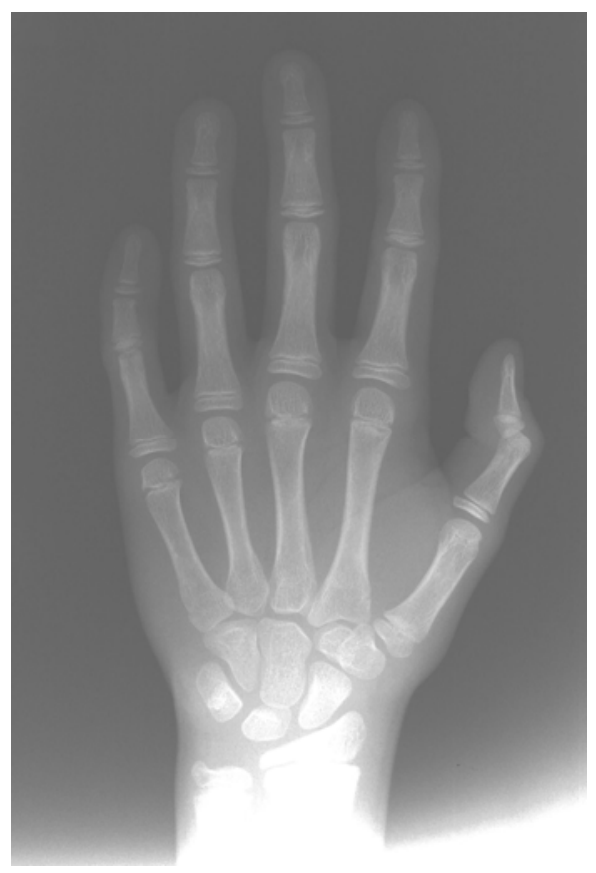

Figura 7 - Radiografia carpal ilustrando o efeito Heel Fonte: Tavano (2001)

Como pode ser visto na Figura 7, esta diferença na distribuição dos raios-X causa uma diferença muito grande na iluminação em certas regiões do filme, onde 
a parte inferior foi pouco sensibilizada, enquanto a parte superior foi sensibilizada em excesso, prejudicando a uniformidade do contraste necessário para a obtenção de uma boa imagem (BEHIELS et al., 2002).

Embora esta variação não homogênea de intensidade gerada pelo efeito Heel possa ser facilmente corrigida pelo sistema de percepção da visão humana, esta presença dificulta o uso de técnicas de processamento automáticas porque existe uma grande diferença de intensidade em toda a imagem. (FRITZ e LIVINGSTON, 1982).

A distribuição de intensidade depende do posicionamento relativo do dispositivo de gravação em relação à fonte de raios- $X$, podendo variar não uniformemente entre $75 \%$ e $125 \%$ (NASCIMENTO e FRÈRE, 2001). A Figura 8 ilustra esta distribuição de intensidades.

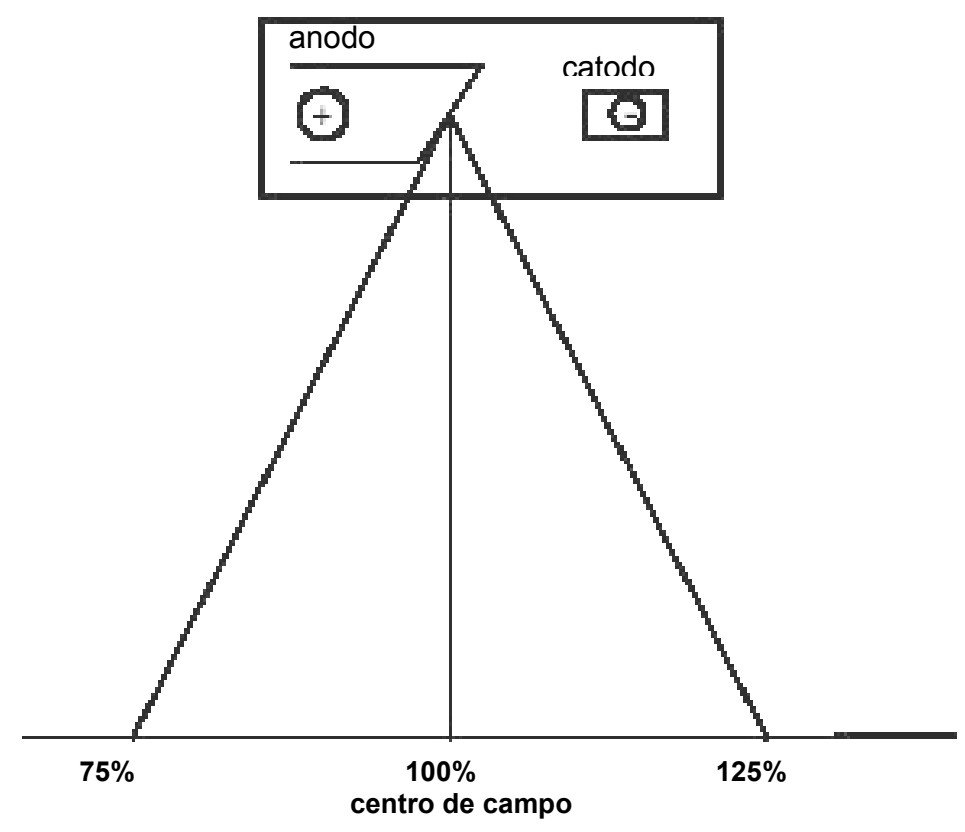

Figura 8 - Distribuição da intensidade do feixe de raios-X Fonte: Scaff (1979)

Como pode ser visto na Figura 8 , os feixes de raios-X que incidirem no filme com uma intensidade de $75 \%$ irão sensibilizar menos do que nas regiões onde a intensidade for de $125 \%$. Esta diferença de intensidade em relação ao 
centro de campo causará na imagem final, uma diferença de contraste em certas partes da imagem (NASCIMENTO et al., 2003).

O efeito Heel pode ser facilmente observado na Figura 7 , onde a parte inferior da imagem apresenta um brilho muito maior do que a parte inferior. Esta região é conhecida por área de exposição direta. Um dos objetivos deste trabalho é corrigir esta distribuição de intensidades extraindo o fundo da imagem para que conseqüentemente a imagem possa ser facilmente binarizada.

\subsubsection{O Modelo do efeito Heel}

Segundo Silva et al. (2000), o efeito Heel pode ser entendido na construção dos tubos de raios- $X$, como descrito esquematicamente na Figura 9. O tubo de raios-X é formado por um catodo e por um anodo, colocado dentro de uma ampola de vidro e submetido a vácuo (BEHIELS et al, 2002). Os elétrons recebem uma tensão da ordem de milhares de volts e são atraídos pela carga positiva do anodo.

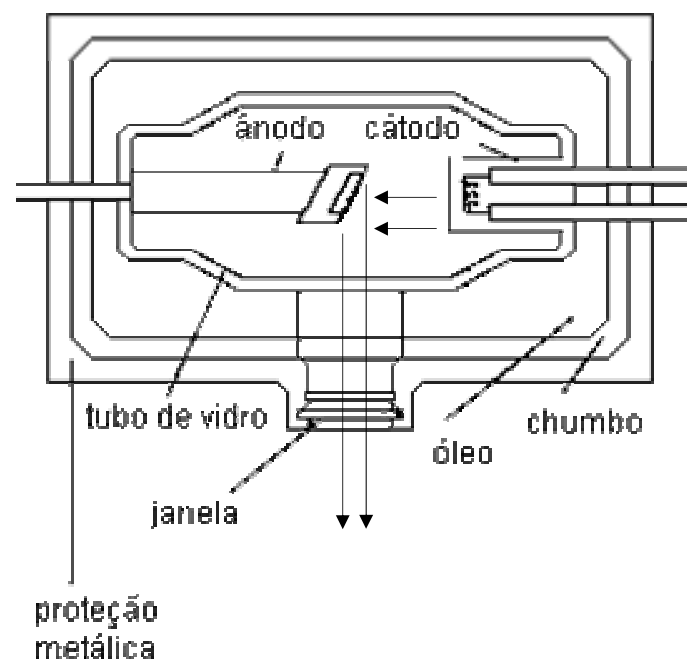

Figura 9 - Visão superficial de um tubo de raios-X

Fonte: Behiels et al., (2002). 
A exposição não uniforme dos raios-X em relação ao centro de campo da imagem variam de $75 \%$ a $125 \%$. Isso pode ser observado analisando o tubo do anodo, presente na Figura 9, que apresenta uma considerável inclinação quando comparado ao tubo do catodo.

Teoricamente, todos os feixes de elétrons atraídos pela carga positiva do anodo deveriam produzir a mesma porcentagem de radiação, mas isso não ocorre, pois, uma certa quantia dos elétrons penetra o material do anodo e produzem a radiação em seu interior, e não na própria superfície. Isso faz com que os fótons absorvam uma quantia diferente de energia, dependendo do caminho percorrido no interior do alvo, provocando assim uma variação de intensidade dos feixes. A Figura 10 ilustra a formação dos fótons de raios-X. (SILVA et al., 2000).

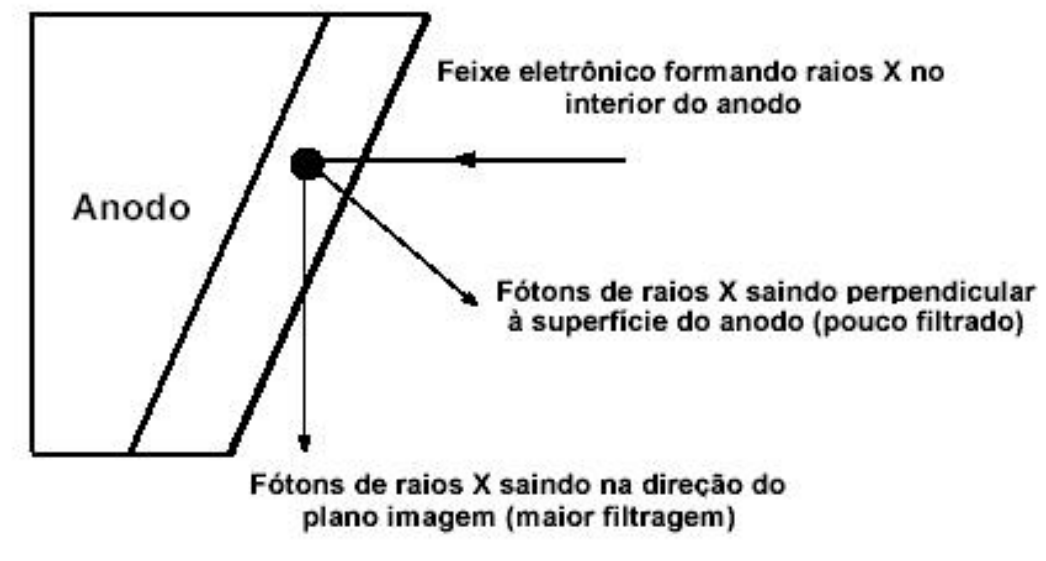

Figura 10 - Esquema simplificado da ocorrência do efeito Heel Fonte: Marques (1998)

Como pode ser visto na Figura 10, os feixes de elétrons são atraídos pelo anodo e uma porcentagem dos fótons de raios- $X$ seguem um caminho de encontro ao plano imagem, já uma outra quantia caminha em uma direção perpendicular à superfície do anodo. A conseqüência disto é uma iluminação não uniforme em algumas regiões da imagem radiográfica da mão, prejudicando assim o seu préprocessamento. 


\section{PROCESSAMENTO DE IMAGENS RADIOGRÁFICAS}

\subsection{Considerações iniciais}

As imagens radiográficas de mão utilizadas neste trabalho foram digitalizadas com resolução de 300 dpi e possuem 256 níveis na escala de cinza. A primeira etapa de um processo de extração de informações em uma imagem normalmente é conhecida por segmentação, e consiste no processo de separar os objetos de interesse presentes na imagem. Neste caso, a segmentação servirá para separar os ossos do tecido e do fundo da imagem carpal. Porém, este processo não é facilmente realizado devido à intensidade não uniforme que o fundo destas imagens apresenta, causadas principalmente pelo efeito $\mathrm{Heel}$, sendo necessária a aplicação de métodos de pré-processamento antes da efetiva segmentação. A seguir, são descritos estes métodos.

- Correção do efeito Heel - O efeito Heel é um fenômeno que produz uma redução na intensidade dos raios- $X$, gerando uma iluminação não uniforme em certas partes da imagem, dificultando o uso de técnicas de pré-processamento. (NASCIMENTO et al., 2003).

- Ajuste da imagem - Após a eliminação do comportamento não uniforme no fundo das imagens, são aplicados filtros de suavização, para eliminar (ou atenuar) pequenos ruídos que possam ter restado nas imagens. $O$ filtro de suavização escolhido foi o da média por vizinhança $11 \times 11$, por 
ser de fácil implementação e apresentar resultados satisfatórios para este tipo de imagem.

- Thresholding - Os métodos de thresholding que apresentaram resultados considerados satisfatórios para as imagens carpais foram: Otsu, Pun, Kapur, Sahoo \& Wong, Niblack e Rosenfeld.

A seguir, são apresentados todos os métodos para corrigir o fundo das imagens (efeito Heel e ajuste da imagem) bem como os métodos de thresholding.

\subsection{Correção do fundo das imagens}

Como já citado anteriormente, foi observado que as imagens apresentavam o fundo com diferentes níveis de intensidade, dificultando assim a segmentação. Para corrigir este problema foi aplicado um algoritmo de correção do efeito $\mathrm{Heel}$, descrito no próximo item.

\subsubsection{Algoritmo para correção do efeito Heel}

Para eliminar as variações da não uniformidade encontrada na região de fundo foi aplicado um algoritmo desenvolvido por Nascimento et al. (2003), baseado na simulação computacional da distribuição da intensidade de radiação, desenvolvido por Marques e Frère (1998), que permite corrigir nas imagens radiográficas, as variações das densidades causadas pelo efeito Heel. Segundo Nascimento et al. (2003), neste algoritmo existem alguns parâmetros de entrada necessários para o processamento, entre eles:

- KVp (variando entre 45 a $50 \mathrm{Kv})$, corrente $(20 \mathrm{~mA})$ e tempo de exposição;

- $\quad$ Material (Tungstênio); 
- $\quad$ Ângulo de inclinação do alvo;

- $\quad$ Espessura da filtração inerente $(3 \mathrm{~cm})$;

- Distância do foco ao plano imagem $(d f o=0 \mathrm{~cm})$

- Distância do foco à janela do tubo $(d f i=100 \mathrm{~cm})$

Para realizar a correção do efeito Heel o algoritmo primeiramente calcula a intensidade de radiação em cada ponto da imagem, pela determinação do caminho que os fótons percorram dentro do alvo, ilustrado pela Figura 11. Em seguida, estes valores são utilizados para corrigir todos os pontos da imagem radiográfica em função do excesso ou da falta de radiação a que eles foram submetidos.

\subsubsection{Cálculo das variações de densidades do fundo da imagem}

Inicialmente é necessário calcular o ângulo de inclinação do anodo, levando em consideração os seguintes parâmetros: determinação do centro de campo do feixe de radiação, determinação da distância foco - filme, determinação do ponto de "cut-off" com uma matriz de orifícios utilizando o principio mostrado na Figura 11 que permite calcular ponto a partir da orientação das projeções do ponto focal (NASCIMENTO et al., 2003). Em seguida, o ângulo de inclinação é calculado a partir da equação:

$$
\alpha=\arctan \left(\frac{\text { acentro *( }\left(\frac{d x}{d 1+d 2}\right)}{a^{\prime}-\text { acentro }}\right)
$$

onde: $a_{\text {centro: }}$ é o valor da dimensão maior do ponto focal no centro de campo (posição C); 
a': é o valor da dimensão maior do ponto focal em uma outra posição do eixo catodo / anodo (posição B);

$d x$ : é a distância do centro à nova posição (distância $\mathrm{CB}$ );

$d 1$ : é a distância entre o ponto focal e o objeto;

d2: é a distância entre o objeto e o plano imagem.

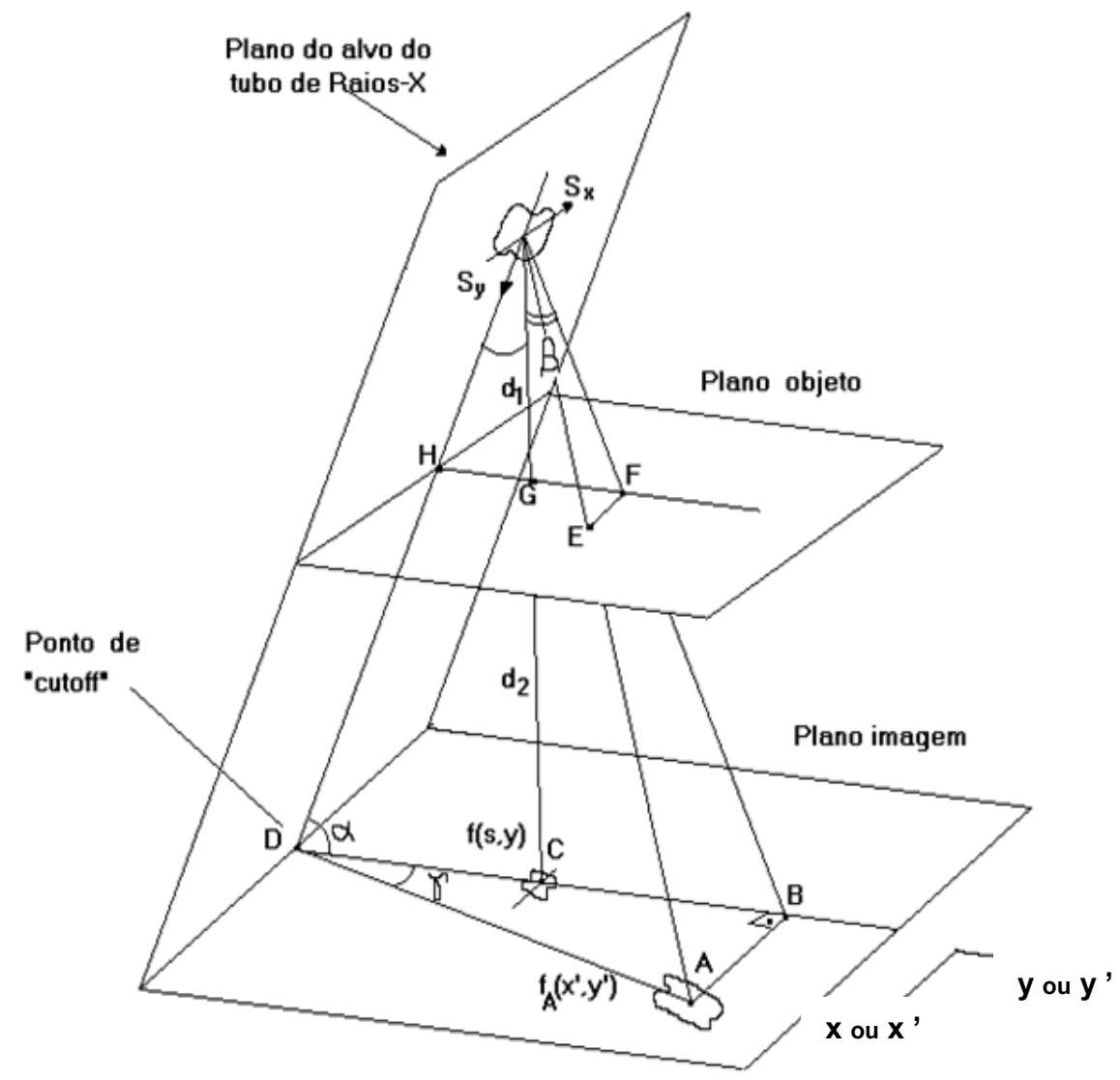

Figura 11 - Projeção do ponto focal no centro e em outra posição do campo Fonte: Nascimento et al. (2003)

Após obter-se o ângulo de inclinação do anodo, calcula-se a intensidade de radiação $I_{0}(E)$, produzido no interior do alvo, para alcançar um ponto no plano imagem, denominado $P_{1}(x, y)$, do campo de radiação. A produção do espectro no centro do campo é dado por Fritz e Livingston (1982), através da seguinte equação: 


$$
\mathrm{I} 0(E)=C Z(E 0-E)\left(\frac{V_{0}}{c^{2}}\right)
$$

onde: $E$ é a energia do fóton;

$E_{0}$ é a energia de emissão dos elétrons;

$Z$ é o número atômico do anodo;

$V_{0}$ é a velocidade inicial do elétron;

$C$ é uma constante;

$c$ é a velocidade da luz.

O valor da constante $C$, utilizado na equação acima, é fornecido de acordo com o material do anodo. Neste caso utiliza-se o anodo de tungstênio, cujo valor é $1,02 \times 10^{11}$. (FRITZ e LIVINGSTON, 1982). Utilizando a eq.(2) e a característica de campo, calcula-se a energia do espectro para as demais posições do campo de radiação através de um método computacional, desenvolvido por Marques (1998). Neste modelo é assumido que o espectro foi produzido por uma única camada com filtração apropriada, sendo este processo ilustrado pela Figura 12.

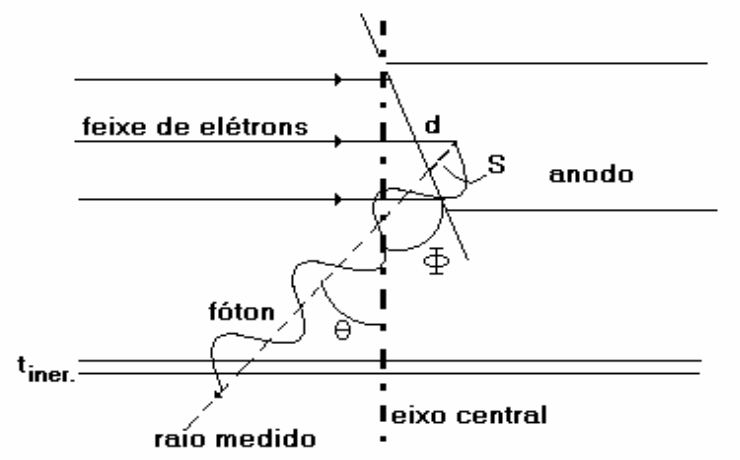

Figura 12 - Processo de emissão dos fótons pelo anodo Fonte: Nascimento et al. (2003)

Segundo Fritz e Livingston (1982), o comprimento da atenuação para o anodo pode ser calculado, e não dependo do ponto no qual o elétron entra no anodo, quando se assume que as dimensões do anodo são consideravelmente 
maiores que a dimensão do ponto focal. A relação entre o comprimento do caminho $s$ e o ângulo $\theta$ é dada por:

$$
s(\theta)=\frac{d \cos (\phi)}{\operatorname{sen}(\theta+\phi)}
$$

onde: s é o comprimento do caminho;

$\theta$ é o ângulo entre o eixo central e o raio medido;

$d$ é a profundidade da penetração do espectro;

$\phi$ é o ângulo de inclinação do anodo

Para cada energia $E$, o espectro foi filtrado considerando a atenuação devida à espessura do material do alvo atravessada pelos fótons, ou seja, cada espessura $s(\theta)$ bem como a filtração inerente. Depois, o espectro foi integrado sobre $E$ para se obter a intensidade total sobre o raio de ângulo $\theta$, e corrigindo em função da lei do inverso do quadrado da distância.

Com estes dados acima foi possível simular o efeito Heel e com o algoritmo desenvolvido determinamos o centro de campo e a variação da intensidade incidente em todos os pontos da imagem. Com estes dados, elaboramos uma matriz onde todas as variações de intensidades são expressas em percentuais relativos a intensidade no centro de campo. Esta matriz é denominada matriz de fundo.

\subsubsection{Correção do efeito Heel na imagem}

Para realizar a correção, devemos subtrair ou acrescentar a cada ponto da matriz imagem expressa em níveis de cinza, um valor dado pelo seu ponto correspondente na imagem de fundo. Para tanto, é necessário determinar a correspondência de cada ponto da matriz imagem na matriz fundo. Então, 
procura-se localizar o eixo cátodo / ânodo indicado por $B$ e $D$ (ver Figura 11) e o centro do campo $C$.

A seguir, divide-se a matriz da imagem radiográfica em duas regiões iguais: região $A$ e região $B$, conforme ilustrado na Figura 13. Armazena-se a primeira linha da região $A$ em um vetor e a compara com todas as linhas da região $B$. A comparação ponto a ponto é feita até encontrar a linha que apresenta o maior percentual de semelhança das densidades óticas, denomina-se B1. De fato, sabese que o efeito Heel provoca variações de densidades iguais em cada lado do eixo cátodo / ânodo. Para verificar se a localização encontrada é correta, escolhe-se a quinta linha da região A (A5) e a compara-se com a quinta linha anterior à linha B1 (B5) e calcula-se o percentual de semelhança entre elas. Caso haja concordância, determina-se que a metade da distância entre a primeira linha da região A e a primeira linha de maior semelhança na região B indica o eixo cátodo / ânodo.

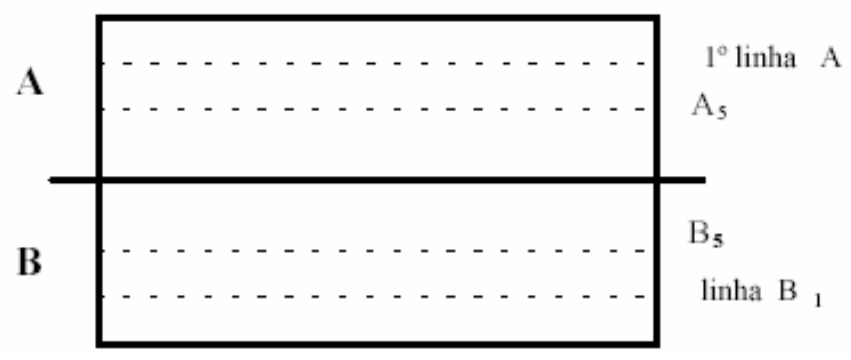

Figura 13 - Divisões da matriz de fundo para determinação do eixo ânodo / cátodo Fonte: Nascimento et al. (2003)

Devido ao fato de o efeito Heel gerar uma exponencial no eixo cátodo/ânodo, para obter-se o centro do campo de radiação levantamos a curva da imagem simulada. Como o centro já é determinado nesta curva, procura-se pontos de superposição com a curva exponencial do efeito Heel produzido na imagem radiográfica. Em seguida, corrige-se cada ponto da matriz imagem em função do percentual de variação de densidade da matriz fundo. 


\subsubsection{Ajuste da imagem}

Após a eliminação do comportamento não uniforme no fundo das imagens, é aplicado um filtro de passa-baixa, para eliminar (ou atenuar) pequenos ruídos que possam ter restado nas imagens.

Após a suavização, o resultado é armazenado em uma imagem auxiliar e em seguida, é feita a subtração desta auxiliar com a imagem original. A imagem original torna-se a imagem resultante desta operação.

O filtro passa-baixa utilizado na suavização foi a da média por vizinhança $11 \times 11$.

\subsubsection{Filtro passa - baixa}

O filtro passa-baixa no domínio do espaço pressupõe a aplicação de uma máscara, sendo o exemplo mais típico o filtro da média. Para uma vizinhança elementar $3 \times 3$, por exemplo, a máscara $\boldsymbol{h}$ pode ser dada por:

\begin{tabular}{|c|c|c|c|}
\hline \multirow{3}{*}{$h=\frac{1}{9} x$} & 1 & 1 & 1 \\
\hline & 1 & 1 & 1 \\
\hline & 1 & 1 & 1 \\
\hline
\end{tabular}

A máscara inicialmente testada nas imagens radiográficas da mão foi a $3 \mathrm{x}$ 3 , trazendo um resultado insatisfatório em todos os casos, restando muitos ruídos na imagem final. Em seguida, foram feitas as filtragens nas imagens utilizando máscaras de $5 \times 5,7 \times 7,9 \times 9$ e $11 \times 11$.

A filtragem que apresentou um melhor resultado para este tipo de imagem foi a da média por vizinhança de $11 \times 11$. 


\subsubsection{Subtração da imagem}

Após aplicar o filtro de suavização, a imagem final é obtida através da diferença entre a imagem original e a suavizada, representadas respectivamente por Original $(x, y)$ e Auxiliar( $x, y)$ e, esta subtração é expressa da seguinte maneira:

$$
\text { Resultante }(x, y)=\text { Auxiliar }(x, y)-\text { Original }(x, y)
$$

O resultado desta equação acima faz com que apenas as áreas que são distintas entre Auxiliar( $x, y)$ e Original $(x, y)$ apareçam na imagem final como detalhe realçado.

Após a aplicação destes passos descritos acima, todas as imagens estão com os fundos corrigidos podendo agora ser segmentada. A próxima seção traz o conceito de limiarização e os métodos de thresholding utilizados neste trabalho.

\subsection{Métodos de segmentação de imagens}

A limiarização é uma das mais importantes abordagens para a segmentação de imagens, visando a extração de objetos que se encontram em uma imagem, mesclada com o fundo. É o primeiro passo no processamento de imagens para muitas aplicações. Neste trabalho a limiarização será utilizada para separar os ossos da mão do tecido e do fundo da imagem.

O passo inicial para a limiarização é a construção do histograma da imagem carpal. Em muitos casos o histograma pode mostrar-se bimodal, ou seja, com dois picos (ou vales) bem definidos. Mas, tais casos são raros, pois a maioria das imagens não apresenta um histograma tão simples assim, como no caso das imagens carpais, isto significa que a informação encontra-se bastante misturada com o fundo da imagem. Para que se possa obter os objetos de interesse na 
imagem, é necessário transformá-la em uma imagem apenas em preto e branco (ARTERO e TOMMASELLI, 2002).

Os métodos de limiarização (thresholding) podem ser divididos entre processos automáticos globais e adaptativos. Os métodos globais baseiam-se na análise de propriedades do histograma e utilizam os mínimos do histograma que correspondem às tonalidades intermediarias entre as duas bandas. Em geral o operador escolhe a tonalidade próxima à banda de interesse, e busca os mínimos mais próximos, em ambos os lados da banda.

Basicamente todos os pixels que estão dentro de uma faixa de intensidade são classificados como pertencentes a uma mesma região. Em sua forma mais geral a limiarização pode ser descrita matematicamente como: $\mathbf{S}(i, j)=\boldsymbol{k}$ se $\boldsymbol{T}_{\boldsymbol{k - 1}} \leq$ $\boldsymbol{f}(i, j)<\boldsymbol{T}_{\boldsymbol{k}}$ para $\mathrm{k}=1,2, . ., \mathrm{m}$ onde $\boldsymbol{S}(\boldsymbol{i}, j)$ é a função resultante, $\boldsymbol{f}(i, j)$ é a função original (imagem), $\boldsymbol{T}_{0}, \ldots \boldsymbol{T}_{\boldsymbol{m}}$ são os valores de limiarização (thresholding) e $\boldsymbol{m}$ é o número de classes distintas a serem aplicadas à imagem (ARTERO e TOMMASELLI, 1999).

Neste tipo de limiarização existem dois problemas: os vales podem ser muito largos e planos, tornando a escolha de um valor mínimo arbitrária e os vales podem assumir valores muito baixos, ficando muito sensíveis a ruídos.

Já a limiarização adaptativa subdivide a imagem, aplica uma limiarização a cada subdivisão, obtendo assim vários valores de limiar. Em seguida, interpola os valores obtidos para as subdivisões para obter um novo valor de intensidade para cada pixel da imagem. As vantagens desta técnica são: a menor sensibilidade à irregularidade de fundo e às variações locais. A lentidão do processo vem a ser a principal desvantagem.

\subsubsection{Métodos selecionados}

A tarefa de escolha dos métodos de limiarização é muito extenuante, pois existem alguns que são específicos para determinados tipos de imagem e para outros não. Assim, vários estudos e testes foram realizados para verificar quais 
métodos apresentavam o melhor comportamento quando aplicado em imagens radiográficas de mão.

Os métodos globais selecionados foram o de Otsu, Pun e o Kapur, Sahoo \& Wong. Estes métodos encontram um único valor de limiar para toda a imagem, e por isso mostram de uma forma efetiva o resultado da correção do efeito Heel nas imagens. O método de Kapur, Sahoo \& Wong e o de Pun utilizam o mesmo princípio para a obtenção do limiar. Por este motivo, apenas os resultados da limiarização de Pun foram apresentados.

Já os métodos de Niblack e Rosenfeld são métodos adaptativos e encontram um valor de limiar para cada região da imagem, de onde se esperavam resultados de áreas não muito discrepantes entre as imagens com e sem correção do efeito Heel, o que de certa forma ocorreu.

\subsubsection{Limiarização automática}

A seguir são descritos brevemente os métodos de limiarização automática que apresentaram o melhor desempenho quando aplicados nas imagens radiográficas da mão.

\subsection{Método de Otsu}

No método proposto por Otsu, a segmentação de uma imagem em tons de cinza para uma imagem binária é considerada como um problema de classificação, onde duas classes ( $C_{0}$ - imagem e $C_{1}$ - fundo) são geradas a partir de um conjunto de pontos contidos na imagem. A primeira classe define o conjunto de pixels com níveis de cinza igual ou abaixo do valor do limiar $\boldsymbol{k}$, enquanto que a segunda classe define o conjunto de pixels com valores acima do $\operatorname{limiar} \boldsymbol{k}$. 
O valor do limiar é obtido a partir do cálculo de $\boldsymbol{\sigma}_{B}^{2}$ (variância entre as classes) e $\boldsymbol{\sigma}_{T}^{2}$ (variância total) (OTSU, 1997).

\subsection{Método de Pun}

Este método é baseado na teoria da informação, que se baseia na premissa de que a geração de informação pode ser modelada como um processo probabilístico. Por esta teoria define-se que a entropia (quantidade de código necessária para representar um símbolo) de cada ponto da imagem por:

$$
\operatorname{Entropia}(x)=x \cdot \log (x)
$$

A seguir, são definidas duas entropias (do objeto e do fundo da imagem), dadas por:

$$
\begin{aligned}
& \boldsymbol{H}_{\boldsymbol{O}}=\sum_{i=0}^{t} p_{i} * \log \left(\boldsymbol{p}_{i}\right) \\
& \boldsymbol{H}_{\boldsymbol{B}}=\sum_{i=t+1}^{L-1} p_{i} * \log \left(\boldsymbol{p}_{i}\right)
\end{aligned}
$$

onde: $\boldsymbol{H}_{O}$ é a entropia do objeto, $\boldsymbol{H}_{B}$ é a entropia do fundo da imagem. $O$ valor do limiar ótimo é dado por (PARKER, 1996):

$$
T=\operatorname{ArgMax}\left|H_{O}(t)+H_{B}(t)\right|
$$




\subsection{Método de Kapur, Sahoo \& Wong}

Este método também é baseado na teoria da informação, utilizando assim a entropia para obter o valor do limiar (ARTERO e TOMMASELLI, 1999). A entropia do objeto $\left(\boldsymbol{H}_{O}\right)$, e a entropia do fundo da imagem $\left(\boldsymbol{H}_{B}\right)$ são definidos por (PARKER, 1996):

$$
\begin{gathered}
\boldsymbol{H}_{\boldsymbol{O}}(\boldsymbol{t})=-\sum_{i=0}^{t} \frac{p_{i}}{p_{t}} \log \left(\frac{p_{i}}{p_{t}}\right) \\
\boldsymbol{H}_{\boldsymbol{B}}(\boldsymbol{t})=-\sum_{i=t+1}^{l-1} \frac{p_{i}}{1-p_{t}} \log \left(\frac{p_{i}}{1-p_{t}}\right)
\end{gathered}
$$

O valor do limiar ótimo é dado por:

$$
T=\operatorname{ArgMax}\left|H_{O}(t)+H_{B}(t)\right|
$$

\subsubsection{Limiarização adaptativa}

A seguir são descritos brevemente os métodos de thresholding adaptativos selecionados que apresentaram o melhor desempenho quando aplicados nas imagens radiográficas da mão.

\subsection{Método de Niblack}

O algoritmo de binarização de Niblack calcula para cada pixel da imagem a média $(\mu)$ e o desvio padrão( $\sigma)$ da vizinhança em torno dele, e a seguir, compara o 
valor do pixel analisado com o limiar $\mathrm{T}(\mathrm{x}, \mathrm{y})$, conforme demonstrado na equação (12). Se o valor do pixel for maior que $T(x, y)$, ele é considerado pertencente ao fundo, caso contrário, é considerado pertencente à algum objeto.

$$
\mathrm{T}(\mathrm{x}, \mathrm{y})=-\alpha \cdot \sigma(\mathrm{x}, \mathrm{y})+\mu(\mathrm{x}, \mathrm{y})
$$

O valor $\alpha$ controla a influência do desvio padrão sobre a média da janela. Para uma mesma imagem, uma mudança no valor $\alpha$ representa uma mudança no valor do limiar da etapa de binarização, variando a imagem resultante do algoritmo (FACON, 2003).

\subsection{Método de Rosenfeld por Relaxação}

A limiarização de imagens por relaxação é um método que, a partir de uma imagem binária, realiza basicamente duas análises: uma análise pixel a pixel, para a obtenção das probabilidades de intensidades de cada pixel e uma segunda análise para a qualificação da compatibilidade dos mesmos.

O método de Rosenfeld por Relaxação é um método iterativo. Neste caso, o limiar da imagem em cada iteração é computado como uma função de acordo com a mesma vizinhança da iteração anterior (PARKER, 1996). 


\section{RESULTADOS DA SEGMENTAÇÃO}

5.1 Resultados sobre uma imagem sem a correção do efeito Heel

Neste item são apresentados os resultados dos métodos de thresholding implementados sobre uma imagem uma imagem ajustada (suavizada) e sem a correção do efeito Heel, ilustrada pela Figura 14.

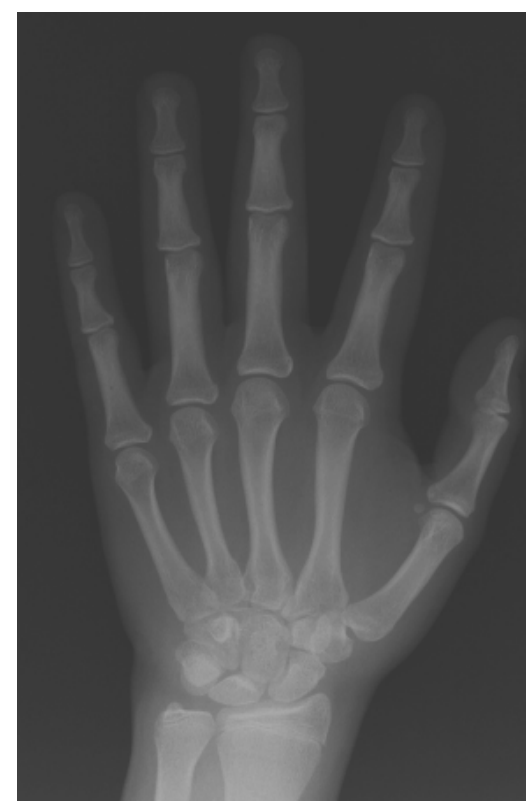

Figura 14 - Imagem Original

Fonte: Tavano (2001) 
Analisando a Figura 14, nota-se que os níveis de cinza do fundo da imagem apresentam um comportamento não uniforme e este fenômeno está diretamente relacionado com o efeito Heel. A Figura 15 ilustra o resultado da aplicação dos métodos utilizando thresholding de Otsu, Pun, Niblack e Rosenfeld, sobre a imagem suavizada (Figura 14).

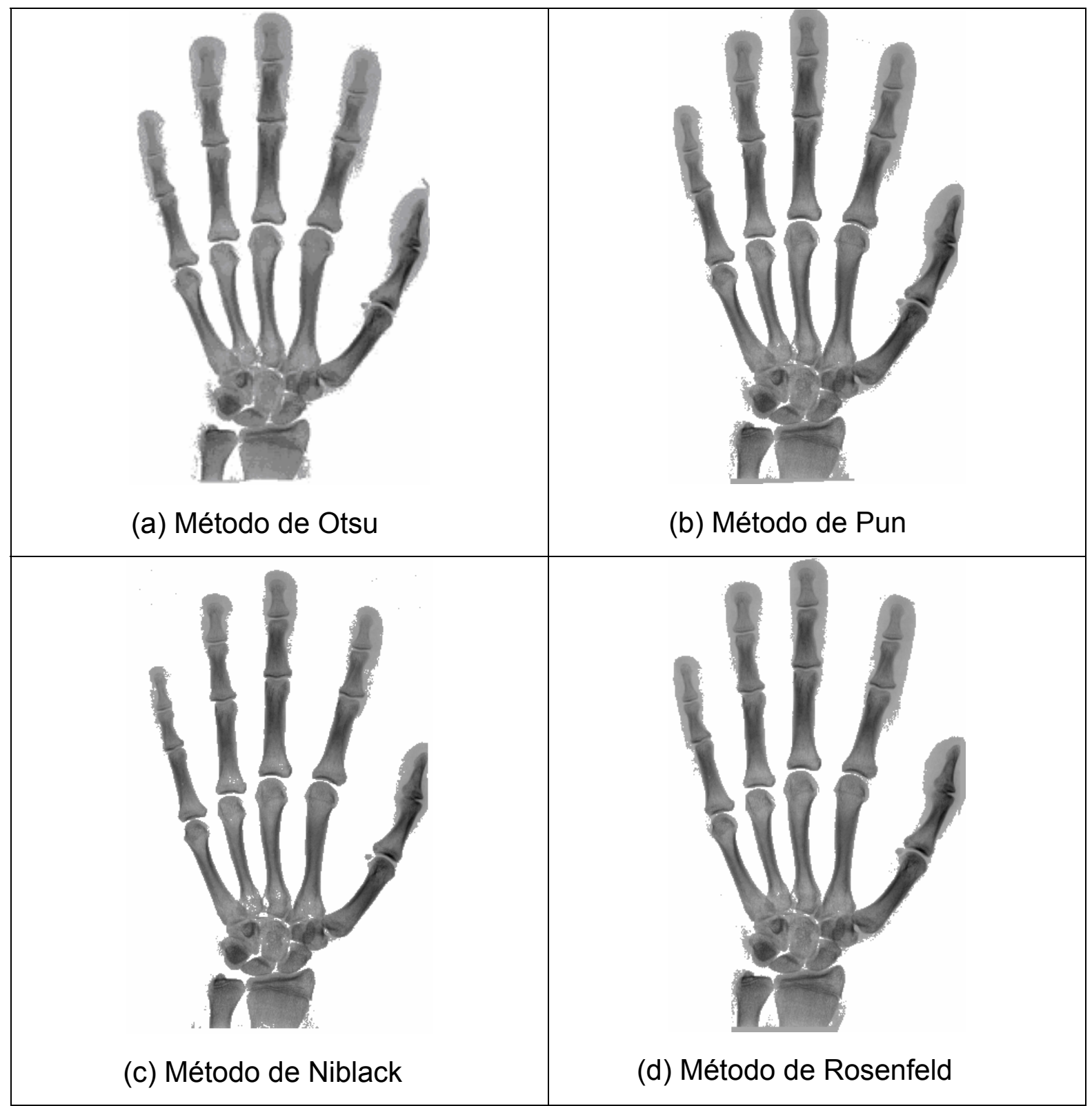

Figura 15(a,b,c,d) - Imagens processadas pelos métodos de thresholding sem a correção do efeito Heel: (a):Otsu. (b): Pun. (c): Niblack e (d): Rosenfeld 
Após a obtenção das imagens processadas sem correção do efeito Heel, como se pode observar o exemplo na Figura 15, pode-se observar que a aplicação dos métodos de limiarização sobre uma imagem sem a correção do efeito Heel não apresentou uma segmentação total dos ossos, restando alguns pixels pertencentes ao tecido da mão, devido à presença da iluminação não uniforme no fundo da imagem. Essa observação foi também demonstrada em Olivete, Nascimento e Rodrigues (2004a).

\subsection{Resultados sobre uma Imagem após a correção do efeito Heel}

Neste item são apresentados os resultados dos métodos de limiarização sobre a imagem original (Figura 14), porém após a aplicação do algoritmo de correção do efeito Heel. A Figura 16 ilustra o resultado de cada um dos métodos.

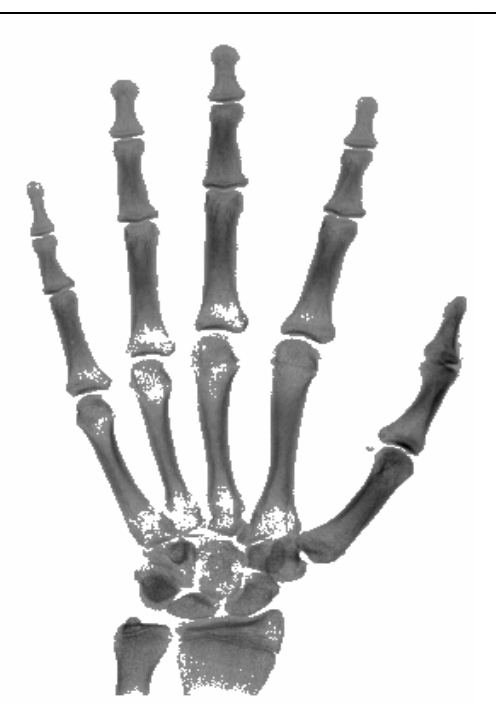

(a) Método de Otsu

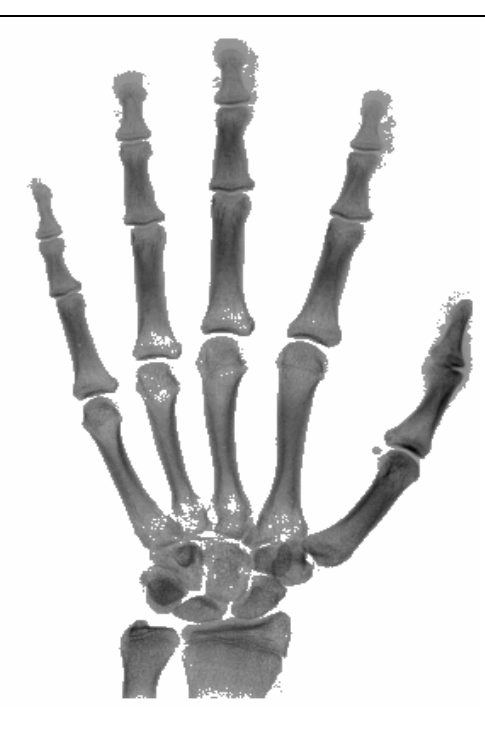

(b) Método de Pun 


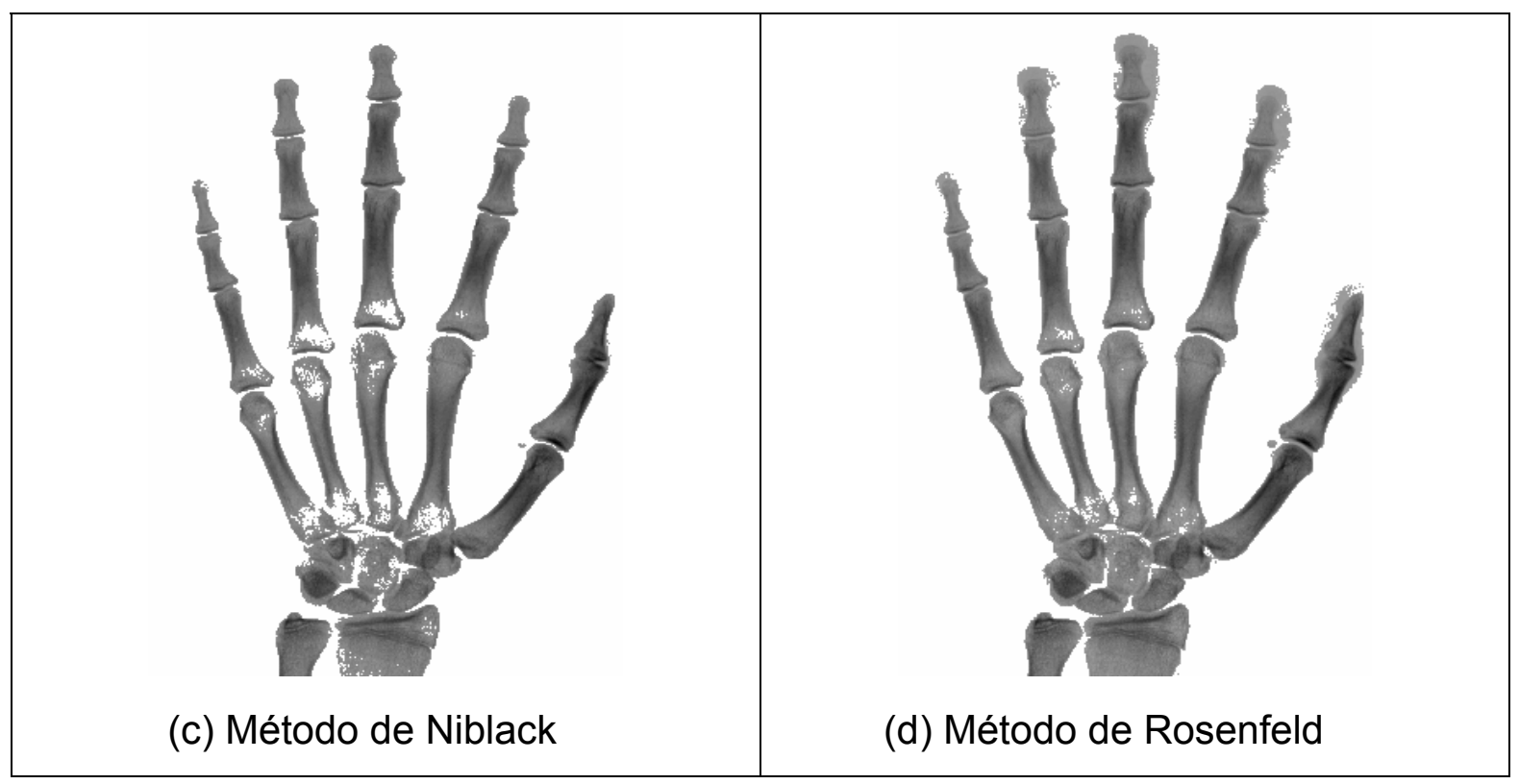

Figura 16(a,b,c,d) - Imagens processadas pelos métodos de thresholding após a correção do efeito Heel: (a):Otsu. (b): Pun. (c): Niblack e (d): Rosenfeld

Observando a Figura 16, nota-se que os resultados dos processamentos dos métodos de thresholding sobre uma imagem após a correção do efeito Heel apresentaram um resultado bem mais satisfatório quando comparados com os obtidos na Figura 15. Estes resultados também foram demonstrados em Olivete, Nascimento e Rodrigues (2004b).

\subsection{Conclusões sobre a segmentação}

Os métodos de limiarização globais de Otsu e Pun foram escolhidos porque encontram um único valor de limiar para toda a imagem, e por isso mostram de uma forma efetiva o resultado da correção do efeito Heel nas imagens. Já os de Niblack e Rosenfeld são métodos adaptativos e encontram um valor de limiar para cada região da imagem, de onde se esperavam resultados de áreas não muito discrepantes entre as imagens com e sem correção do efeito Heel, o que de certa forma ocorreu. 
Os métodos globais e adaptativos foram aplicados em todas as imagens do banco de dados, e verificou-se que o método de Rosenfeld foi o que apresentou o pior resultado. Já a limiarização de Otsu foi a que obteve o melhor resultado em todos os casos, sendo então o método escolhido para segmentar as imagens conforme também observado por Olivete, Nascimento e Rodrigues (2004a).

A etapa da segmentação foi muito importante porque eliminou todos os pixels que de fato não pertenciam aos ossos, proporcionando uma medida exata dos comprimentos e larguras de alguns centros de ossificação, utilizados para a obtenção dos coeficientes de correlação para estimar a idade.

Conforme descrito no item 2.2.3, o método de Eklof \& Ringertz utiliza parâmetros baseados nas informações de 10 ossos da mão. Observando os resultados obtidos (Figura 15 e 15) nota-se que alguns ossos analisados, especificamente os do carpo, apresentam ossos sobrepostos, tornando bastante difícil a obtenção precisa destes parâmetros. Como parte das propostas deste trabalho, que é a obtenção de uma simplificação do método de Eklof \& Ringertz, estes centros de ossificação não deverão participar do processo de estimação da idade óssea. Para verificar a precisão desta simplificação, todos os resultados serão comparados com o laudo médico. A seguir, são descritos os passos necessário para a estimativa da idade óssea.

- Banco de dados de imagens carpais - O banco de dados servirá para armazenar as imagens radiográficas da mão e suas informações (nome do paciente, idade cronológica, resolução em que foi digitalizada a imagem, sexo, entre outras). Foram inseridas 200 imagens no banco de dados juntamente com o laudo médico e mais 250 imagens sem os laudos médico.

- Banco de dados de medidas - Também foi criado um banco de dados com as medidas (em milímetros) de cada centro de ossificação e as suas idades correspondentes para os 10 centros utilizados pelo método de Eklof \& Ringertz. 
- Marcação dos centros de ossificação - A marcação dos centros de ossificação servirá para delimitar o início e o fim de cada osso utilizado na estimativa da idade óssea.

- Obtenção das medidas - Após a seleção de todos os centros de ossificação, é calculado o comprimento de cada um dos ossos utilizando a distância Euclidiana.

- Estimativa da idade óssea - De posse das medidas, é feita uma busca no banco de dados de medidas e estimada a idade óssea.

No próximo capítulo são apresentados os resultados obtidos pela metodologia de Eklof \& Ringertz, utilizando todos os centros de ossificação (10) ossos. Em seguida, são descritos detalhadamente todos os passos, que vão desde a criação do banco de dados de imagens radiográficas da mão até a estimativa da idade óssea. Por fim, é mostrada uma comparação entre o método completo e a simplificação proposta. 


\section{ESTIMATIVA DA IDADE ÓSSEA}

\subsection{Banco de dados de imagens e de medidas}

O banco de dados de imagens carpais é utilizado para armazenar todas as imagens pré-processadas (segmentadas), com as suas respectivas informações, facilitando assim o acesso às mesmas. A Figura 17 mostra a tabela "mão", na qual são armazenados os dados: código da mão, data de nascimento da pessoa analisada, sexo, idade óssea (laudo), resolução da imagem, entre outras. Já a Figura 17b traz a tabela "metacarpico_2_m" que ilustra como são armazenadas as medidas originais propostas pelo método de Eklof \& Ringertz.

\begin{tabular}{|l|} 
mao \\
\hline mao_cod \\
mao_data_rasc \\
mao_sexo \\
mao_idade_ossea \\
mao_resolucao \\
mao_nome \\
mao_imagem \\
mao_idade_cronologica \\
mao_data_analiacao
\end{tabular}

(a)

\begin{tabular}{l} 
metacarpico_2_m \\
\hline cod_idade \\
\hline medida
\end{tabular}

(b)

Figura 17 - Tabelas do banco de dados. (a): mão . (b) metacárpico II 
Como pode ser visto na Figura 17b, a tabela serve para armazenar apenas as informações para o osso metacárpico II do sexo masculino. Para cada osso foi construída uma tabela e inseridos os valores das tabelas mostradas no Anexo A.

\subsection{Marcação dos centros de ossificação}

Como descrito no capítulo de análise carpal, o método de Eklof \& Ringertz estima a idade baseando-se na análise de 10 centros de ossificação, localizados entre os ossos da mão e do punho, sendo necessária a marcação de 2 pontos (início e fim) para cada centro, totalizando assim 20 pontos. Um dos grandes problemas encontrados durante esse procedimento está diretamente relacionado com os ossos do carpo e do punho, que se encontram sobrepostos, dificultando assim a delimitação correta dos ossos e, conseqüentemente, a obtenção exata de comprimento/largura dos mesmos. Este e outros problemas encontrados nesta região da mão estão descritos no capítulo 3.

A proposta deste trabalho é a utilização do método de Eklof \& Ringertz, propondo porém, uma simplificação do mesmo baseada na redução do número de centros de ossificação a serem analisados para a estimativa da idade óssea. Nesta metodologia serão utilizados apenas 5 centros de ossificação (localizados apenas nos dedos), sendo necessária a inserção de apenas 10 marcadores. Para facilitar a estimativa, os marcadores são automaticamente inseridos. Os passos do algoritmo que insere os marcadores são descritos a seguir:

- Inicialmente vale ressaltar que todas as imagens estão em níveis de cinza e segmentadas, mantendo-se as intensidades originais dos pixels para os dedos, punho e carpo, exceto o fundo que apresenta valor de intensidade igual a 255, atribuído após a utilização de um algoritmo de limiarização (Otsu), descrito no capítulo 4. O resultado desta segmentação é apresentado no capítulo 5. 
- Para selecionar os dedos da imagem analisada construiu-se um procedimento que realiza uma varredura na horizontal (colunas $\mathrm{x}$ linhas), partindo-se da coluna e linha inicial (zero), até encontrar um pixel com intensidade diferente de 255 (cor do fundo). Levando em consideração que o terceiro dedo (que contém ao metacárpico III) é o maior, então o primeiro pixel encontrado indicará o seu início (coluna_inicial). Após a localização desse ponto é traçada uma curva a partir desta coluna selecionada (coluna_inicial_metacarpico_3) até o extremo inferior daquele metacárpico (altura total), guiando-se pelos pixels vizinhos imediatos desta coluna que apresentam valores de intensidades diferentes de 255 (fundo). Para encontrar os outros dois dedos necessários para a análise do método de Eklof \& Ringertz são utilizados os mesmos procedimentos, sendo que para localizar o início do segundo dedo (o qual contém o metacárpico II) é feita uma varredura a partir da coluna tomada como "coluna_inicial_metacarpico_3" somando 30 pixels, ou seja, partindo-se da região imediatamente ao lado do terceiro dedo. Para a localização do quarto dedo (metacárpico IV), é atribuído um valor para a coluna igual a coluna_inicial_metacarpico_3 - 30 pixels, e o procedimento se repete. Essas curvas irão servir como referência para isolar os centros de ossificação;

- O primeiro e o último dedo são descartados, pois a metodologia irá utilizar apenas os ossos do metacárpico II, III e IV e falange proximal II e III (ossos representados por 6, 7, 8, 9, 10 da Figura 18);

- É feita uma varredura a partir da primeira curva traçada (dedo do meio) do início para o fim, analisando um pixel da direita e um da esquerda dessa linha. Se o valor de intensidade deste pixel for igual a 255 (indica que é o fundo da imagem e portanto, a separação entre ossos) é inserido um marcador inicial e busca-se o próximo vale (valor 255 
vizinho da reta) para inserir o marcador final deste osso, isolando assim um centro de ossificação. Prosseguindo assim até o final da reta.

- Este passo é realizado para os outros dois dedos. Na primeira reta analisada (dedo do meio) e na reta pertencente ao dedo do segundo metacárpico, são desconsiderados os dois primeiros centros de ossificação obtidos (falange distal e média), mantendo-se apenas os centros de ossificação das falanges proximais e dos metacárpicos. No dedo onde se encontra o metacárpico IV são desconsiderados os três primeiros centros de ossificação obtidos (falanges), mantendo-se apenas o do metacárpico IV. Após a eliminação de todos estes centros citados acima, restam apenas 10 marcadores, resultando em 5 centros de ossificação para estimação da idade óssea, tratando-se assim de uma simplificação do método de Eklof \& Ringertz.

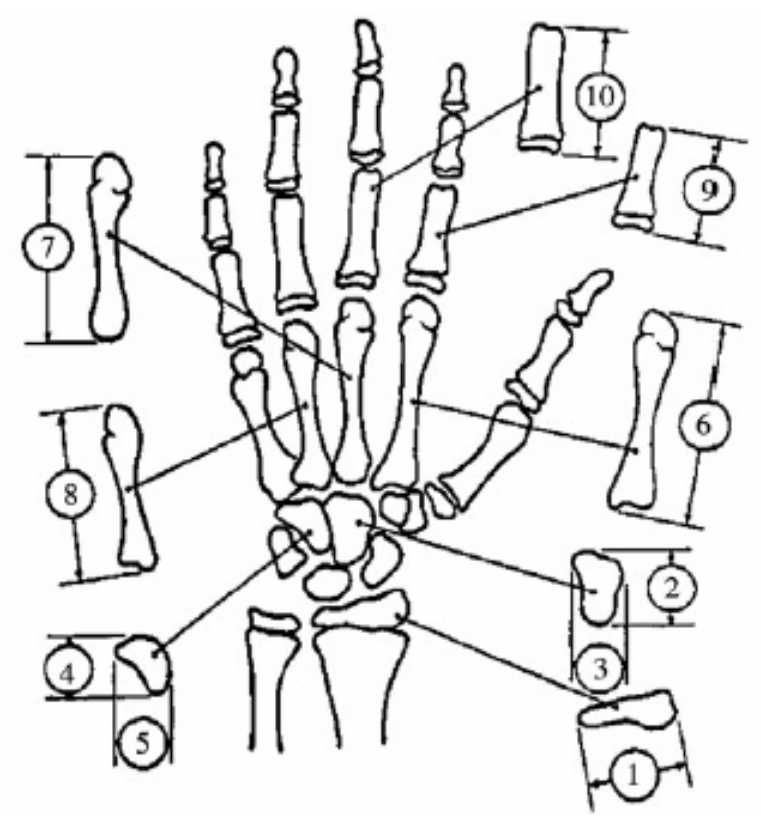

Figura 18 - Centros de ossificação utilizados pelo método 
Ao final, poderá ser verificado juntamente a um mapa, semelhante ao da Figura 18, se os marcadores foram corretamente inseridos, sendo possível alterar a posição final de cada um deles. Este e os outros passos para a estimativa da idade óssea estão exemplificados no capítulo 7 .

A Figura 18 já foi utilizada no capítulo 2, mas foi novamente inserida nesta seção para facilitar a visualização dos centros de ossificação utilizados para estimar a idade óssea.

\subsection{Obtenção das medidas e estimativa da idade óssea}

Após a inserção dos marcadores, é calculado o comprimento de cada marcador utilizando-se a distância Euclidiana (SWOKOWSKI, 1994) obtendo-se assim um valor em pixels. Como a tabela de medidas proposta pelo método de Eklof \& Ringertz trabalha com unidade em milímetros, é necessário realizar a conversão de pixels para milímetros. A conversão é feita baseando-se na resolução da imagem, sendo este um critério importante no momento da inserção da imagem no banco de dados. A resolução da imagem é definida pelo scanner, sendo medida em pontos por polegada (ou dpi, dots per inch), o que informa quantos pontos de informação existem numa determinada área digitalizada pelo equipamento. A dimensão de cada pixel é obtido dividindo-se o valor da polegada $(25,4 \mathrm{~mm})$ pela resolução em que foi digitalizada a imagem. (DALMOLIN, et. al., 1998).

Como dito anteriormente, o método de Eklof \& Ringertz estima a idade óssea a partir da análise das dimensões de alguns centros de ossificação, em milímetros $(\mathrm{mm})$. A dimensão para cada um dos centros de ossificação (ver Figura $18)$ é obtida através da seguinte equação:

$$
\text { Dist }=\left(\left(\frac{P}{R}\right) * D\right)
$$


onde: $\mathrm{P}$ é o valor da polegada $(25,4 \mathrm{~mm}), \mathrm{R}$ a resolução em que foi digitalizada a imagem, D é a dimensão encontrada, em milímetros $(\mathrm{mm})$, para o centro de ossificação em análise, utilizando a Distância Euclidiana.

De posse das medidas dos ossos em $\mathrm{mm}$ é feita uma busca osso a osso, no banco de dados, na tabela de medidas, para verificar qual é a idade que mais se aproxima desta medida. A idade final é obtida através da média da idade obtida pelos cinco ossos.

No próximo item são apresentado os resultados da estimativa da idade óssea obtidos, utilizando os 10 centros de ossificação (método completo).

\subsection{Resultados obtidos utilizando a metodologia proposta por Eklof \& Ringertz}

Neste item serão apresentados os resultados da estimativa da idade óssea utilizando todos os pontos de análise (10 centros de ossificação) propostos pelo método de Eklof \& Ringertz em sua forma original.

Inicialmente utilizou-se, de forma manual, o software desenvolvido para marcar os 10 centros de ossificação e estimar a idade óssea em todas as imagens do banco de dados que apresentavam valores de laudo médico, num total de 200 imagens, sendo 100 de cada sexo. Considerou-se valores de desvio padrão no intervalo que varia de 0.1 a 0.5 anos. A Figura 19 ilustra os resultados obtidos utilizando o intervalo de desvio padrão, em relação ao laudo médico, para as imagens do sexo feminino e masculino. 


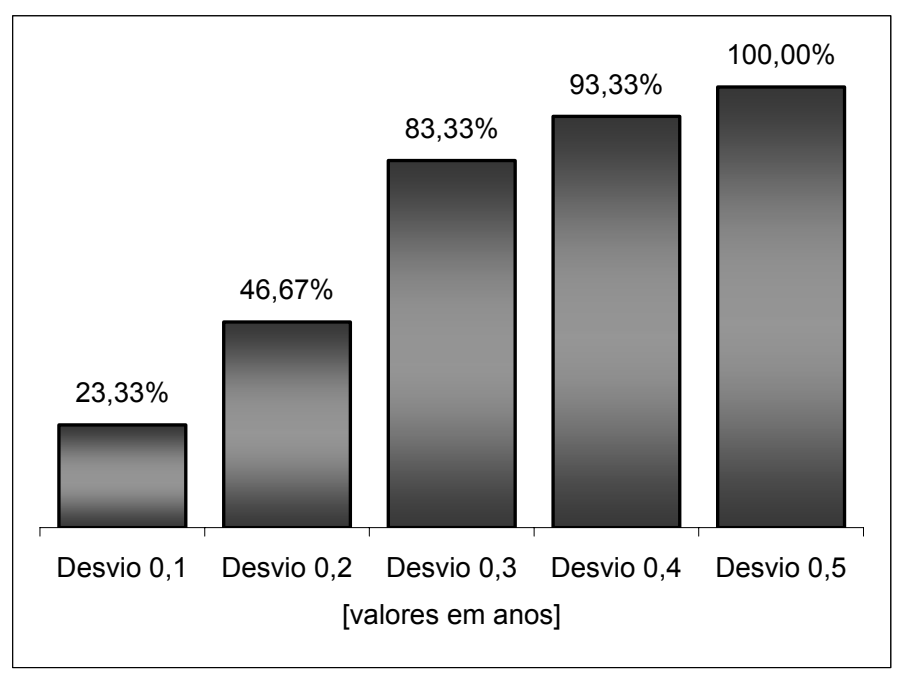

(a) Conjunto de imagens do sexo feminino

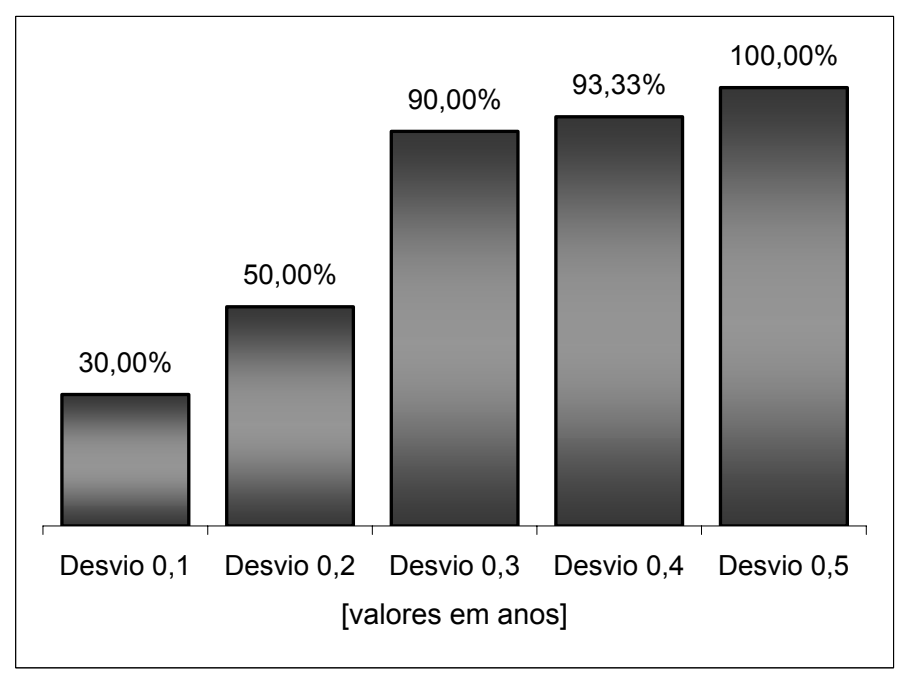

(b) Conjunto de imagens do sexo feminino

Figura 19 - Resultados obtidos utilizando os 10 centros de ossificação comparados com os laudos médicos. (a): imagens do sexo feminino . (b): sexo masculino

Analisando a Figura 19, verifica-se que quando utilizados os valores de desvio padrão de 0.1 e 0.2 anos, a porcentagem de concordância com o laudo médico foi muito baixa. Estes resultados já eram esperados, pois neste intervalo de desvio padrão estão representados valores menores que 1 e 2 meses de idade respectivamente. Quando utilizado desvio de 0,3 anos os resultados apresentam uma concordância de $90 \%$. Utilizando-se desvio de 0.4 anos, os resultados foram bastante melhores $(93,33 \%$ em ambos os casos). Quando utilizado o desvio 
padrão de 0.5 anos, o resultado foi de $100 \%$ de concordância. Com essa análise conclui-se que o valor de desvio padrão de 0.4 anos pode ser usado para estimar a idade óssea com uma boa margem de concordância com o laudo médico.

Como dito anteriormente, todos os laudos obtidos a partir do software foram comparados com os laudos médicos. Realizou-se também uma segunda análise utilizando um fantoma antropomórfico de mão da Phantom Laboratory (Figura 20), pertencente à Universidade de Mogi das Cruzes no laboratório de imagens médicas da professora Dra Márcia A. S. Bissaco. É um fantoma de imagem, obtido de um modelo com dimensões apropriadas para testes de controle de qualidade de imagem. As espessuras dos materiais utilizados para envolver os ossos são equivalentes às dimensões das estruturas das extremidades do corpo. Trata-se de um fantoma constituído de ossos da mão e do punho, do sexo masculino com idade de 14 anos (RANDO, 2005). A Figura 20 ilustra o fantoma.

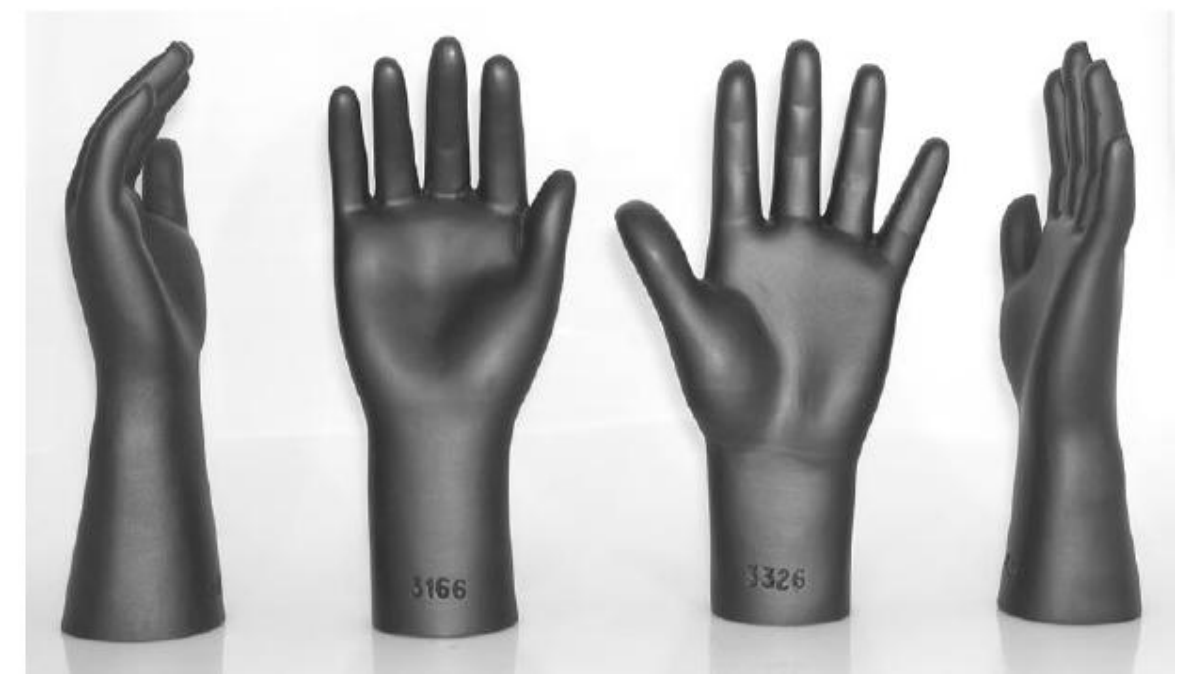

Figura 20 - Fantoma antropomórfico utilizado para realizar testes Fonte: Rando (2005)

A Figura 21 ilustra a imagem digitalizada do fantoma, utilizando resolução de 300 dpi. 


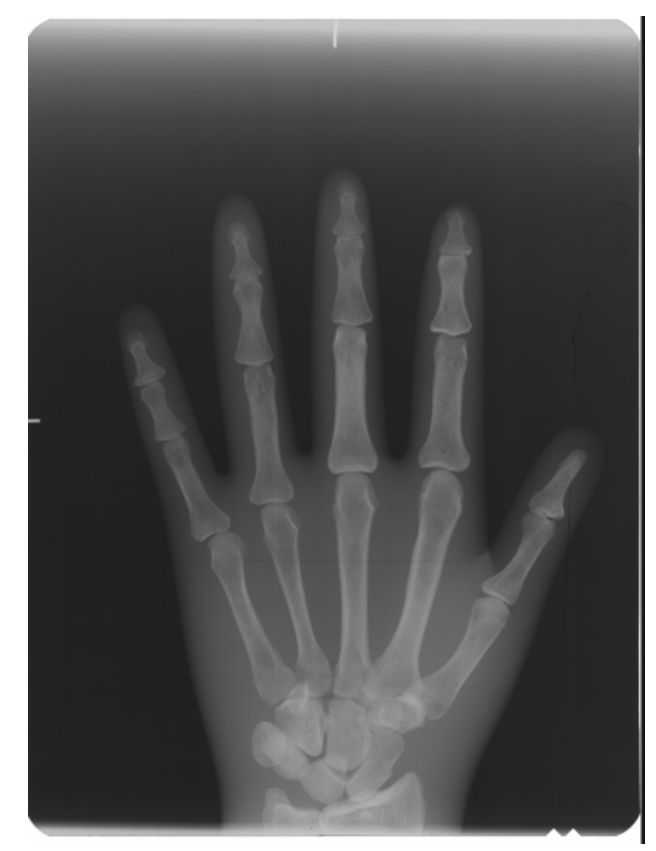

Figura 21 - Imagem digitalizada do fantoma antropomórfico

Inicialmente foi obtida a idade óssea com o software desenvolvido para este trabalho, utilizando uma imagem com resolução de 300 dpi, e em seguida, foi novamente estimada a idade óssea, porém, com uma resolução inferior, obtendose os mesmos resultados em ambos os casos. Confirmando assim a precisão do software em relação ao valor da resolução de digitalização.

Como citado anteriormente, alguns ossos do carpo e do punho, em alguns casos, se apresentam sobrepostos, dificultando assim a delimitação e obtenção das medidas dos centros de ossificação. Como tentativa de solução deste problema, a estimativa da idade óssea será baseada na análise de apenas 5 centros de ossificação, compostos por falanges e metacarpos, descartando os do carpo e punho. 


\section{SOFTWARE DESENVOLVIDO}

Neste capítulo serão mostradas todas as funcionalidades do software, e os passos necessários desde o cadastro da imagem no banco de dados, até a estimativa da idade óssea utilizando uma simplificação do método de Eklof \& Ringertz.

O software foi desenvolvido utilizando a linguagem $\mathrm{C}++$ através da plataforma de desenvolvimento Borland $\mathrm{C}++$ Builder 5.0. $\mathrm{O}$ banco de dados utilizado foi o Interbase 6.0.

\subsection{Funcionalidades do software}

O software foi desenvolvido utilizando a plataforma de programação da Borland, o C++ Builder 5.0. Na tela principal do software encontram-se todos os processamentos descritos nos capítulos anteriores, como por exemplo: abrir e segmentar uma imagem, cadastrar a imagem no banco de dados, fazer as marcações dos centros de ossificação, estimar a idade óssea, entre outras. A Figura 22 ilustra a tela principal do software. 


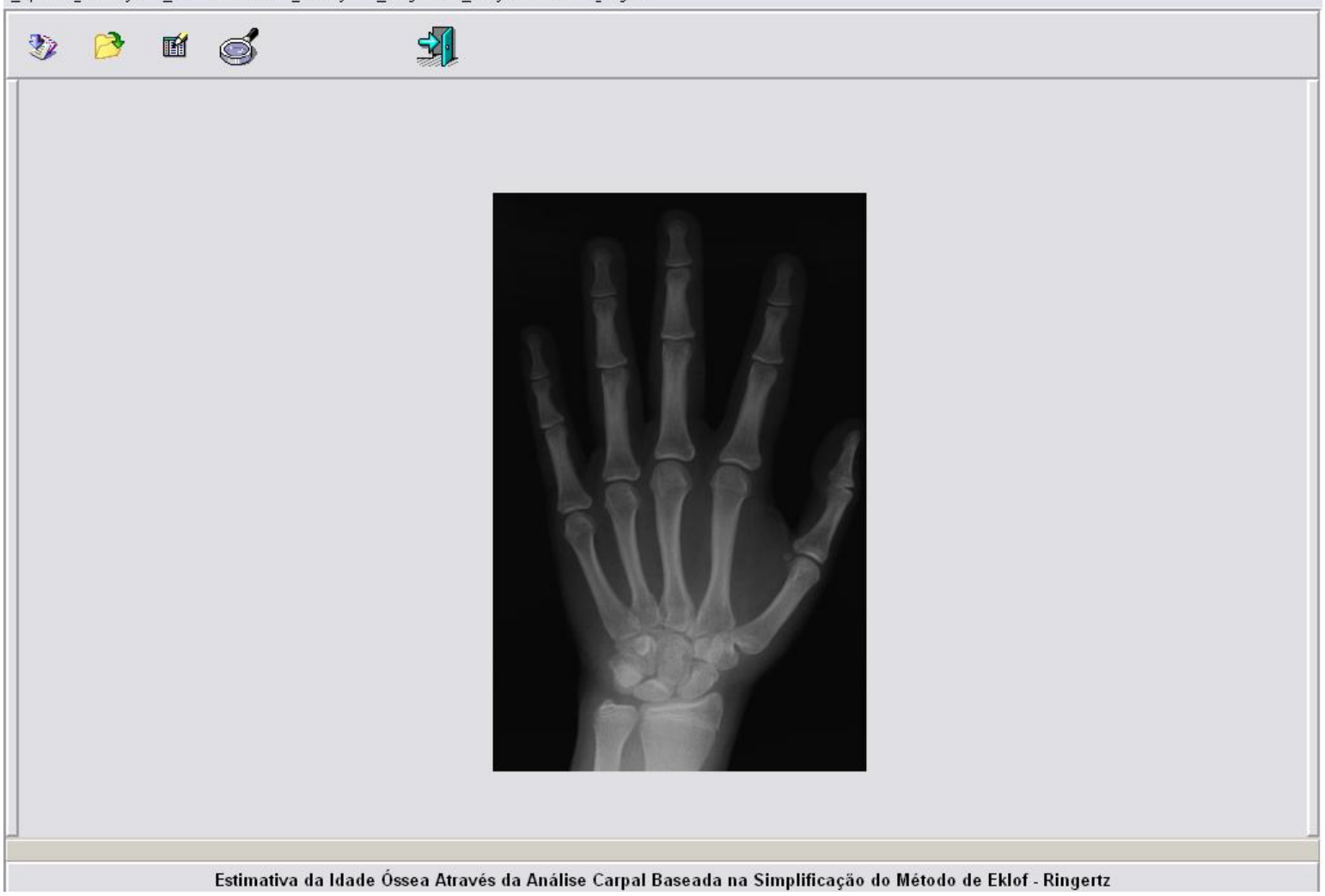

Figura 22 - Tela principal do software

\subsubsection{Segmentando a imagem}

Para segmentar uma imagem é necessário que ela se apresente no padrão Bitmap ( ${ }^{*}$.bmp) com 256 níveis de intensidade na escala de cinza. Os passos para a segmentação são: abrir a imagem original (Figura 23a), aplicar o filtro de suavização (média 11 x 11) (Figura 23b) e, em seguida, aplicar um método de limiarização (Figura 23c). 


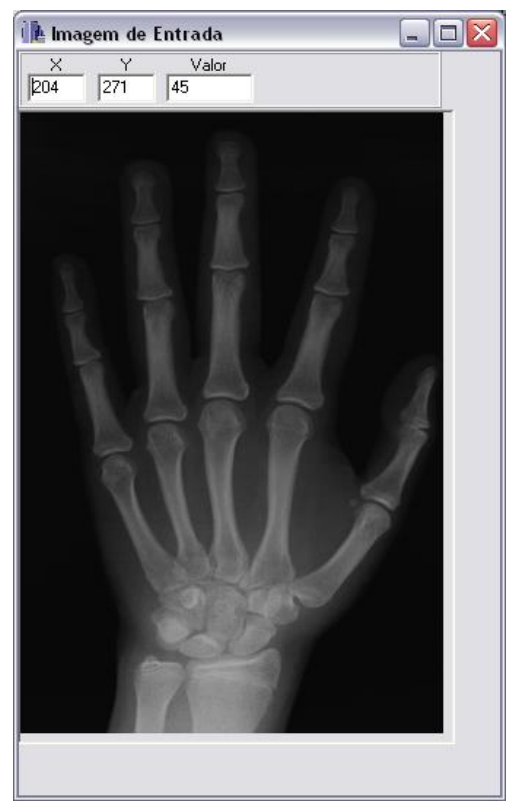

(a)

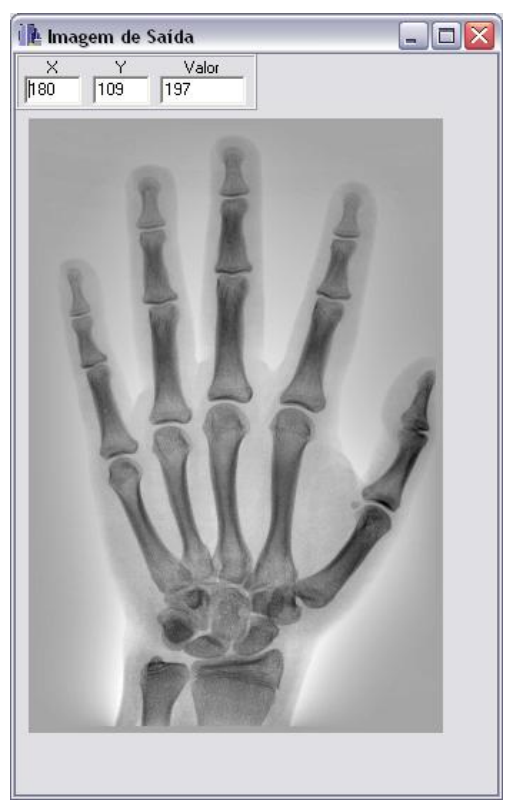

(b)

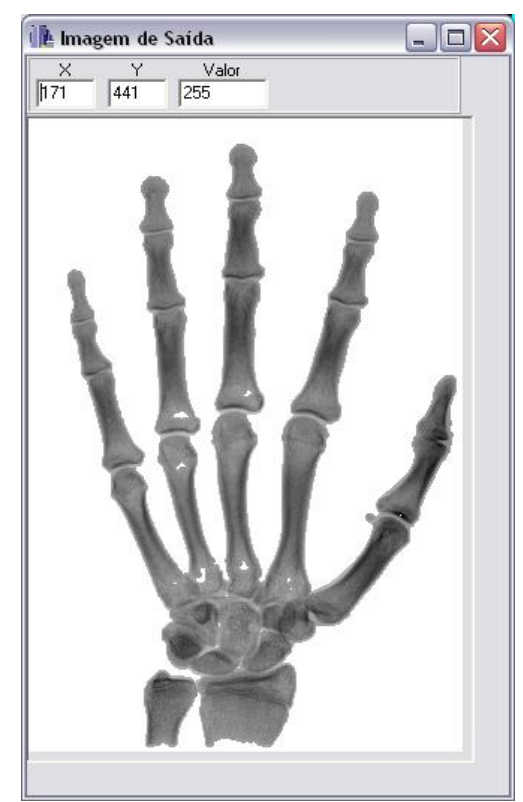

(c)

Figura 23 - (a): Imagem de entrada. (b): imagem suavizada. (c): imagem segmentada

Como pode ser visto na Figura 23, a imagem resultante (Figura 23c) contem apenas os ossos da mão, mostrando que os passos da segmentação conseguiram fornecer uma imagem adequada para as análises posteriores, eliminando o efeito Heel, através do uso de um procedimento computacional desenvolvido por Nascimento et al. (2003), e eliminando o fundo e tecido da mão através dessa metodologia desenvolvida. Após ter sido segmentada, a imagem deverá ser cadastrada no banco de dados.

\subsubsection{Cadastrando a imagem no banco de dados}

Para cadastrar a imagem no banco de dados (utilizou-se o Interbase 6.0) é necessário ter em mãos todas as informações sobre a imagem radiográfica carpal, como: o nome do paciente, a data de nascimento, a data de avaliação, o sexo e a resolução em que foi digitalizada a imagem. Uma informação importante é a resolução da imagem, pois é utilizada para calcular-se o comprimento de cada um dos centros de ossificação utilizados pela metodologia de Eklof \& Ringertz. A 
Figura 24 ilustra a tela do software para cadastro das imagens pré-processadas (segmentadas) no banco de dados.

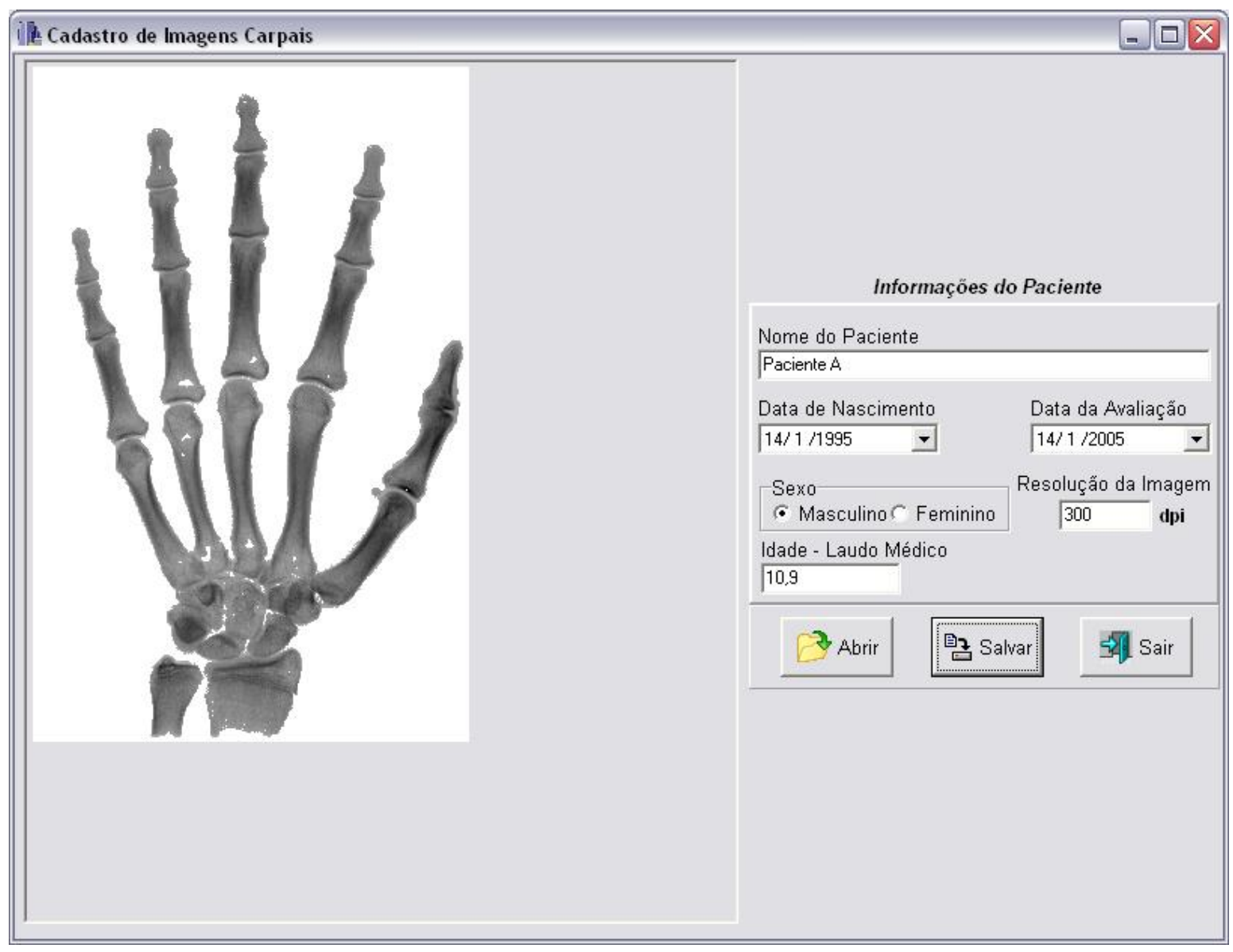

Figura 24 - Cadastro de imagens segmentadas no banco de dados

\subsubsection{Localizando uma imagem no banco de dados}

Como as imagens foram armazenadas no banco com todas as informações então é possível realizar uma consulta às imagens restringindo o sexo e uma faixa etária, tornando a busca bastante rápida e precisa. A tela de consulta ao banco de dados é mostrada pela Figura 25. 


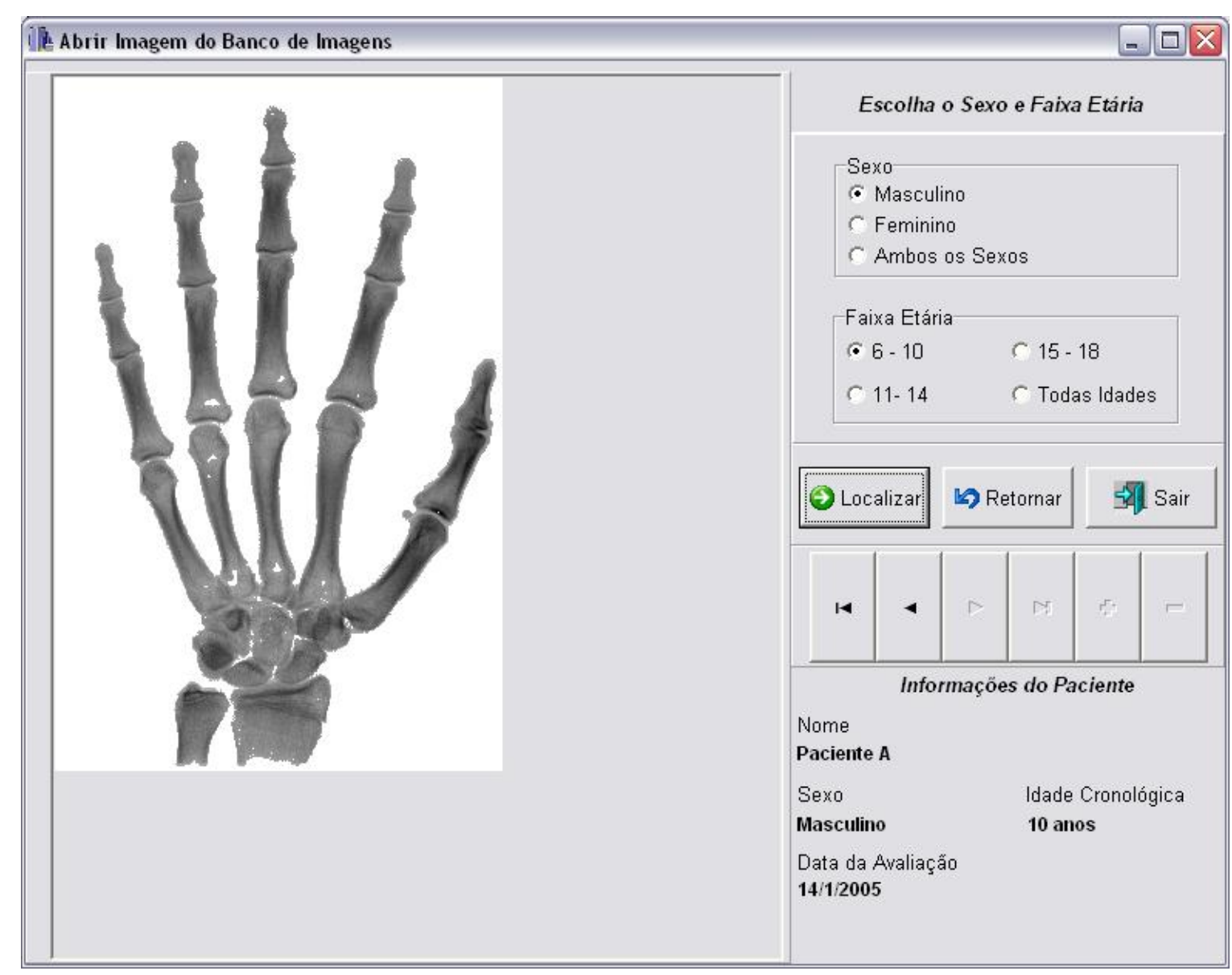

Figura 25 - Localizando uma imagem no banco de dados

Após a localização da imagem carpal, o próximo passo é a realização das marcações dos centros de ossificação utilizados pelo método de Eklof \& Ringertz.

\subsubsection{Marcando os centros de ossificação}

Inicialmente o software realiza automaticamente as marcações dos centros de ossificação (Figura 26a), e em seguida, é disponibilizado um mapa (Figura 26b) com as posições corretas dos 10 centros de ossificação. O próximo passo é verificar se os pontos que foram automaticamente inseridos estão nas posições corretas, caso contrário, será necessário ajusta-los. A posição de cada ponto poderá ser alterada clicando-se sobre o ponto e arrastando-o para a posição 
desejada, tendo como referência o mapa proposto pelo método de Eklof \& Ringertz (Figura 26b).

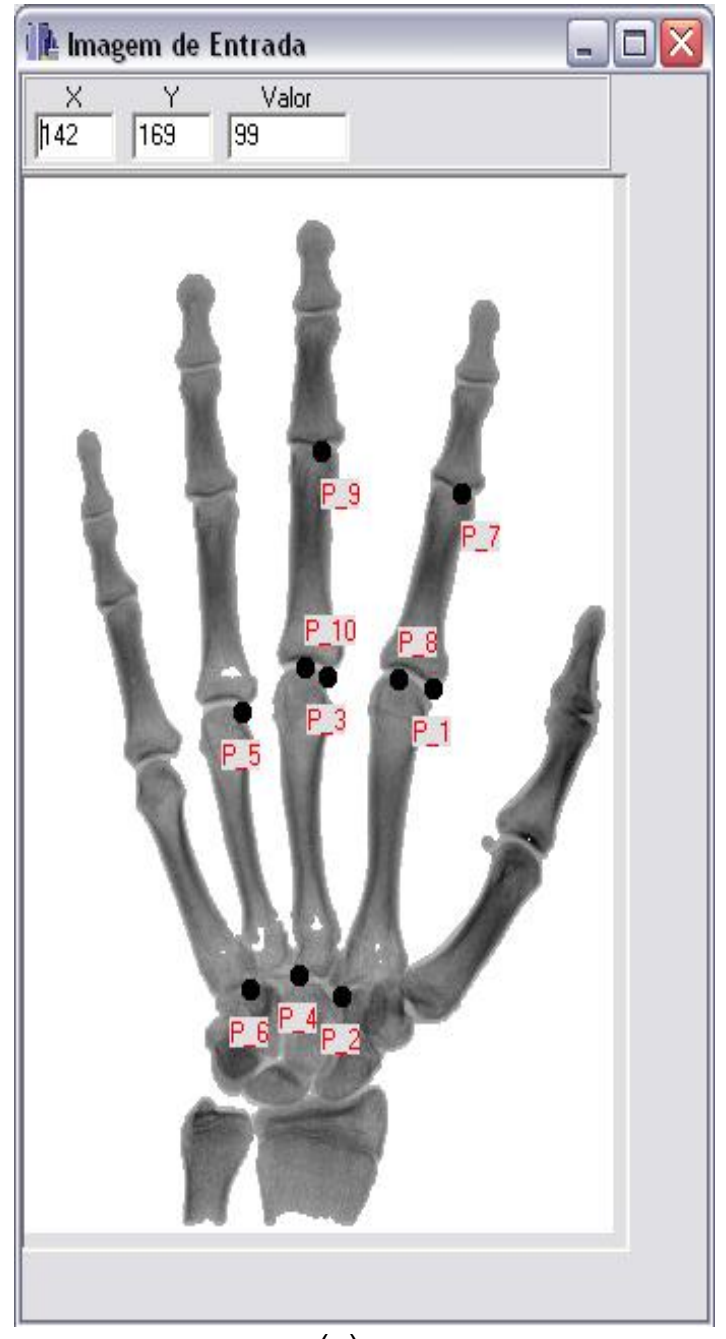

(a)

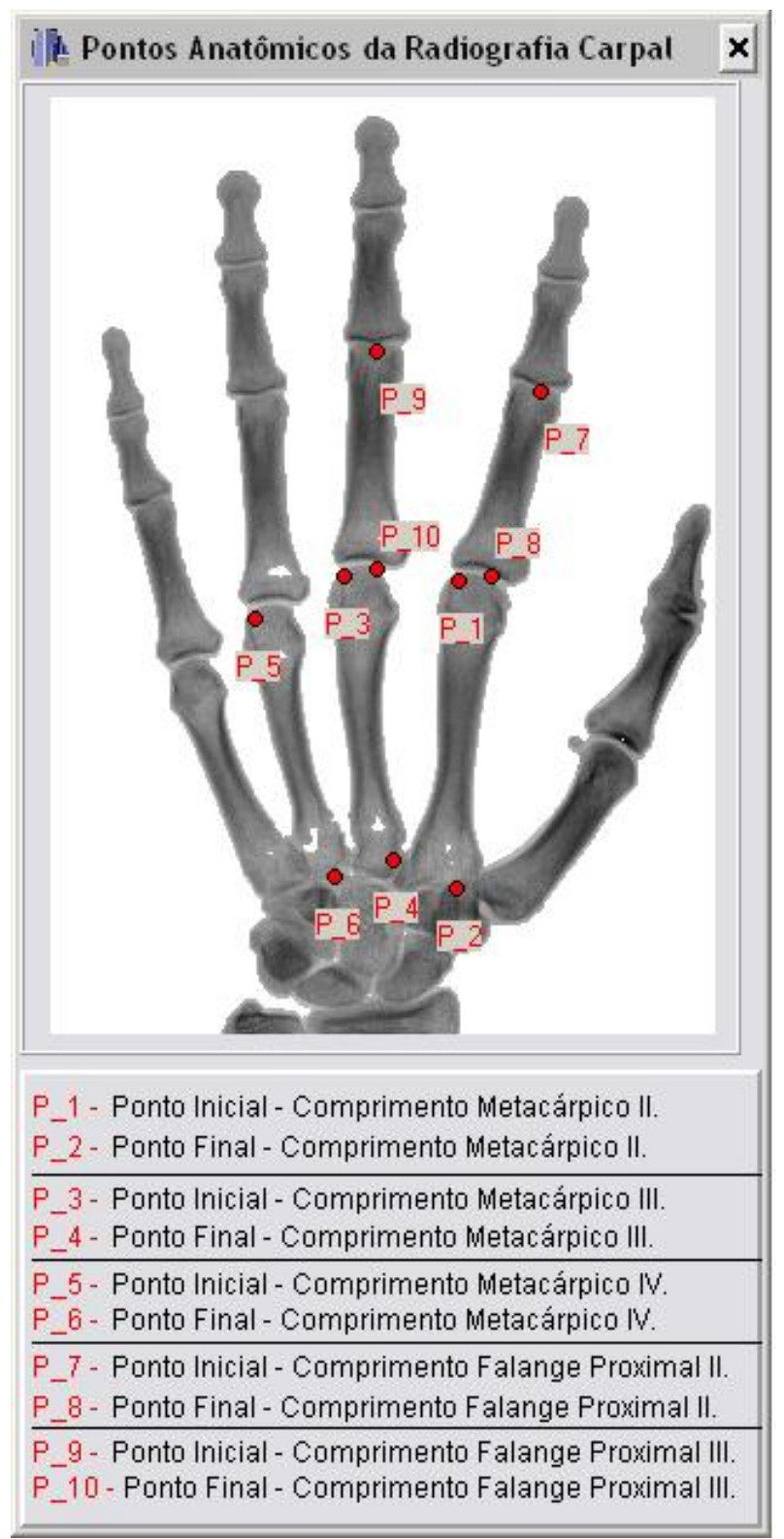

(b)

Figura 26 - (a): Marcações estimada dos centros de ossificação. (b): localização correta dos pontos utilizada por Eklof \& Ringertz

Após o ajuste de todos os pontos que formam os centros de ossificação, é apresentada uma tela com as medidas (em milímetros) encontradas para o metacárpico II (P_1 e P_2), metacárpico III (P_3 e P_4), metacárpico IV (P_5 e 
P_6), falange proximal II (P_7 e P_8) e falange proximal III (P_9 e P_10). A Figura 27 ilustra todas essas medidas.

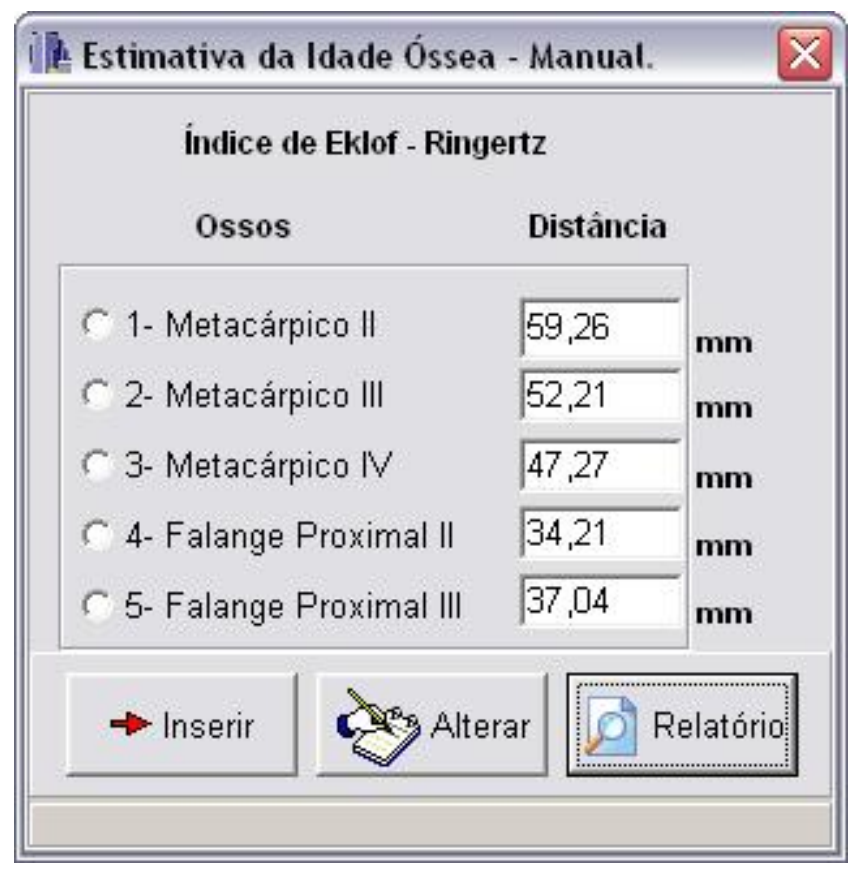

Figura 27 - Dimensões encontradas para os centros de ossificação

\subsubsection{Estimando a idade óssea}

De posse das dimensões dos centros de ossificação, é realizada uma busca na tabela padrão de medidas utilizada pelo método de Eklof \& Ringertz, disponibilizada no ítem 2.2.3., estimando assim a idade óssea de todos estes centros. A idade óssea final é obtida através da média das idades encontradas para os cinco ossos.

Para visualizar esta estimativa é necessário apenas escolher a opção relatório, mostrada na Figura 27, e o software disponibilizará uma tela em formato de relatório, contendo todos os dados da radiografia carpal, bem como as dimensões e idades obtidas para cada centro de ossificação e a idade óssea final estimada. 
A Figura 28 mostra o relatório gerado pelo software da estimativa da idade óssea encontrada para a imagem de entrada (Figura 25).

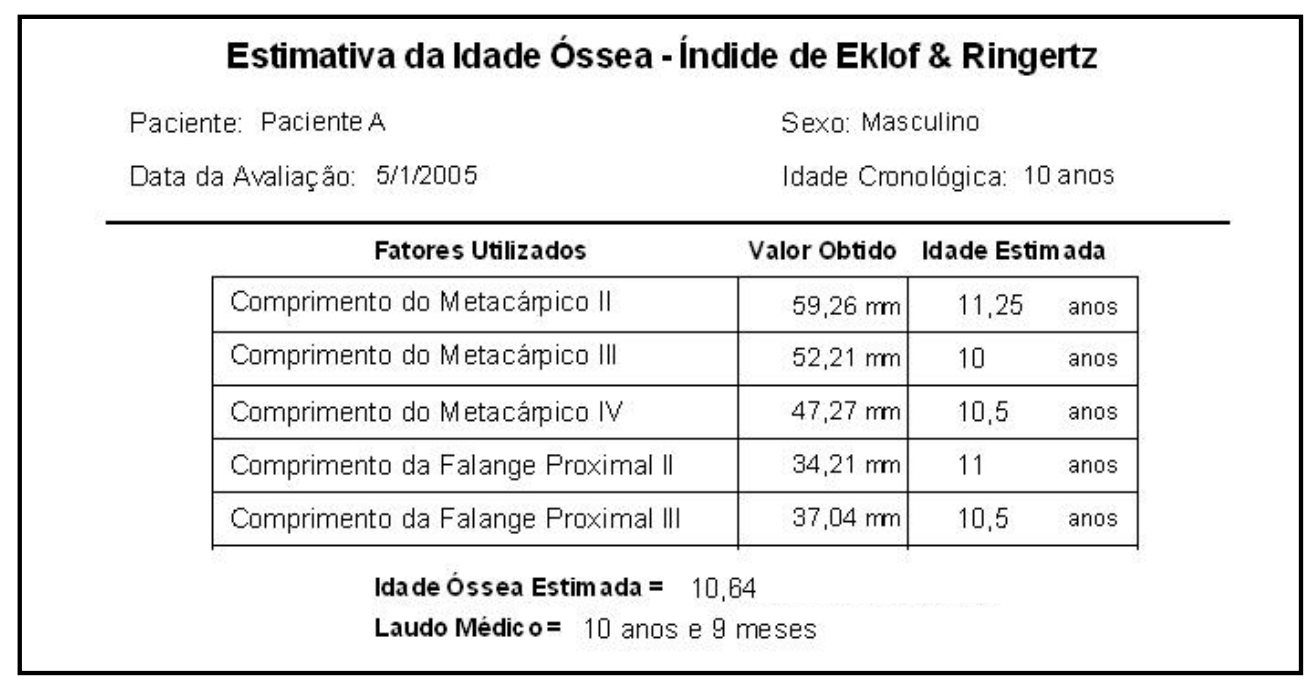

Figura 28 - Relatório da estimativa da idade óssea gerado pelo software

Analisando a Figura 28, nota-se que para cada um dos ossos analisados o software encontrou uma idade óssea diferente e a idade média obtida entre eles foi aproximadamente de 10 anos e 7 meses. A idade cronológica deste paciente, obtida de informações do médico, é de 10 anos. A idade óssea estimada pelo software apresentou apenas 2 meses de diferença com relação ao laudo médico.

O próximo capítulo traz um estudo com o intuito de comprovar a eficiência da simplificação em relação ao laudo médico, em dois conjuntos de imagens (200 imagens no total, sendo 100 de cada sexo). 


\section{RESULTADOS DA SIMPLIFICAÇÃO DO MÉTODO DE EKLOF \& RINGERTZ}

Neste capítulo serão apresentados todos os resultados desta metodologia empregada para realizar a simplificação. É mostrado também um estudo comparativo em todas as imagens do conjunto masculino e feminino, mostrando a eficiência da simplificação realizada sobre o método de Eklof \& Ringertz, utilizando como base de informação os valores obtidos através do laudo médico de cada imagem.

\subsection{Método original $X$ simplificação proposta}

Neste item é apresentada uma comparação entre os resultados obtidos para a estimativa da idade óssea utilizando todos os pontos de análise (10 centros de ossificação) e a simplificação proposta, baseada na análise de 5 centros de ossificação.

Inicialmente foram obtidas todas as idades (utilizando 10 e 5 centros de ossificação) para as imagens do sexo feminino e masculino, levando em consideração um valor de desvio padrão variando de 0.1 a 0.5 anos e, em seguida, gerou-se gráficos para ilustrar a relação das idades estimadas em relação ao laudo médico. A Figura 29 ilustra os resultados da comparação entre o método completo ( $1^{\mathrm{a}}$ coluna do gráfico) e o método simplificado $\left(2^{\mathrm{a}}\right.$ coluna do 
gráfico), que utiliza-se de apenas 5 centros de ossificação, em relação ao laudo médico, para as imagens do sexo feminino. Na Figura 30 são apresentados os percentuais de concordância em relação ao laudo médico para o sexo masculino.
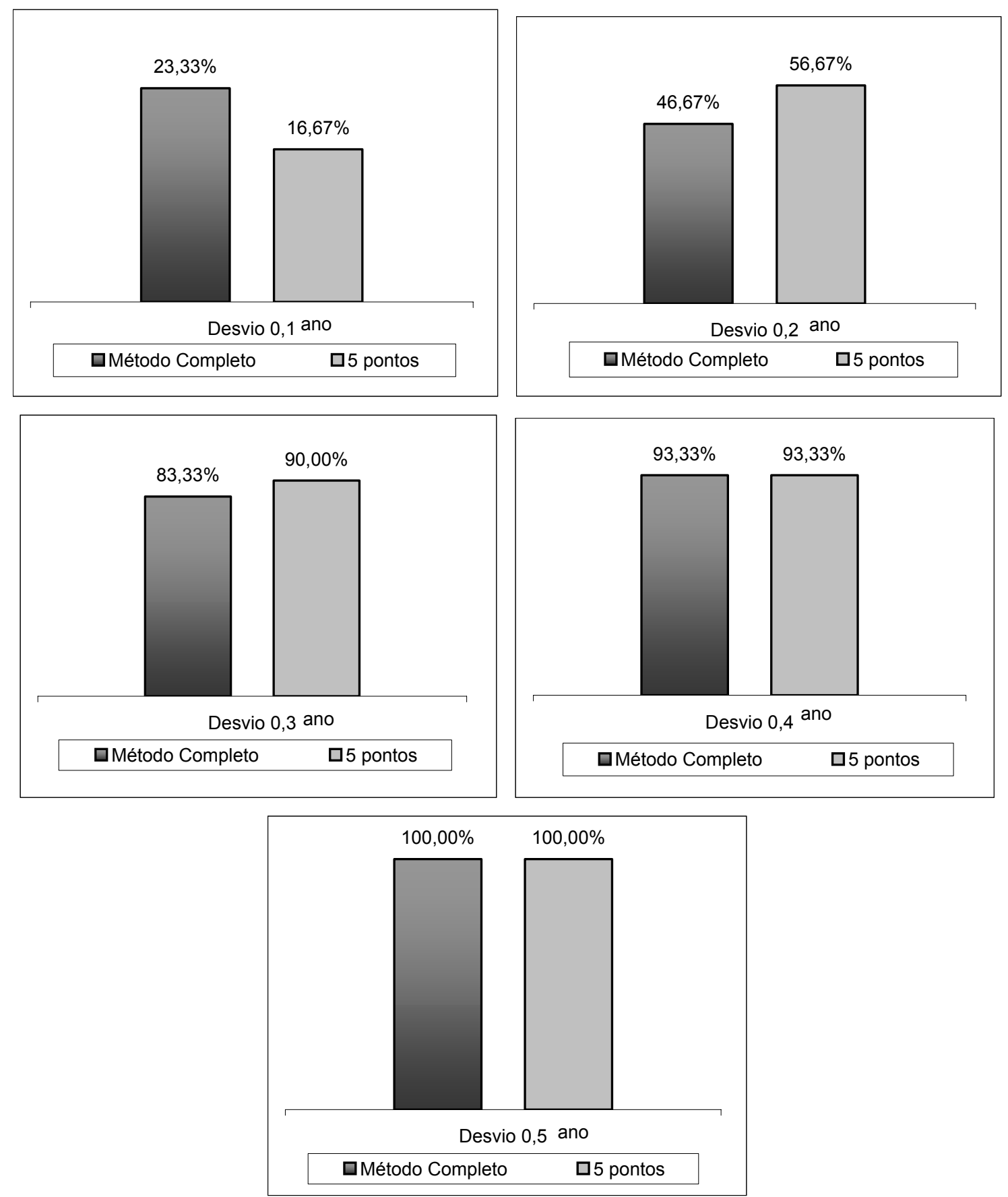

Figura 29 - Método completo X simplificação (5 centros de ossificação) para as imagens do sexo feminino 

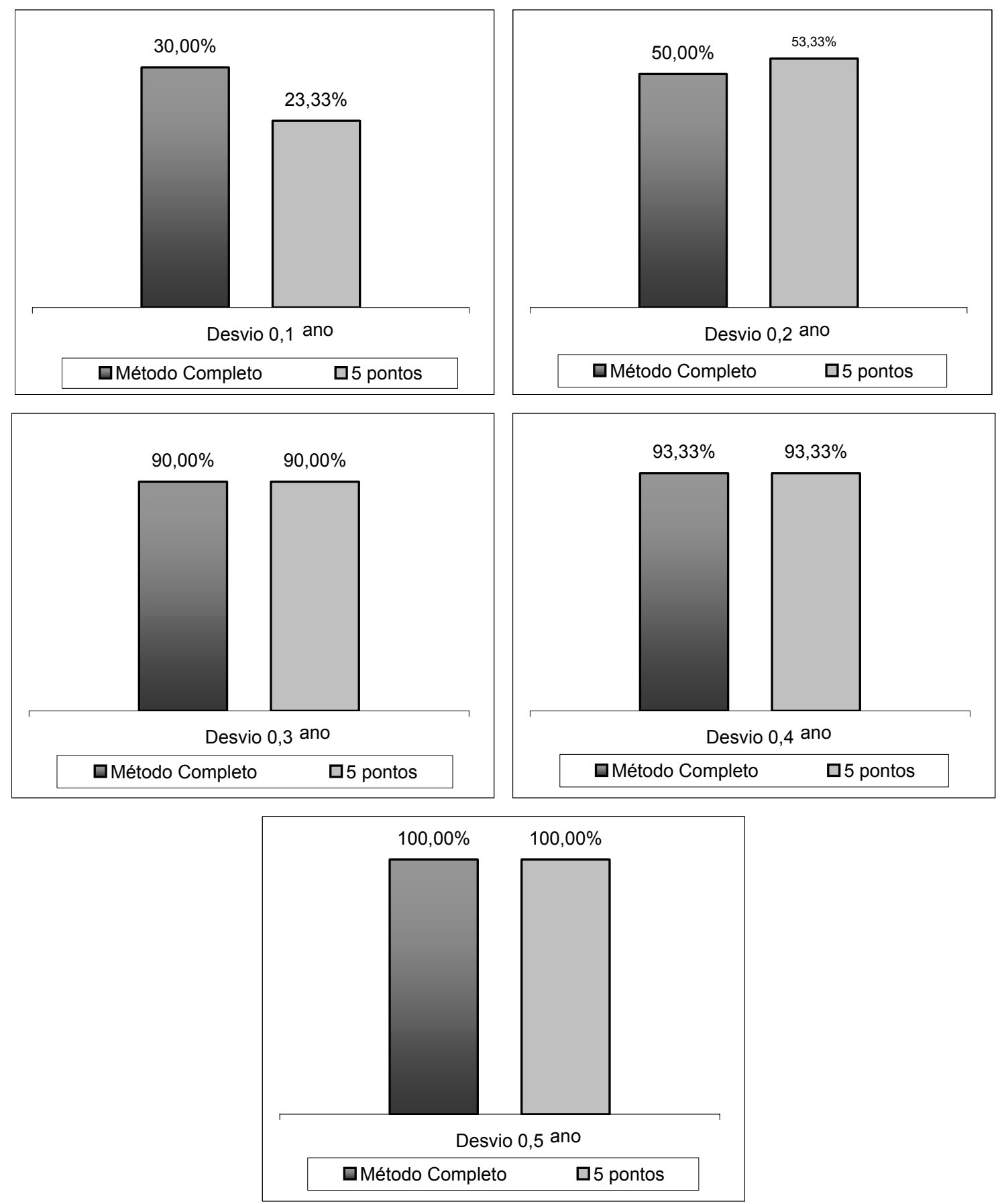

Figura 30 - Método completo X simplificação (5 centros de ossificação) para as imagens do sexo masculino

Analisando as Figuras 29 e 30, nota-se que quando utilizados os valores de desvio padrão de 0.1 e 0.2 anos, para o método completo e para o método simplificado, a porcentagem de concordância foi baixa. Quando utilizados os 
desvios de $0.3,0.4$ e 0.5 anos, os resultados foram bem parecidos, obtendo-se uma discordância de 16,67\% para o pior caso (desvio de 0,3 no sexo feminino) e chegando a $100 \%$ de concordância quando utilizado o desvio padrão de 0.5 anos em ambos os sexos. Com esses resultados pode-se observar que com a análise dos 5 centros de ossificação escolhidos (simplificação) pode-se estimar com confiança a idade óssea a partir do método de Eklof \& Ringertz.

\subsection{Análise da simplificação proposta}

De posse dos resultados apresentados pela simplificação (5 centros de ossificação) buscou-se verificar uma nova simplificação, ou seja, estimar a idade óssea baseando-se na análise de um número inferior a 5 centros de observação. Para isto, foram feitas todas as combinações possíveis entre os 5 ossos selecionados no estudo, comparando-as com o laudo médico e também com os valores obtidos utilizando todos os centros de ossificação (num total de 10 ossos) propostos pelo método de Eklof \& Ringertz. Por se tratar de uma análise com uma quantidade de combinações elevada, foram selecionadas 60 imagens (30 para cada sexo) do banco de dados.

A denominação dos ossos utilizada nas combinações foi: P1 - comprimento do metacárpico II, P2 - comprimento do metacárpico III, P3 - comprimento do metacárpico IV, P4 - comprimento da falange proximal II e P5 - comprimento da falange proximal III.

As combinações entre os cinco centros de ossificação foram: combinação de 5 tomado 2 a 2, 5 tomado 3 a 3, média entre os 5 e média entre os 10 , totalizando 26 combinações, conforme ilustrado no apêndice A. Em seguida, foram gerados gráficos para cada imagem do conjunto, para analisar quais combinações mais se aproximaram do valor do laudo médico. Todos os pontos que apresentaram o mesmo valor do laudo médico, foram selecionados. Quando isso não ocorreu, foram escolhidos os dois que mais se aproximaram do valor ideal, levando em consideração um desvio padrão de 0.4 anos para mais ou para 
menos dos pontos de análise. Este critério foi adotado após um estudo do comportamento destes pontos em relação ao laudo médico e, verificou-se que quando escolhidos os que mais se aproximaram do laudo, também foi possível obter um valor estimado da idade óssea bem perto do ideal.

A Figura 31 ilustra o gráfico com todas as combinações para uma imagem (eixo X). O eixo Y, mostra a idade óssea obtida por cada combinação.

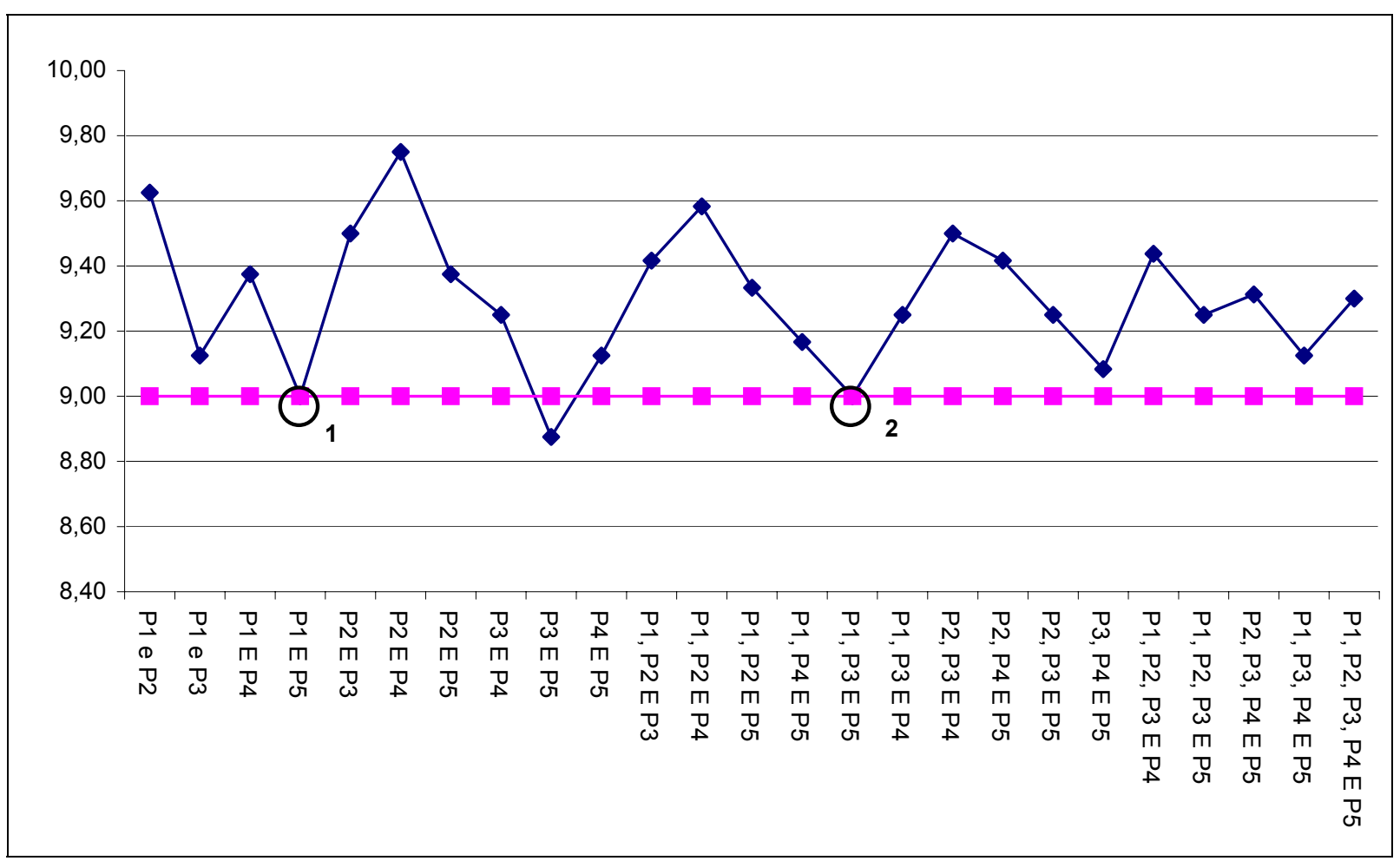

Figura 31 - Gráfico das combinações em relação ao laudo médico

A linha traçada no gráfico refere-se ao laudo médico. Os pontos selecionados para esta imagem (Figura 31) foram as combinações: P1 e P5, P1 P3 e P5, representados pelos círculos nesta seqüência.

Levando em consideração um grande número de imagens analisadas para cada sexo, foram selecionadas algumas imagens e inseridos os seus respectivos gráficos mostrando o comportamento de todas as combinações em relação ao laudo médico. No apêndice B são mostrados os resultados para as imagens do sexo feminino e no apêndice $C$, as do sexo masculino. 
Após analisar todas as imagens do sexo feminino, gerou-se um gráfico (Figura 32) com todas as combinações selecionadas em cada imagem, onde o eixo $\mathrm{X}$ representa a lista de combinações e o $\mathrm{Y}$, o somatório.

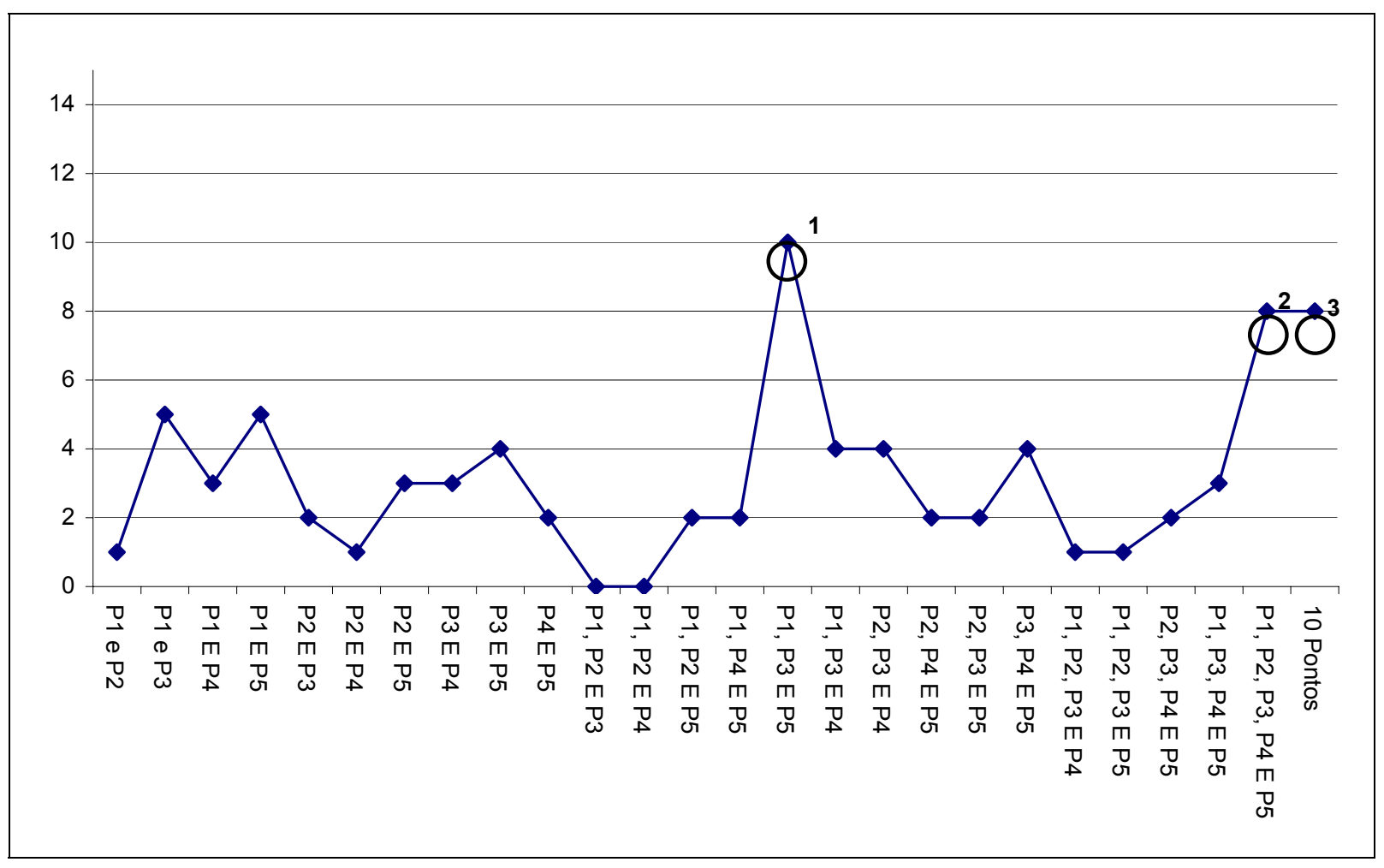

Figura 32 - Gráfico com o somatório das combinações em todas as imagens do sexo feminino

Analisando a Figura 32, pode-se notar que a combinação entre P1, P3 e P5, círculo de número 1, obteve a melhor média para todos os casos, alcançando a idade óssea coincidente com o laudo médico em 10 imagens. A combinação entre os 5 e 10 centros de ossificação, circulo 2 e 3 respectivamente, também obtiveram um somatório bem próximo da melhor combinação.

Foram realizados os mesmos passos para todo o conjunto de imagens do sexo masculino. A Figura 33 mostra o resultado final do somatório de todas as combinações em relação ao conjunto de imagens. 


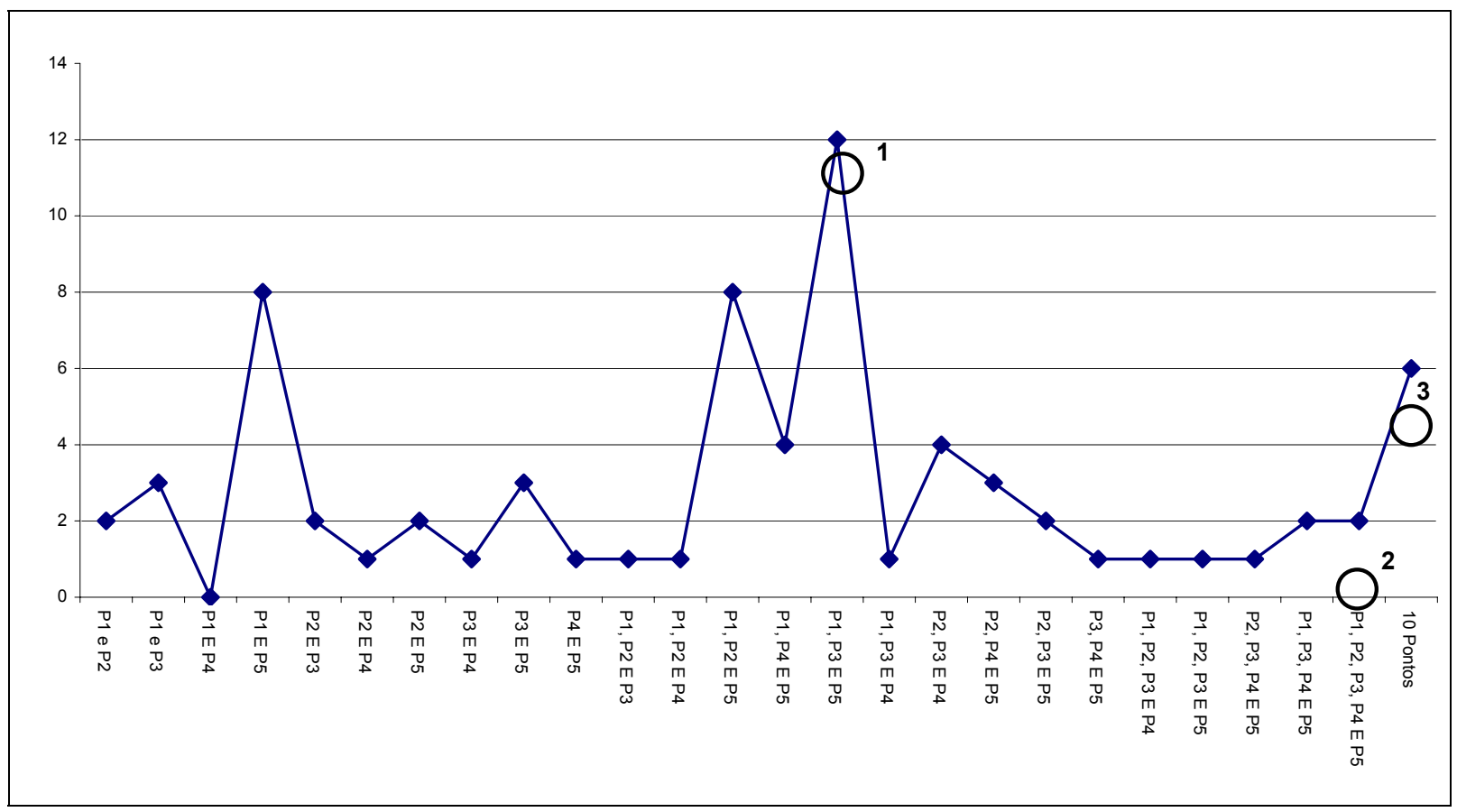

Figura 33 - Gráfico com o somatório das combinações em todas as imagens do sexo masculino

Analisando a Figura 33, observa-se que a combinação entre P1, P3 e P5, representada pelo círculo de número 1 , obteve a melhor média para todos os casos, obtendo a idade óssea coincidente com o laudo médico em 12 imagens. Também obteve um melhor desempenho quando comparado ao resultado obtido para o sexo feminino. Já os resultados obtidos pelas combinações entre os 5 e 10 centros de ossificação, circulo 2 e 3 respectivamente, apresentaram pior desempenho quando comparado ao obtido para o sexo feminino (Figura 32). Observando os gráficos do sexo feminino e masculino, Figuras 32 e 33, nota-se que a média da combinação (P1, P3 e P5) obteve excelente aproximação em relação ao valor do laudo médico, indicando assim uma possível nova simplificação para o método. Para mostrar a eficiência da metodologia e ilustrar os resultados das simplificações, utilizando 5 e 3 centros de ossificação em relação ao método completo (10 centros) baseando-se nos valores dos laudos médicos, foram gerados gráficos, para ambos os sexos, levando em consideração um 
desvio padrão variando de 0.1 a 0.5 anos para mais ou menos. Na Figura 34, são apresentados os gráficos dos resultados obtidos para estas simplificações no conjunto de imagens do sexo feminino.
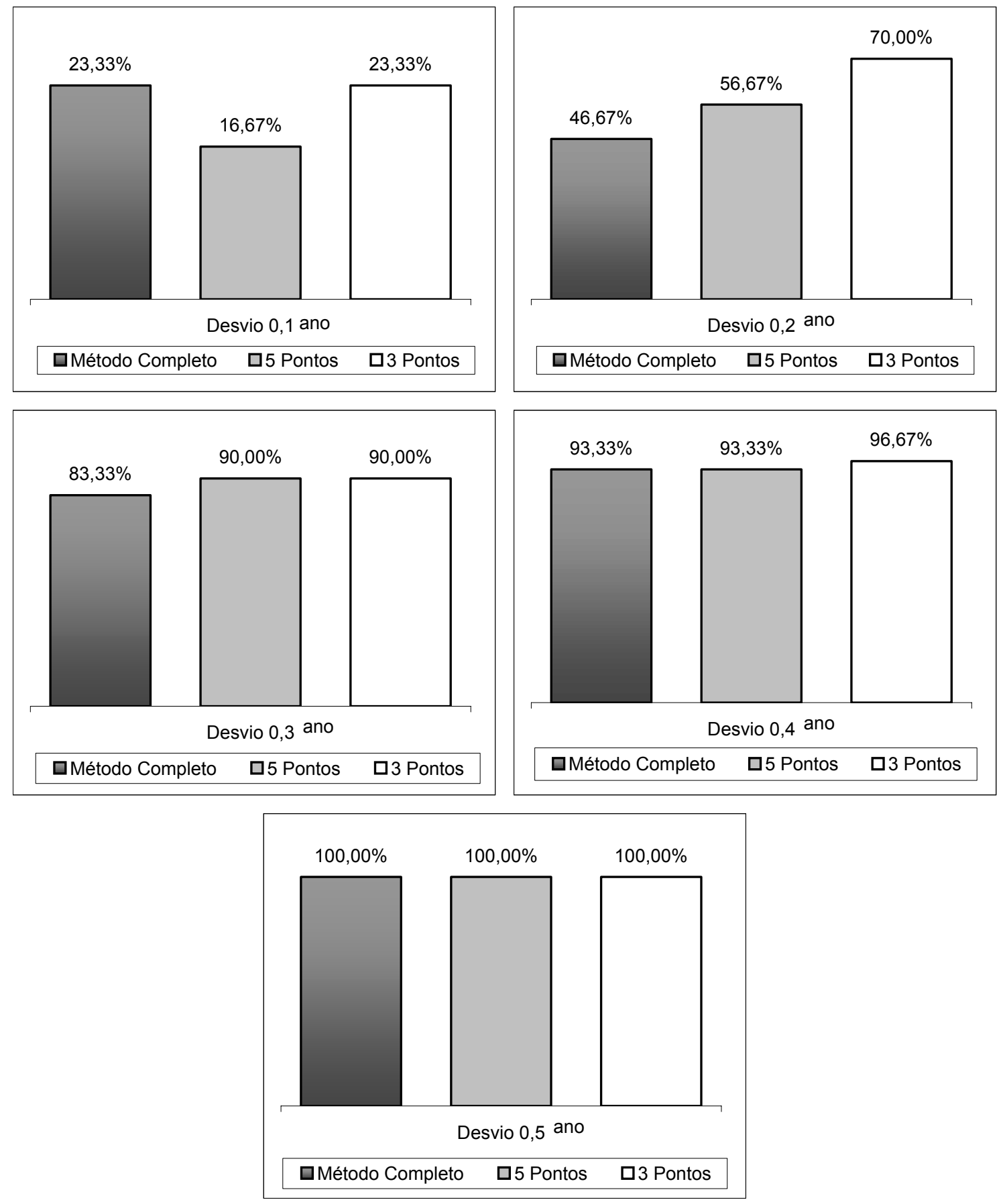

Figura 34 - Comparação entre método completo $X$ simplificação inicial (5 centros de ossificação) e simplificação final (3 centros) para as imagens do sexo feminino 
Analisando a Figura 34, nota-se que a simplificação utilizando apenas 3 centros de ossificação apresentou o melhor resultado em todos os casos. $\mathrm{Na}$ Figura 35 são apresentados os gráficos dos resultados obtidos no conjunto de imagens do sexo masculino.
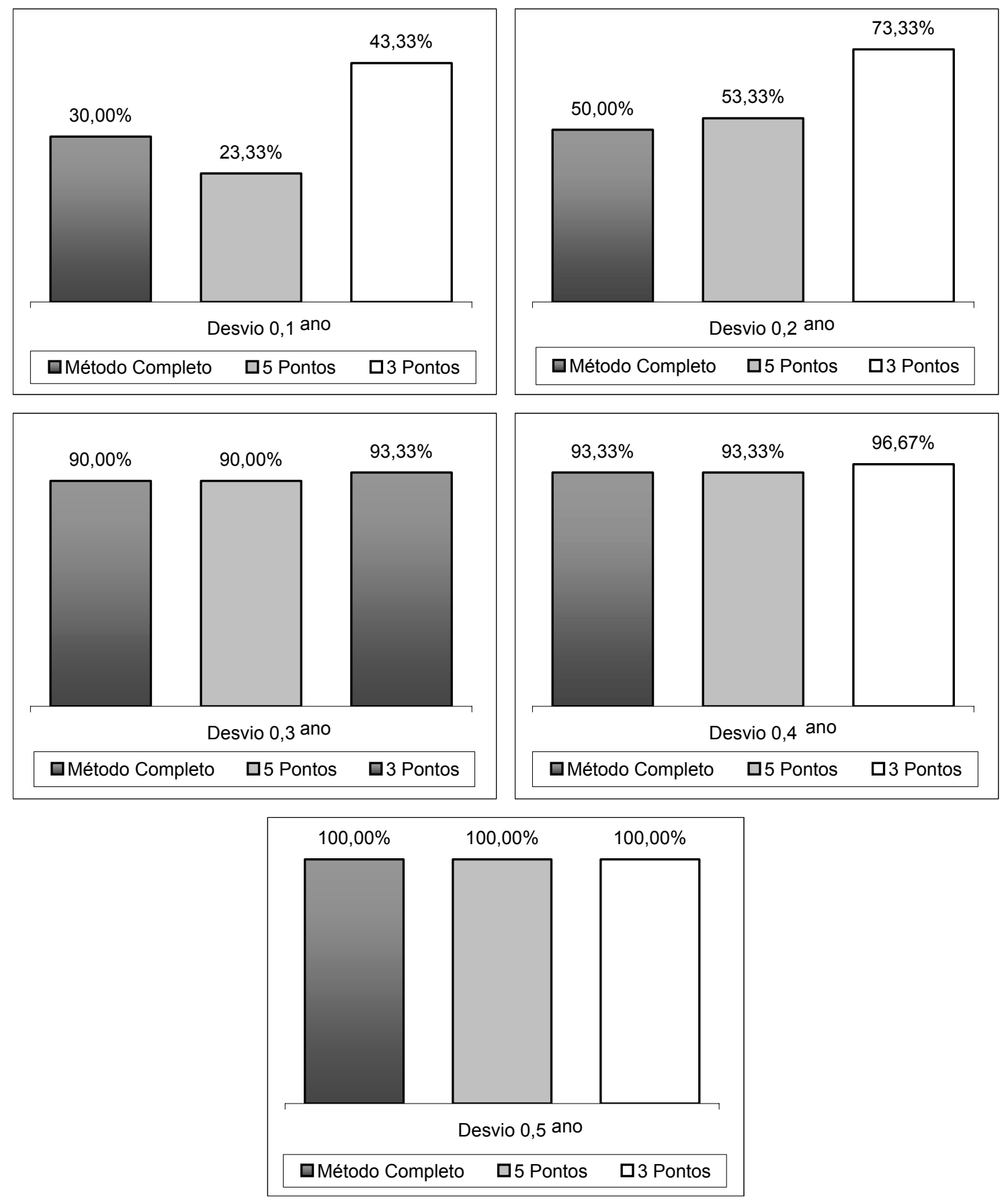

Figura 35 - Comparação entre método completo $X$ simplificação inicial (5 centros de ossificação) e simplificação final (3 centros) para as imagens do sexo masculino 
Analisando as Figuras 34 e 35, nota-se que os resultados obtidos tanto para o sexo feminino quanto para o sexo masculino foram satisfatórios, obtendo uma boa aproximação dos valores do laudo médico, quando utilizado os valores de 0.4 e 0.5 anos para o desvio padrão. Com os resultados mostrados nas figuras acima, pode-se concluir que a estimativa da idade óssea pode ser feita de uma maneira bastante simplificada e mais rápida, com base na análise de apenas 3 centros de ossificação.

\subsubsection{Análise da simplificação}

Para estimar a idade a partir do método original são necessários 20 pontos, ou seja, 2 pontos para cada centro de ossificação em análise. Para estimar a idade utilizando a simplificação para 5 centros de ossificação são necessários apenas 10 pontos, e os resultados mostraram a mesma eficiência do método original.

Durante o estudo, constatou-se que esta simplificação poderia ser ainda maior, utilizando apenas 3 ossos para estimar a idade. Isso faz com que o tempo de processamento diminua ainda mais. Assim, são necessários apenas 6 pontos, contra 20 pontos do método original e 10 pontos para 5 centros de ossificação. Com a verificação dos resultados descritos acima, foram necessárias algumas adaptações no software desenvolvido, para que o mesmo pudesse operar com essa nova simplificação. Depois disso, foram estimadas as idades para outros 2 conjuntos de imagens (sexo masculino e feminino) e, em seguida, os laudos do software foram comparados com os laudos médicos. Este estudo é apresentado no próximo item.

\subsection{Laudo do software X laudo médico}


Para apresentar os resultados obtidos pelo software utilizando a simplificação mínima (análise de 3 centros de ossificação), foram selecionadas mais 68 imagens do banco de dados, sendo 34 do sexo masculino e 34 do sexo feminino e estimadas as suas idades ósseas. Após estimar todas as idades através do software modificado, foram gerados gráficos ilustrando o comportamento do laudo do software em relação ao laudo médico. A Figura 36 representa esta relação para as imagens do conjunto feminino, no qual o eixo $X$ representa o total de imagens e o eixo $\mathrm{Y}$, a faixa de idades.

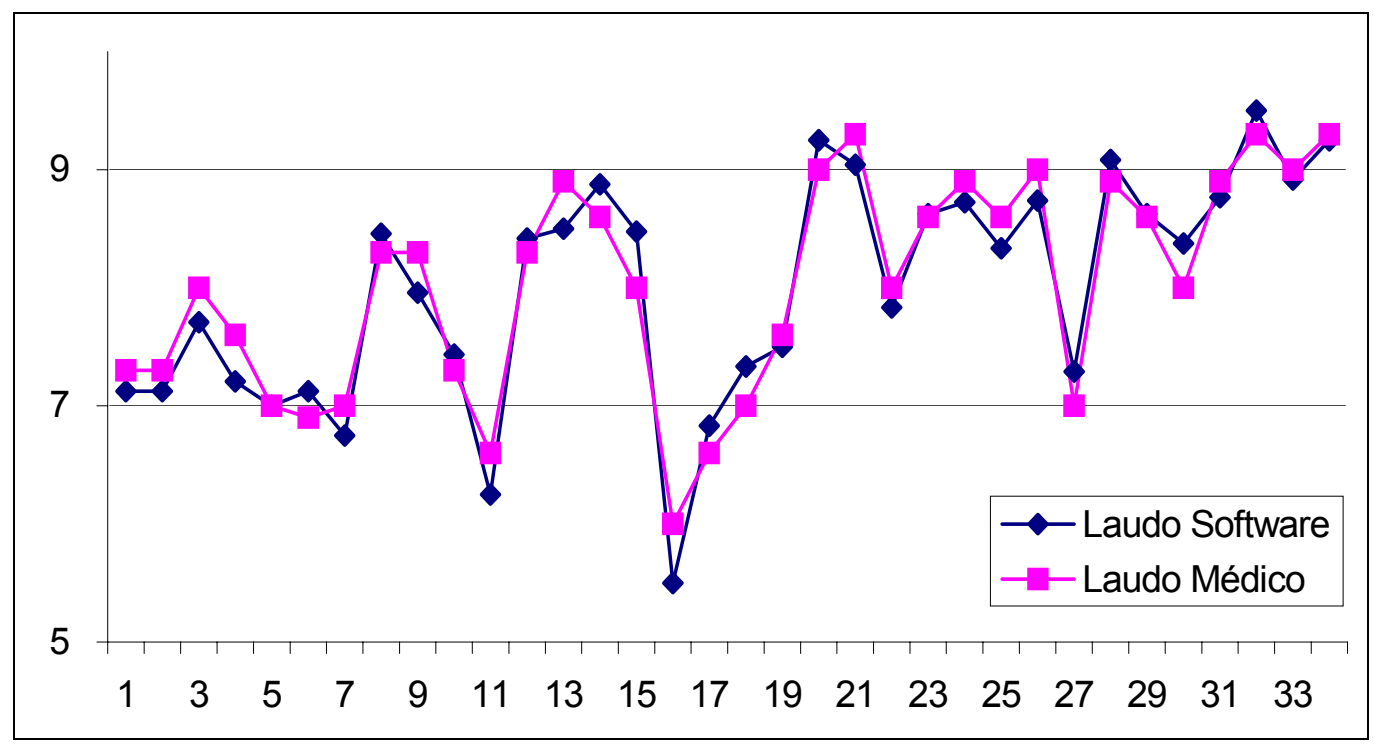

Figura 36 - Resultados do software X laudo médico para o conjunto de imagens do sexo feminino

A Figura 37 mostra as relações obtidas para o sexo masculino. 


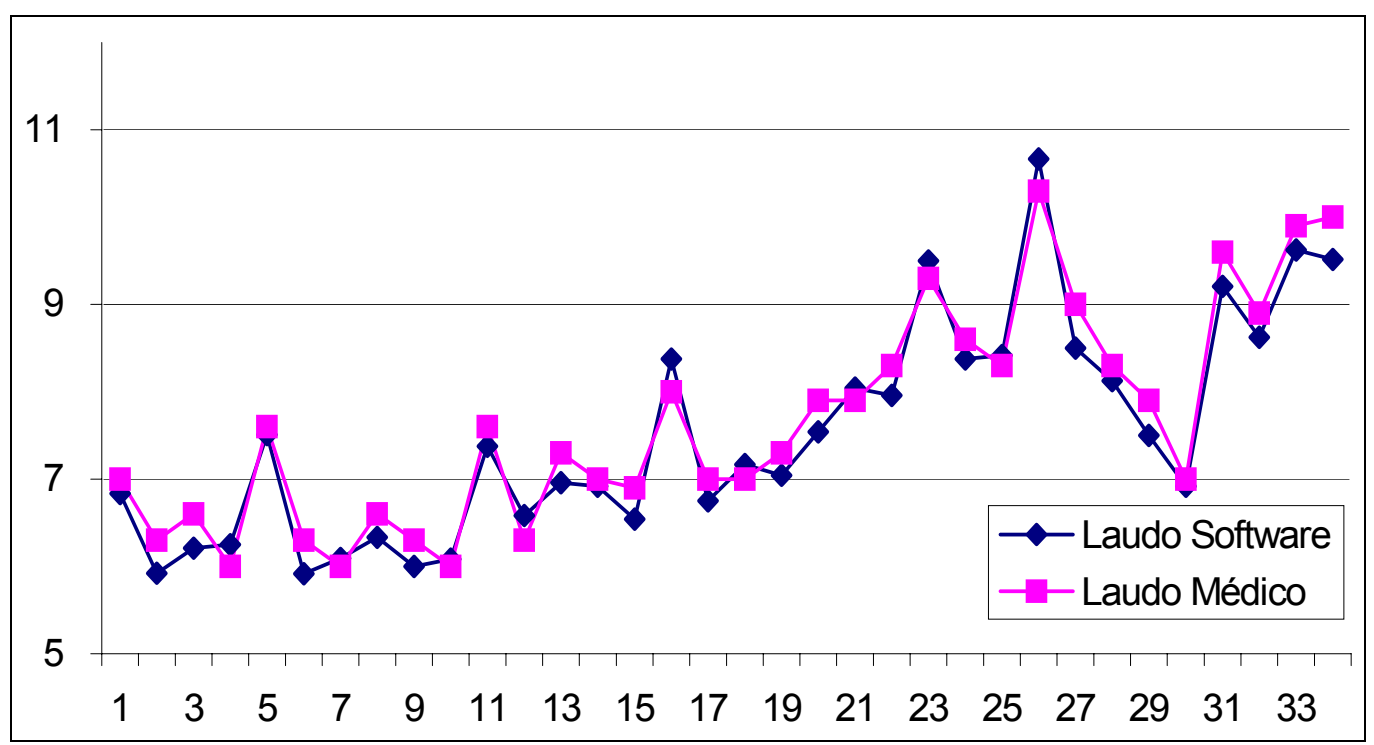

Figura 37 - Resultados do software X laudo médico para o conjunto de imagens do sexo masculino

Analisando os gráficos das Figuras 36 e 37, verifica-se que as idades estimadas para ambos os sexos, utilizando a simplificação, ficaram bem próximas dos valores ideais (laudo médico). Para medir a eficiência da simplificação utilizada no software, foram obtidas as idades ósseas para 68 imagens do banco de dados e, em seguida, realizou-se a confrontação entre os laudos do software e do médico. $O$ desvio padrão utilizado variou de 0.1 a 0.5 anos. $O$ gráfico da Figura 38 ilustra os resultados da simplificação para o sexo masculino.

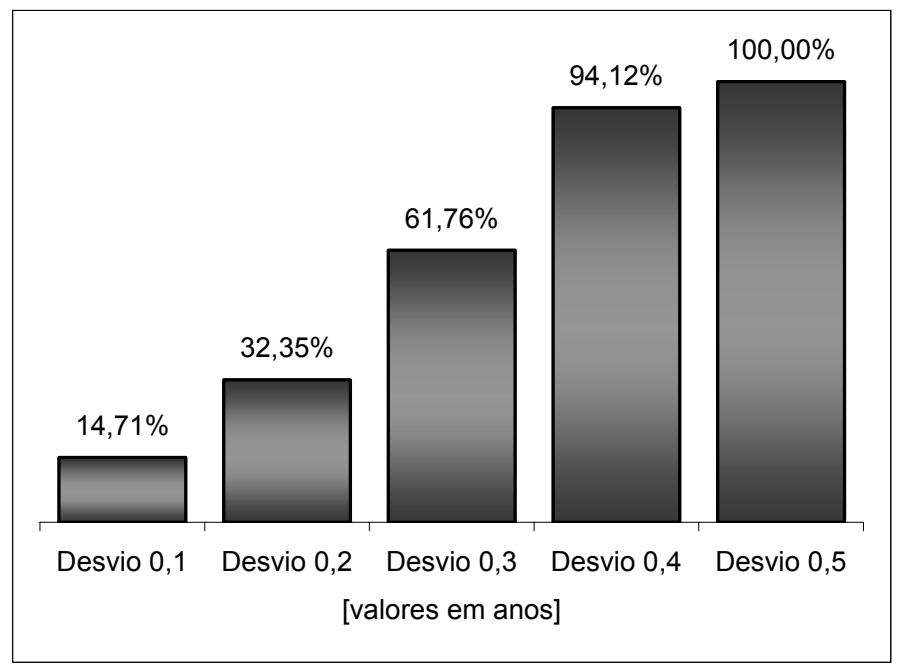

Figura 38 - Porcentagem de acertos do software X laudo médico para o sexo masculino 
Analisando o gráfico da Figura 38, nota-se que quando utilizado o desvio padrão de 0.1 a 0.3 anos ocorreu baixa taxa de concordância, ficando 38,24\% abaixo do valor do laudo médico no melhor caso (desvio padrão de 0.3 anos). Quando utilizado o desvio padrão de 0.4 anos o resultado foi excelente, obtendo concordância em 94,12\%. Levando em consideração um total de 34 imagens, o software só não encontrou a idade ideal em 2 imagens. E, conseqüentemente, chegando a $100 \%$ quando o desvio padrão foi aumentado para 0.5 anos. No gráfico da Figura 39 é mostrado o desempenho do software para as imagens do sexo feminino.

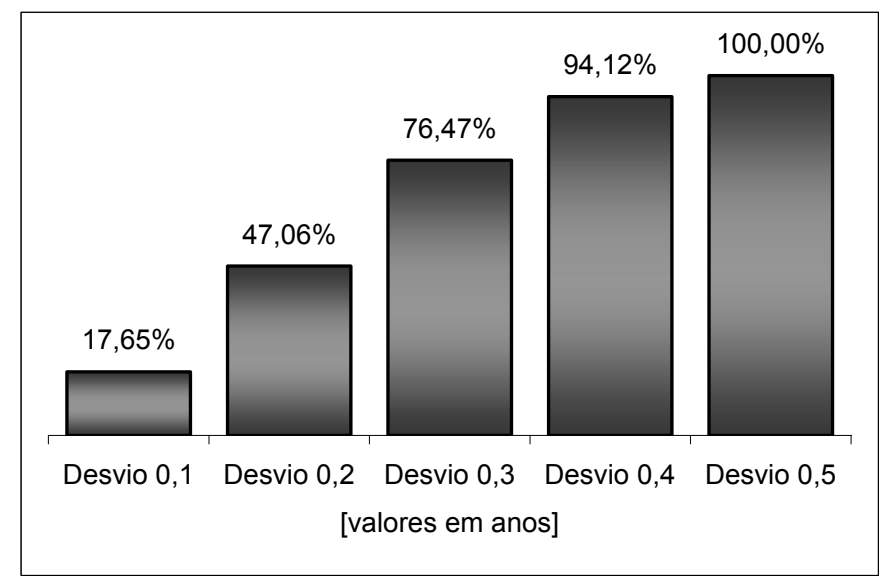

Figura 39 - Porcentagem de acertos do software X laudo médico para o sexo feminino

Como pode-se observar na Figura 39, o software conseguiu obter um resultado ligeiramente melhor, em relação ao sexo masculino, quando utilizado o intervalo de desvio padrão de 0.1 a 0.3 anos. O melhor resultado ficou $23.53 \%$ abaixo do laudo médico, utilizando o desvio padrão de 0.3 anos, o que representa um total de 26 acertos dentro do conjunto de 34 imagens.

Analisando os gráficos das Figuras 38 e 39, conclui-se que o software obteve o mesmo resultado em ambos os sexos quando utilizado o desvio padrão de 0.4 e 0.5 anos. 


\subsection{Comparações entre método original $X$ simplificações}

Neste item, serão apresentados os gráficos ilustrando a eficiência dos resultados obtidos utilizando o método completo (10 centros de ossificação) de Eklof \& Ringertz, a simplificação utilizando 5 e 3 centros, em relação ao laudo médico. Foi utilizado um intervalo de desvio padrão de 0.1 a 0.5 anos, mostrando o comportamento da metodologia dentro desse intervalo de idade. Os gráficos da Figura 40 ilustram os resultados obtidos para as imagens do sexo feminino.

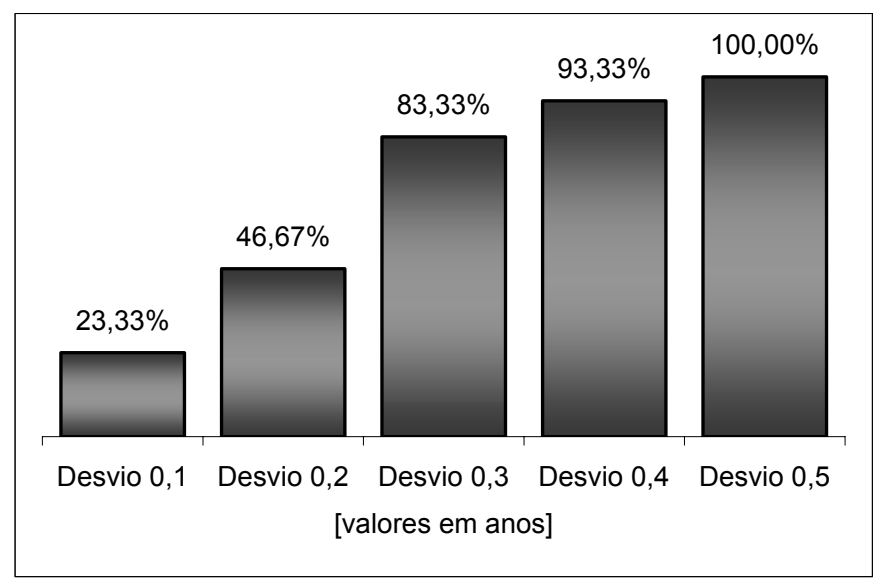

(a) Método completo

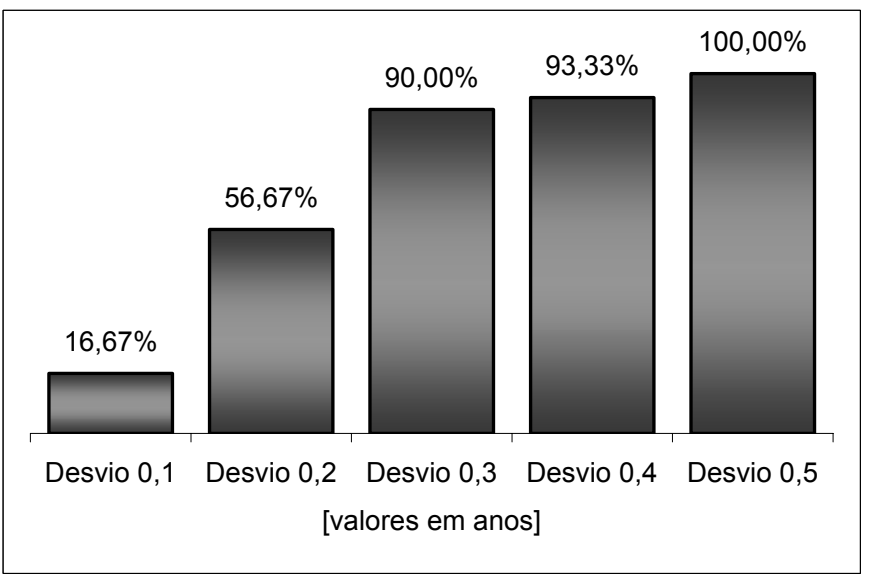

(b) Simplificação para 5 pontos 


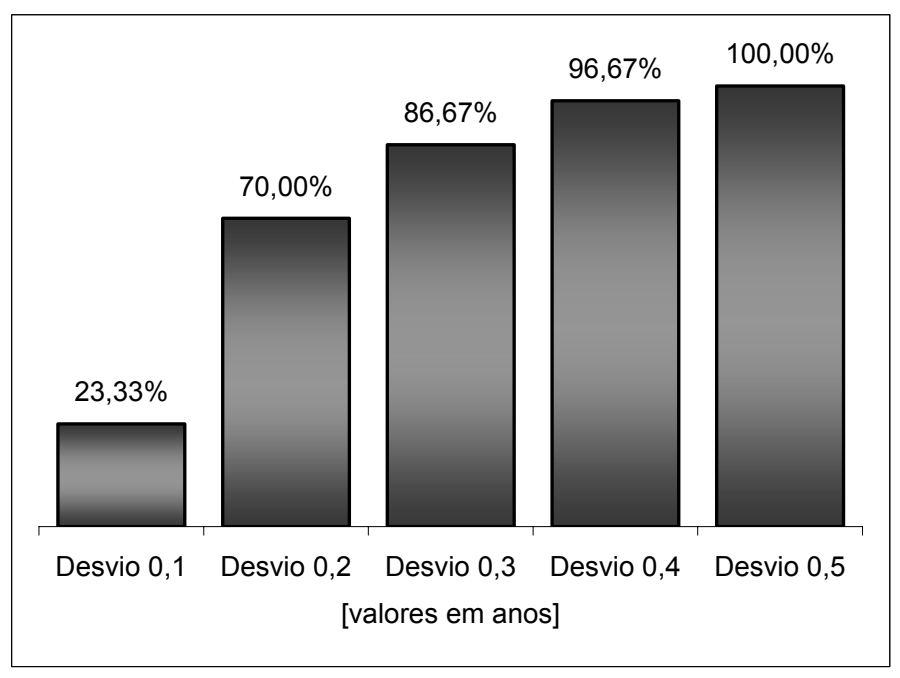

(c) Simplificação para 3 pontos

Figura 40 - (a): resultado do método completo. (b): resultado utilizando a simplificação para 5 centros de ossificação e (c): utilizando 3 centros de ossificação para as imagens do sexo feminino

Observando os gráficos da Figura 40, verifica-se que quando utilizado o desvio padrão de 0.1 e 0.2 anos, a porcentagem de concordância do software em todos os casos foi bem baixa, obtendo média mínima de $46,67 \%$ para o pior caso (método completo) e, 70\%, no melhor caso (simplificação de 3 centros). Quando utilizado o desvio padrão de 0.3 anos, foi obtido um resultado perto do ideal, variando entre $83,33 \%$ e $90 \%$. Já com o desvio padrão de 0.4 anos o resultado foi muito bom, obtendo uma taxa de concordância entre $93,33 \%$ e $96,67 \%$. O software obteve $100 \%$ de acerto em todos os casos quando o desvio padrão utilizado foi de 0.5 anos. No gráfico da Figura 41 é mostrado o desempenho do software para as imagens do sexo masculino. 


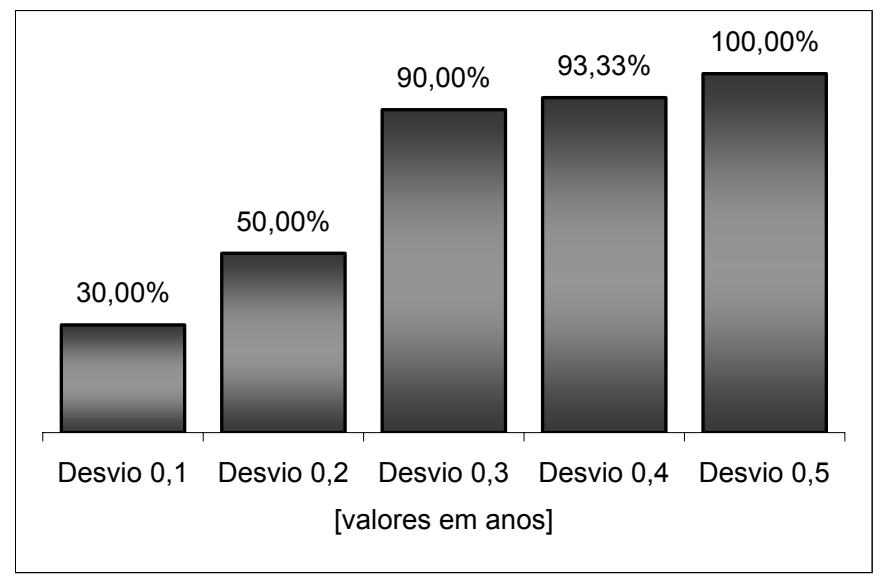

(a) Método completo

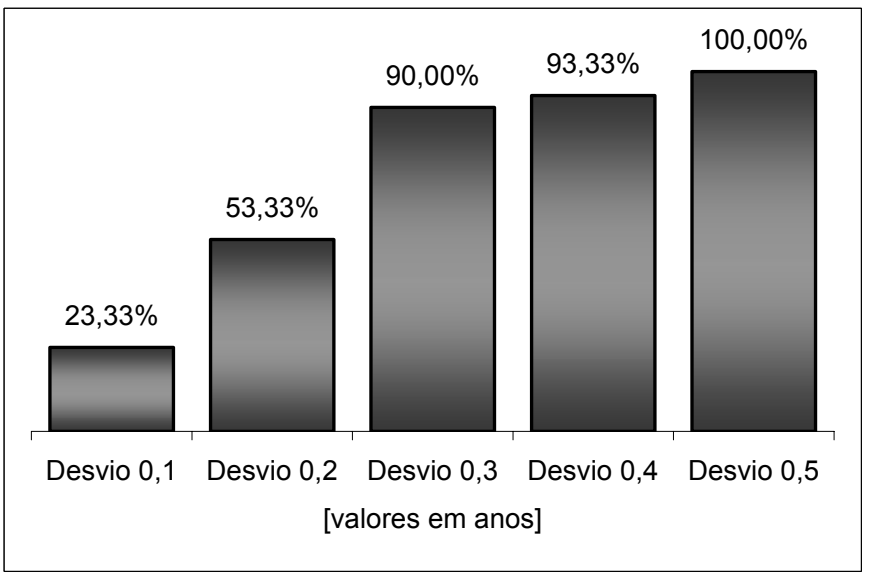

(b) Simplificação para 5 pontos

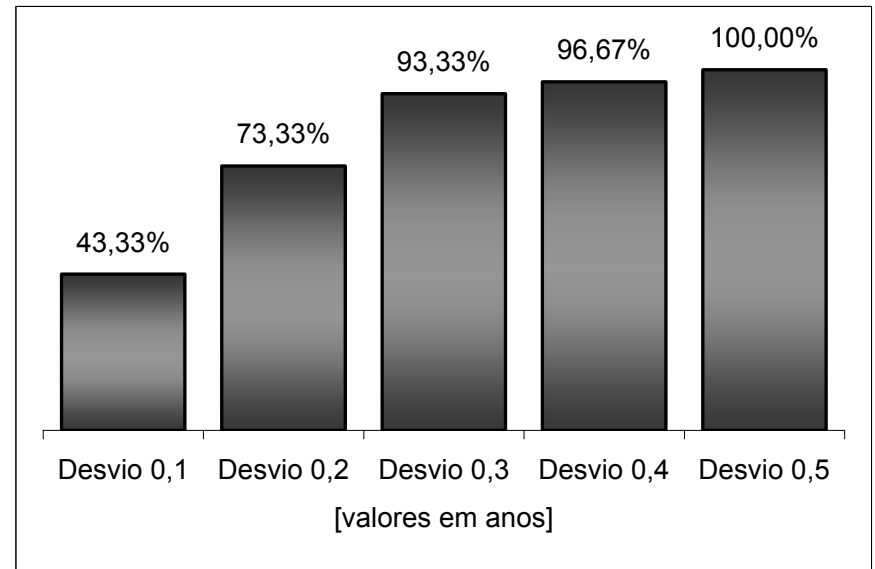

(c) Simplificação para 3 pontos

Figura 41 - (a): resultado do método completo. (b): resultado da simplificação utilizando 5 centros de ossificação e (c): utilizando 3 centros de ossificação para as imagens do sexo masculino 
Analisando os resultados expressos nos gráficos da Figura 41, nota-se que são parecidos com os resultados obtidos para o conjunto de imagens do sexo feminino. Com isso, conclui-se que um valor aceitável de desvio padrão é de 0.4 anos, pois obteve um ótimo resultado nos dois conjuntos de imagens. E, que a simplificação baseada na análise de 3 centros de ossificação foi a que apresentou o melhor resultado, conforme ilustrado nos gráficos das Figuras 40 e 41.

Com base nestes resultados conclui-se que quando utilizado mais algum osso para estimar a idade, como por exemplo, 10 e 5 centros de ossificação, os valores dos laudos tendem a piorar, conforme demonstrado no item "Análise da simplificação proposta" do capítulo 8 , onde a estimativa da idade óssea feita através da análise de 3 centros sempre apresentou resultado igual ou superior às outras análise (método completo e simplificação para 5 centros). Isso comprova a eficiência da simplificação para 3 centros de ossificação.

\subsection{Expandindo as medidas do método de Eklof \& Ringertz}

Levando em consideração que as medidas (originais) apresentadas pelo método de Eklof \& Ringertz só contém resultados para idades ósseas de 1 a 15 anos, realizou-se um estudo sobre todas as imagens radiográficas do banco de dados que possuíam laudo médico para idades acima de a 15 anos, com o objetivo de observar a possibilidade da aplicação do método para essa faixa etária. Foram analisadas 138 imagens, sendo 69 de cada sexo, com idades ósseas entre 15 e 18 anos e, em seguida, foram obtidas as medidas para este intervalo de idade. O gráfico da Figura 42 ilustra a linha de crescimento ósseo para os metacárpicos (II, III e IV), baseado na tabela original do método (até os 15 anos), e também a expansão da idade até os 18 anos, gerada a partir da análise feita em todo o banco de imagens. 


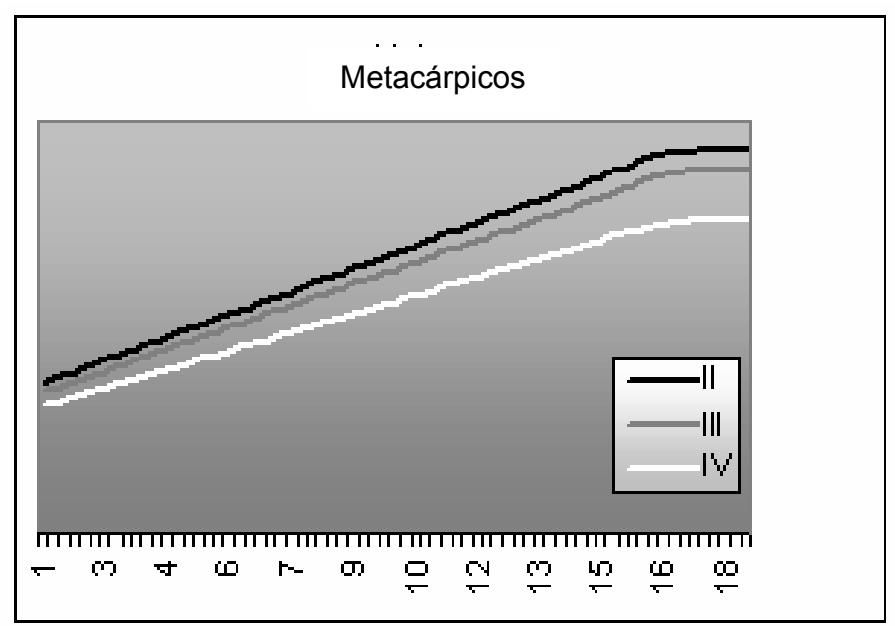

Figura 42 - Linha de crescimento ósseo para os metacárpicos (II, III, IV) baseado no método de Eklof \& Ringertz

Analisando o gráfico da Figura 42, nota-se que o crescimento até os 15 anos é constante, não apresentando picos durante esta faixa de idade. Com os estudos realizados, constatou-se que dos 15 aos 17 ainda existe crescimento, com menor velocidade do que as idades inferiores. Já no intervalo dos 17 aos 18 anos verificou-se que não existe mais crescimento dos metacárpicos, estabelecendo os mesmos valores da idade inferior (17 anos), limitando portanto a atuação do método ao limite de 17 anos. A Tabela 1 apresenta estes novos valores obtidos para as idades de 15 a 18 anos de idades baseando-se no método de Eklof \& Ringertz para o sexo feminino e, a Tabela 2, para o sexo masculino.

Tabela 1 - Extensão para as medidas do índice de Eklof \& Ringertz, no sexo feminino

\begin{tabular}{|c|c|c|c|c|c|c|c|c|c|c|}
\hline \multirow{2}{*}{ Idade } & \multirow{2}{*}{ Radio } & \multicolumn{2}{|c|}{ Capitato } & \multicolumn{2}{c|}{ Hamato } & \multicolumn{3}{c|}{ Metacárpico } & \multicolumn{2}{c|}{ Falange } \\
\cline { 3 - 12 } & & Comp. & Larg. & Comp. & Larg. & II & III & IV & II & III \\
\hline & $\mathbf{1}$ & $\mathbf{2}$ & $\mathbf{3}$ & $\mathbf{4}$ & $\mathbf{5}$ & $\mathbf{6}$ & $\mathbf{7}$ & $\mathbf{8}$ & $\mathbf{9}$ & $\mathbf{1 0}$ \\
\hline $\mathbf{1 6 , 0 0}$ & 34,8 & 25,85 & 16,25 & 21,15 & 17,15 & 73,55 & 69,85 & 60,1 & 42,15 & 46,75 \\
\hline $\mathbf{1 7 , 0 0}$ & 35,4 & 26,25 & 16,45 & 21,45 & 17,35 & 74,85 & 70,75 & 60,8 & 42,65 & 47,4 \\
\hline $\mathbf{1 8 , 0 0}$ & 35,4 & 26,25 & 16,45 & 21,45 & 17,35 & 74,85 & 70,75 & 60,8 & 42,65 & 47,4 \\
\hline
\end{tabular}

Tabela 2 - Extensão para as medidas do índice de Eklof \& Ringertz, no sexo masculino

\begin{tabular}{|c|c|c|c|c|c|c|c|c|c|c|}
\hline \multirow{2}{*}{ Idade } & \multirow{2}{*}{ Radio } & \multicolumn{2}{|c|}{ Capitato } & \multicolumn{2}{c|}{ Hamato } & \multicolumn{3}{c|}{ Metacárpico } & \multicolumn{2}{c|}{ Falange } \\
\cline { 3 - 12 } & & Comp. & Larg. & Comp. & Larg. & II & III & IV & II & III \\
\hline & $\mathbf{1}$ & $\mathbf{2}$ & $\mathbf{3}$ & $\mathbf{4}$ & $\mathbf{5}$ & $\mathbf{6}$ & $\mathbf{7}$ & $\mathbf{8}$ & $\mathbf{9}$ & $\mathbf{1 0}$ \\
\hline $\mathbf{1 6 , 0 0}$ & 36,45 & 27,05 & 16,95 & 21,6 & 17,62 & 72,6 & 68,45 & 60,55 & 41,3 & 46,05 \\
\hline $\mathbf{1 7 , 0 0}$ & 37,25 & 27,55 & 17,25 & 22,00 & 17,82 & 73,70 & 69,35 & 61,35 & 41,80 & 46,65 \\
\hline $\mathbf{1 8 , 0 0}$ & 37,25 & 27,55 & 17,25 & 22,00 & 17,82 & 73,70 & 69,35 & 61,35 & 41,80 & 46,65 \\
\hline
\end{tabular}


Durante os estudos buscou-se analisar todas as imagens do banco de dados que apresentavam idades superiores a 15 anos para buscar novos valores que ajudassem a estender a tabela de medidas do método de Eklof \& Ringertz. Como citado anteriormente e com os valores mostrados nas tabelas 1 e 2 , o software irá abranger toda a fase de crescimento ósseo, desde crianças de 1 ano de idade até a idade de 17 anos em ambos os sexos. 


\section{CONCLUSÕES}

- Com o algoritmo de correção do efeito Heel foi possível eliminar todas as variações de intensidade do fundo das imagens. O algoritmo de ajuste da imagem também contribuiu, eliminando (ou atenuando) pequenos ruídos que prejudicavam a aplicação dos métodos de limiarização implementados.

- Com base nos estudos conclui-se que é possível estimar com confiança a idade óssea baseando-se apenas nos ossos da mão, excluindo da análise os ossos do carpo e do punho, que são ossos necessários na análise completa do método de Eklof \& Ringertz.

- Durante a análise do método completo (10 centros de ossificação), simplificação mínima e máxima (5 e 3 centros respectivamente), verificou-se que as dimensões obtidas em alguns centros de ossificação, quando participam da média, não contribuem positivamente para a obtenção de uma idade óssea final esperada, conforme o laudo médico, produzindo resultados com elevado desvio padrão.

- Conclui-se que a média da combinação (P1 P3 e P5) foi a que apresentou uma melhor aproximação em relação ao laudo médico, sendo possível estimar a idade óssea pelo método de Eklof \& Ringertz baseando-se na análise apenas dos metacárpicos II e IV e da terceira falange. 
- Um dos softwares atualmente existentes para estimar a idade óssea, conhecido por Radiocef Studio 2.0, baseado no método de Eklof \& Ringertz é operado de forma manual. Todos os pontos que compõem os centros de ossificação são marcados manualmente, o que resulta em um tempo elevado para a fixação dos 20 pontos necessários para estimar a idade óssea. Durante a pesquisa foram estimadas algumas idades utilizando este software, juntamente com o acompanhamento do médico Dr. Romeu Santini, do Instituto de Diagnóstico Romeu Santini, a fim de verificar assim essas características do software. Neste trabalho desenvolveu-se um software que trabalha de forma automática e simplificada, pois os marcadores são inseridos automaticamente e são utilizados apenas 6 pontos ( 3 ossos) para a estimação da idade óssea. Radiocef Studio 2.0: fabricado em 1994 pela empresa Radio Memory Ltda., localizada em Belo Horizonte, MG, Brasil. Home Page: $<$ http://www.radiomemory.com.br>.

- A extensão das medidas para o método de Eklof \& Ringertz, também foi muito importante, fazendo com que o software seja capaz de estimar idade óssea desde crianças ( 1 ano de idade) até pessoas com idade de 17 anos.

\section{Trabalhos Futuros}

- Adaptar o banco de dados construído, disponibilizando-o na Internet para que profissionais e pesquisadores da área possam ter acesso à estas imagens (e aos seus laudos) para realização de pesquisa na área.

- Inserir procedimentos ao software atual, para que o mesmo seja capaz de operar on-line (através da Internet), restringindo o acesso à 
universidades que tenham interesse em realizar pesquisas baseadas em estimativa da idade óssea utilizando a análise carpal.

- Pesquisar a utilização de outras técnicas de pré-processamento das imagens para otimizar a segmentação dos ossos do punho, podendo assim pesquisar a interferência daqueles centros de ossificação (num total de 10) propostos pelo método de Eklof \& Ringertz.

- Construir banco de imagens carpais geradas por equipamentos digitais - sem a utilização de filme radiográfico no processo. Avaliar os benefícios/malefícios introduzidos no processo de estimação da idade óssea observando o processo de geração das imagens utilizadas.

- Adicionar novos procedimentos no software, como por exemplo, uma rotina que seja capaz de digitalizar as radiografias carpais a partir do scanner, não sendo necessário o uso de um software adicional, buscando assim a construção de uma plataforma completa voltada para a análise carpal. 


\section{REFERÊNCIAS BIBLIOGRÁFICAS}

ACHESON, R. M.; VINICIUS, J. H.; FOWER, G. B. (1966). Studies in the reliability of assessing skeletal maturity from $X$ rays. Part III. Greulich-Pyle and TannerWhitehouse method contrasted. Hum Biol, v. 38, n. 3, páginas 204-218.

ANDRADE, M.C. (2000). Um Algoritmo Interativo para Suavização e Segmentação de Imagens Digitais, Centro de Desenvolvimento da Tecnologia Nuclear - CDTN, Belo Horizonte, MG, Brasil.

ARTERO, A. O.; TOMMASELLI, A. M. G. (1999). Técnicas para a Extração Automática de Feições Retas em Imagens Digitais, Presidente Prudente, Dissertação (Mestrado) - Faculdade de Ciências e Tecnologia da UNESP, Universidade do Estado de São Paulo.

ARTERO, A. O.; TOMMASELLI, A. M. G. (2002). Extração de Feições Retas em Imagens Digitais: Adaptação e Avaliação de Diferentes Técnicas. Revista da Comissão Brasileira de Geodésia, v.2., p.72-74.

BEHIELS, G. et al. (2002), Retrospective Correction of the Heel Effect in Hand Radiographs, Medical Image Analysis, Volume 6, páginas 183 - 190. 
BOSQUIERO, M.R. et al. (2001). Determination of Skeletal Maturity and Estimate of the Age Through Carpal Radiographics, Rev. Cons. Reg. Odontol. Pernambuco, v.4, n.1, p. 59-66, Janeiro/Junho 2001.

DALMOLIN, Q. et al. (1998). Análise Qualitativa na Conversão Analógico/Digital de Bases Cartográficas para Serem Utilizadas em Sig's. Revista Brasileira de Ciência Geodésia, v.3, p. 82-84.

FACON, J.(2003). Estudo e Processamento de Algoritmos para a Binarização de Imagens, Pontífice Universidade Católica do Paraná - PUCPR, 2003. Disponível em: <http://www.ppgia.pucpr.br/ facon/IndexPrincipalBrBinarizacao.htm>. Acesso em: 20/08/2003.

FRANÇA, B.H.S. et al. (1998). Estimativa de Idade em Indivíduo Adulto Jovem, Congresso Brasileiro de Odontologia, Recife.

FRITZ, S. L.; LIVINGSTON, W. H. (1982). A comparison of computed and measured heel effect for various target angles. Medical Physics, v.9, n.2, p.216219.

FRITZ, S. L.; LIVINGSTON, W. H. (1985). The effect of anode curvature on radiographic heel effect. Medical Physics, v.12, n.4, p.443-446.

GONZALEZ, R. C.; WOODS, R. E. (1993). Digital Image Processing Techniques, Addison Wesley, New York.

GRATALE, P,; WRIGHT, D. L.; DAUGHTRY, L. (1990). Using the anode heel effect for extremity radiography. Radiologic Technology, v.61, n.3, p.195-198. 
GREULICH, W. W.; PYLE, S. I. (1992). Radiographic Atlas of Skeletetal Development of the Hand and Wrist. 2.ed., Ed. University Press.

HAITER N., F.; ALMEIDA, S. M.; LEITE, C. C. (2000). Comparative Study of the Greulich \& Pyle and Tanner \& Whitehouse Methods for Estimating Skeletal Age, Revista Odontológica Brasileira, v. 14, n. 4, p. 378-384.

MARQUES, A. M. S et al. (2001). On Determining a Signature for Skeletal Maturity, Proceedings of the 14th Brazilian Symposium on Computer Graphics and Image Processing, p. 246-251.

MARQUES, M. A.; FRÈRE, A. F. (1998). Simulação Computacional de Parâmetros Importantes de Sistemas Radiológicos, São Carlos, Tese (Doutorado) - Instituto de Física de São Carlos, Universidade de São Paulo.

MORAES, M.E.L. et al. (2003). Reliability of Greulich \& Pyle and Eklof \& Ringertz methods for skeletal age evaluation in brazilian children. Rev. Odontol. UNESP, São Carlos, v. 32, n. 1, p. 9-17, Jan/Jun 2003.

NASCIMENTO, M. Z.; FRÈRE, A. F.. (2001). Desenvolvimento de Algoritmos para a Correção do Efeito Heel nas Imagens Mamográficas, São Carlos, Dissertação (Mestrado) - Escola de Engenharia de São Carlos, Universidade de São Paulo.

NASCIMENTO, M. Z. et al. (2003). Subtraction of images for automatic determination of center of the radiation field, Proc. 25 th Annual International Conf. of the IEEE Eng. in Medicine and Biology Society, Cancún, México, pp. 937-940.

NETLER, F. H. (1990). The Ciba Collection of Medical Illustrations. Part I Anatomy, Phisiology and Metabolic Disorders, Volume 8, Novartis Medical Education Program, Califórnia. 
NIEMEIJER, M. (2002). Automating Skeletal Age Assessment, Master's Thesis, University Utrecht.

OliVETE, C. J.; NASCIMENTO, M. Z.; RODRIGUES, E. L. L. (2004a). Metodologia baseada em thresholding adaptativo aplicada à correção de imagens radiográficas da mão. In: III Latin-American Congress on Biomedical Engineering, 2004, João Pessoa - PB, 2004, volume 1, p. 106-106.

OLIVETE, C. J.; NASCIMENTO, M. Z.; RODRIGUES, E. L. L. (2004b). A correção do efeito Heel aplicada em imagens radiográficas da mão. In: IX Congresso Brasileiro de Informática em Saúde, 2004, Ribeirão Preto - SP, 2004, volume 1, p. 28-28.

OTSU, N. (1997). A Threshold Selection Method from Gray-Level Histograms. In: IEEE Transactions on Systems Man, and Cybernetics, Volume SMC-9, No. 1, pp. 62-66.

PARKER, J. R. (1994). Practical Computer Vision Using C, John Wiley \& Sons, New York.

PARKER, J. R. (1996). Algorithms for Image Processing and Computer Vision, John Wiley \& Sons, New York.

SATO, K.; MITANI, H. (1999). 'Bone age used as parameter was calculated by both Tanner-Whitehouse 2 (TW2) by CASMAS (Computer Aided Skeletal Maturity Assessment System)', The 99th annual session of American Association of Orthodontics, USA.

SCAFF, L. A. M. (1979). Bases Físicas da Radiologia: Diagnóstico e Terapia, São Paulo, Editora Savier. 
RANDO, M. (2005). Sectional Hand Phantoms, The Phantom Laboratory. Disponível em: <http://www.phantomlab.com>. Acesso em: 20/01/2005.

SILVA, M. A. et al. (2000). Heel Effect's Influence on the Performance of Screen Film Combinations, Congresso Brasileiro de Engenharia Biomédica, Florianópolis, SC, Brasil.

SWOKOWSKI, E. W. (1994). Cálculo com geometria analítica, $2^{\mathrm{a}}$ edição, Makron Books, São Paulo.

TAFFAREL, B.; WANGENHEIN, A. V.; SILVA, P. C. A. (2003). Processamento de Imagens para Análise e Estimativa de Problemas de Crescimento Ósseo em Crianças, III Workshop de Informática aplicada à Saúde - CBComp 2003, Universidade Federal de Santa Catarina, Florianópolis, SC, Brasil.

TANNER, J. M.; WHITEHOUSE, R. W.; HEALVY (1969). A New System for Estimating Skeletal Maturity from Hand and Wrist, with Standarts Derived From a Study Of 2600 Healthy British Children, Departament of Growth and Development Institute of Child Health, University of London; and Departament of Statistics, Rothamsted Experimental Station, Harpenden.

TAVANO, O. (2001). Radiografias Carpal e Cefalométrica como Estimadores da Idade Óssea e do Crescimento e Desenvolvimento, Bauru - Brasil.

TODD, T.W. (1937). Atlas of skeletal maturation, St. Louis, Mosby.

TUBIANA, R. (1981). The Hand, New York: W. B. Saunders Publishers. 


\section{APÊNDICE A - Lista de combinações entre os 5 centros de ossificação}

Neste apêndice, são mostrados alguns exemplos de estimativa de idade óssea utilizando 5 centros de ossificação (simplificação), bem como todas as combinações geradas a partir destes centros. A Tabela 3 traz as idades obtidas para o osso metacarpo II, III e IV (representados respectivamente por P1, P2, P3, P4 e P5), para as falange II e III (representadas por P4 e P5) e a idade final estimada, obtida através da média entre os ossos.

Tabela 3 - Idades obtidas pelo software utilizando a simplificação do método de Eklof \& Ringertz

\begin{tabular}{|c|c|c|c|c|c|c|}
\hline & P1 & P2 & P3 & P4 & P5 & $\begin{array}{c}\text { Idade } \\
\text { Estimada }\end{array}$ \\
\hline 1 & 9,875 & 10,25 & 9,75 & 9,875 & 10,75 & 10,10 \\
\hline 2 & 12,00 & 11,25 & 11,875 & 10,6 & 11,5 & 11,45 \\
\hline 3 & 12,25 & 11,00 & 11,75 & 10,75 & 9,25 & 11,00 \\
\hline 4 & 11,00 & 9,875 & 11,00 & 11,75 & 11,00 & 10,95 \\
\hline 5 & 9,875 & 10,75 & 9,00 & 8,75 & 9,75 & 9,625 \\
\hline 6 & 10,375 & 9,25 & 9,625 & 10,375 & 10,00 & 10,00 \\
\hline 7 & 10,75 & 11,5 & 10,75 & 10,25 & 10,5 & 10,75 \\
\hline 8 & 9,875 & 11,00 & 10,25 & 12,25 & 10,765 & 10,80 \\
\hline
\end{tabular}

Na Tabela 3, são apresentados um total de 8 imagens, 4 para cada sexo, sendo que as do sexo feminino são representadas pelas primeiras (1 a 4). A Figura 43 ilustra as imagens do sexo feminino representadas por 1, 2, 3 e 4 na Tabela 3. 


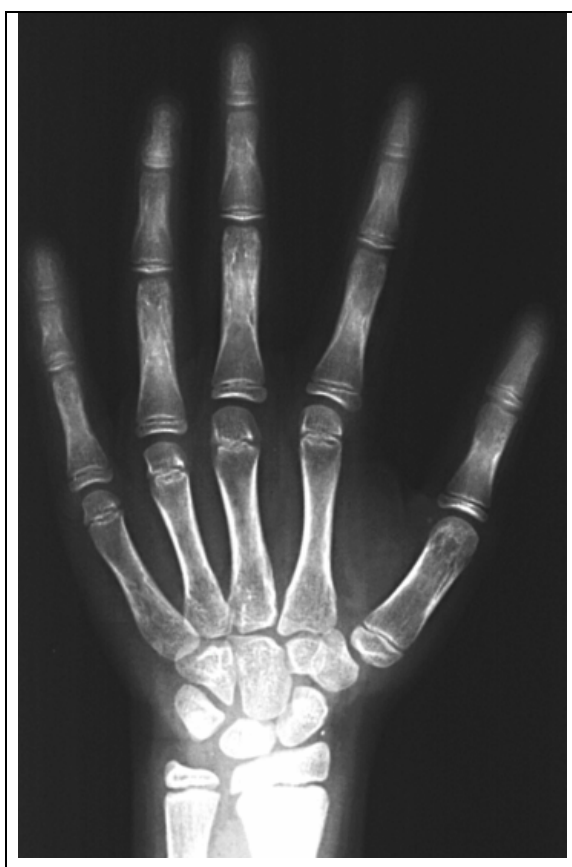

(1)

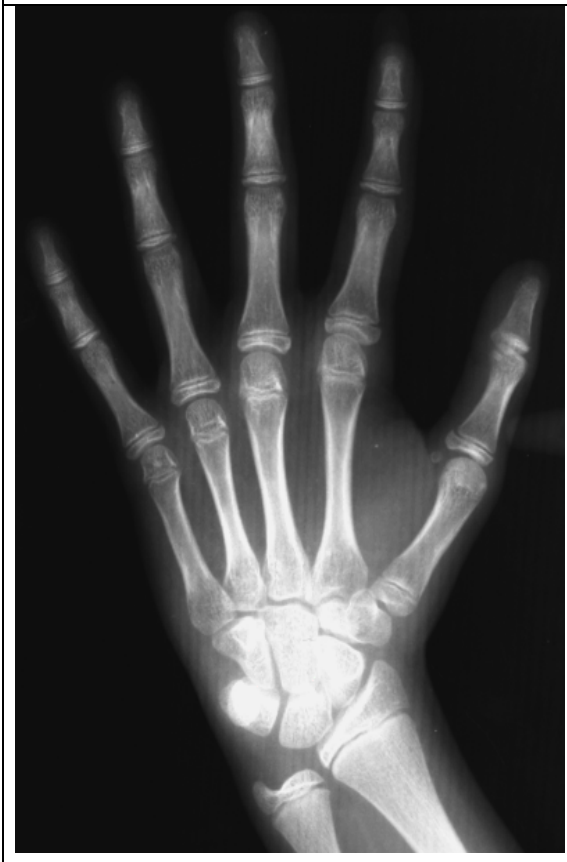

(3)

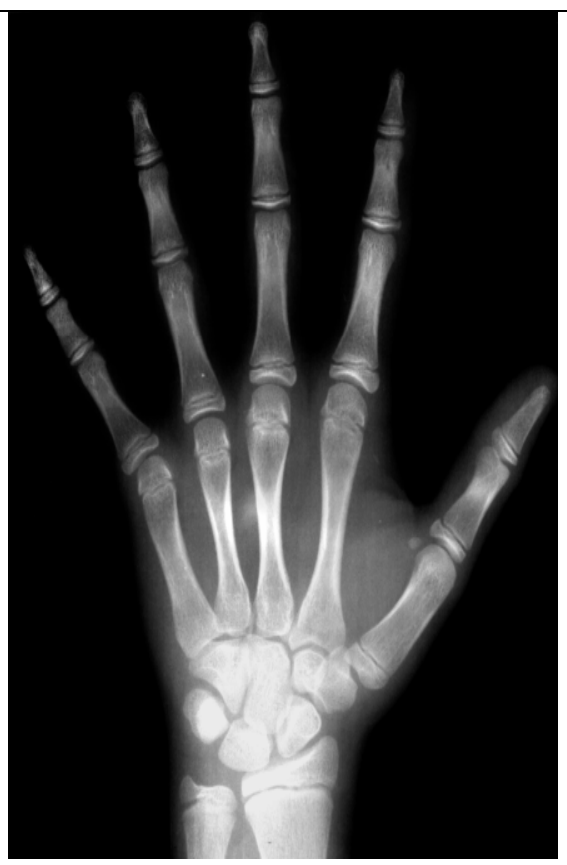

$(2)$

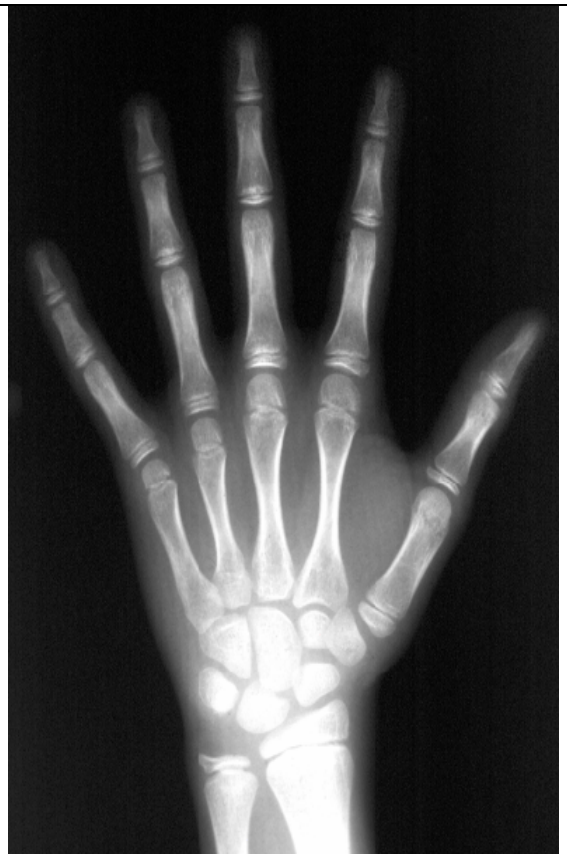

(4)

Figura 43 - Imagens carpais do sexo feminino utilizadas na Tabela 3

A idade obtida através do laudo médico para a imagens da Figura 43 foram: (1): 10,3 anos, (2): 11,6 anos, (3): 10,9 anos e para a imagem (4) foi de 11 anos. 
Na Figura 44, temos as imagens do sexo masculino, representadas pelos números de 5 a 8 da Tabela 3.

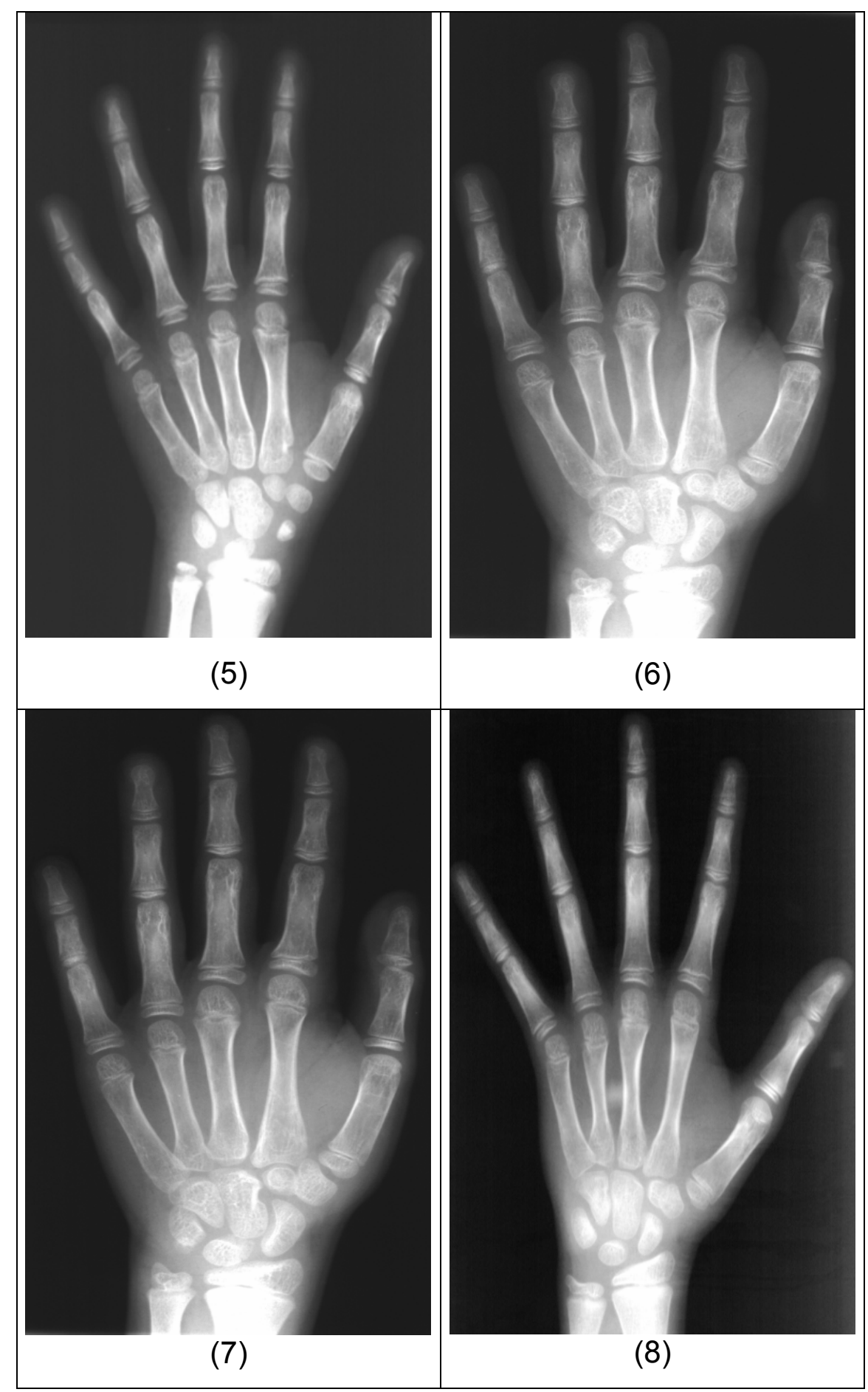

Figura 44 - Imagens carpais do sexo masculino utilizadas na Tabela 3 
A idade obtida através do laudo médico para a imagens da Figura 44 foram: (5): 10,9 anos, (6): 9,6 anos, (7): 10 anos e para a imagem (8) foi de 11,3 anos.

A Tabela 4, ilustra as combinações (num total de 10) obtidas entre estes ossos, tomados 2 a 2, para cada uma destas imagens, na mesma ordem em que foram apresentadas na Tabela 3.

Tabela 4 - Lista das combinações dos 5 centros de ossificação tomados 2 a 2

\begin{tabular}{|c|c|c|c|c|c|c|c|c|c|c|}
\hline & P1 e P2 & P1 e P3 & P1 E P4 & P1 E P5 & P2 E P3 & P2 E P4 & P2 E P5 & P3 E P4 & P3 E P5 & P4 E P5 \\
\hline 1 & 10,06 & 9,81 & 9,88 & 10,31 & 10,00 & 10,06 & 10,50 & 9,81 & 10,25 & 10,31 \\
\hline 2 & 11,63 & 11,94 & 11,30 & 11,75 & 11,56 & 10,93 & 11,38 & 11,24 & 11,69 & 11,05 \\
\hline 3 & 11,67 & 11,33 & 10,83 & 10,75 & 11,08 & 11,58 & 11,17 & 10,33 & 10,67 & 10,58 \\
\hline 4 & 10,63 & 10,88 & 10,63 & 11,25 & 11,00 & 11,25 & 10,88 & 10,88 & 10,63 & 11,25 \\
\hline 5 & 10,31 & 9,44 & 9,31 & 9,81 & 9,88 & 9,75 & 10,25 & 8,88 & 9,38 & 9,25 \\
\hline 6 & 9,81 & 10,00 & 10,38 & 10,19 & 9,44 & 9,81 & 9,63 & 10,00 & 9,81 & 10,19 \\
\hline 7 & 11,13 & 10,75 & 10,50 & 10,63 & 11,13 & 10,88 & 11,00 & 10,50 & 10,63 & 10,38 \\
\hline 8 & 10,44 & 10,06 & 11,06 & 10,32 & 10,63 & 11,63 & 10,88 & 11,25 & 10,51 & 11,51 \\
\hline
\end{tabular}

$\mathrm{Na}$ Tabela 5, são apresentadas as combinações (num total de 10) obtidas entre estes 5 ossos, tomados 3 a 3, para as 8 imagens da Tabela 3. Já na Tabela 6 , são mostrados os resultados das combinações destes ossos tomados 4 a 4 , totalizando 4 combinações.

Tabela 5 - Lista das combinações dos 5 centros de ossificação tomados 3a 3

\begin{tabular}{|c|c|c|c|c|c|c|c|c|c|c|c|}
\hline & P1 P2 P3 & P1 P2 P4 & P1 P2 P5 & P1 P4 P5 P1 P3 P5 P1 P3 P4 & P2 P3 P4 P2 P4 P5 P2 P3 P5 & P3 P4 P5 \\
\hline 1 & 9,96 & 10,00 & 10,29 & 10,17 & 10,13 & 9,83 & 9,96 & 10,29 & 10,25 & 10,13 \\
\hline 2 & 11,71 & 11,28 & 11,58 & 11,37 & 11,79 & 11,49 & 11,24 & 11,12 & 11,54 & 11,33 \\
\hline 3 & 13,75 & 14,08 & 13,63 & 14,08 & 13,75 & 14,21 & 13,96 & 13,83 & 13,50 & 13,96 \\
\hline 4 & 14,54 & 14,50 & 14,54 & 14,83 & 14,88 & 14,83 & 14,63 & 14,63 & 14,67 & 14,96 \\
\hline 5 & 9,88 & 9,79 & 10,13 & 9,46 & 9,54 & 9,21 & 9,50 & 9,75 & 9,83 & 9,17 \\
\hline 6 & 9,75 & 10,00 & 9,88 & 10,25 & 10,00 & 10,13 & 9,75 & 9,88 & 9,63 & 10,00 \\
\hline 7 & 11,00 & 10,83 & 10,92 & 10,50 & 10,67 & 10,58 & 10,83 & 10,75 & 10,92 & 10,50 \\
\hline 8 & 10,38 & 11,04 & 10,55 & 10,96 & 10,30 & 10,79 & 11,17 & 11,34 & 10,67 & 11,09 \\
\hline
\end{tabular}


Tabela 6 - Lista das combinações dos 5 centros de ossificação tomados 4 a 4

\begin{tabular}{|c|c|c|c|c|}
\hline & P1, P2, P3 E P4 & P1, P2, P3 E P5 & P2, P3, P4 E P5 & P1, P3, P4 E P5 \\
\hline 1 & 9,94 & 10,16 & 10,16 & 10,06 \\
\hline 2 & 10,00 & 10,13 & 10,18 & 10,07 \\
\hline 3 & 11,44 & 11,06 & 10,69 & 11,00 \\
\hline 4 & 10,91 & 10,72 & 10,91 & 11,19 \\
\hline 5 & 9,59 & 9,84 & 9,56 & 9,34 \\
\hline 6 & 9,91 & 9,81 & 9,81 & 10,09 \\
\hline 7 & 10,81 & 10,88 & 10,75 & 10,56 \\
\hline 8 & 10,84 & 10,47 & 11,07 & 10,79 \\
\hline
\end{tabular}

Na Tabela 7, é apresentada a média entre estes 5 ossos.

Tabela 7 - Média obtida entre os 5 centros de ossificação

\begin{tabular}{|l|c|}
\hline 1 & 10,10 \\
\hline 2 & 11,45 \\
\hline 3 & 11,00 \\
\hline 4 & 10,93 \\
\hline 5 & 9,63 \\
\hline 6 & 9,93 \\
\hline 7 & 10,75 \\
\hline 8 & 10,83 \\
\hline
\end{tabular}

Somando todas as combinações realizadas entre estes 5 centros de ossificação, apresentadas nas Tabelas de 4 a 7, obtêm-se um total de 25 possíveis combinações.

De posse destas combinações, foram gerados os gráficos de cada uma destas 8 imagens e, em seguida, escolhidos quais eram as que mais se aproximavam do valor do laudo médico, conforme explicado no capítulo 8. Estes gráficos são ilustrados nos apêndices seguintes. 


\section{APÊNDICE B - Gráficos gerados a partir das combinações para as imagens do sexo feminino}

Neste apêndice são apresentados os gráficos gerados através das combinações para o conjunto de imagens do sexo feminino, apresentadas no apêndice $A$.

O gráfico da Figura 45 ilustra os resultados obtidos pelas combinações para a primeira imagem do conjunto do sexo feminino.

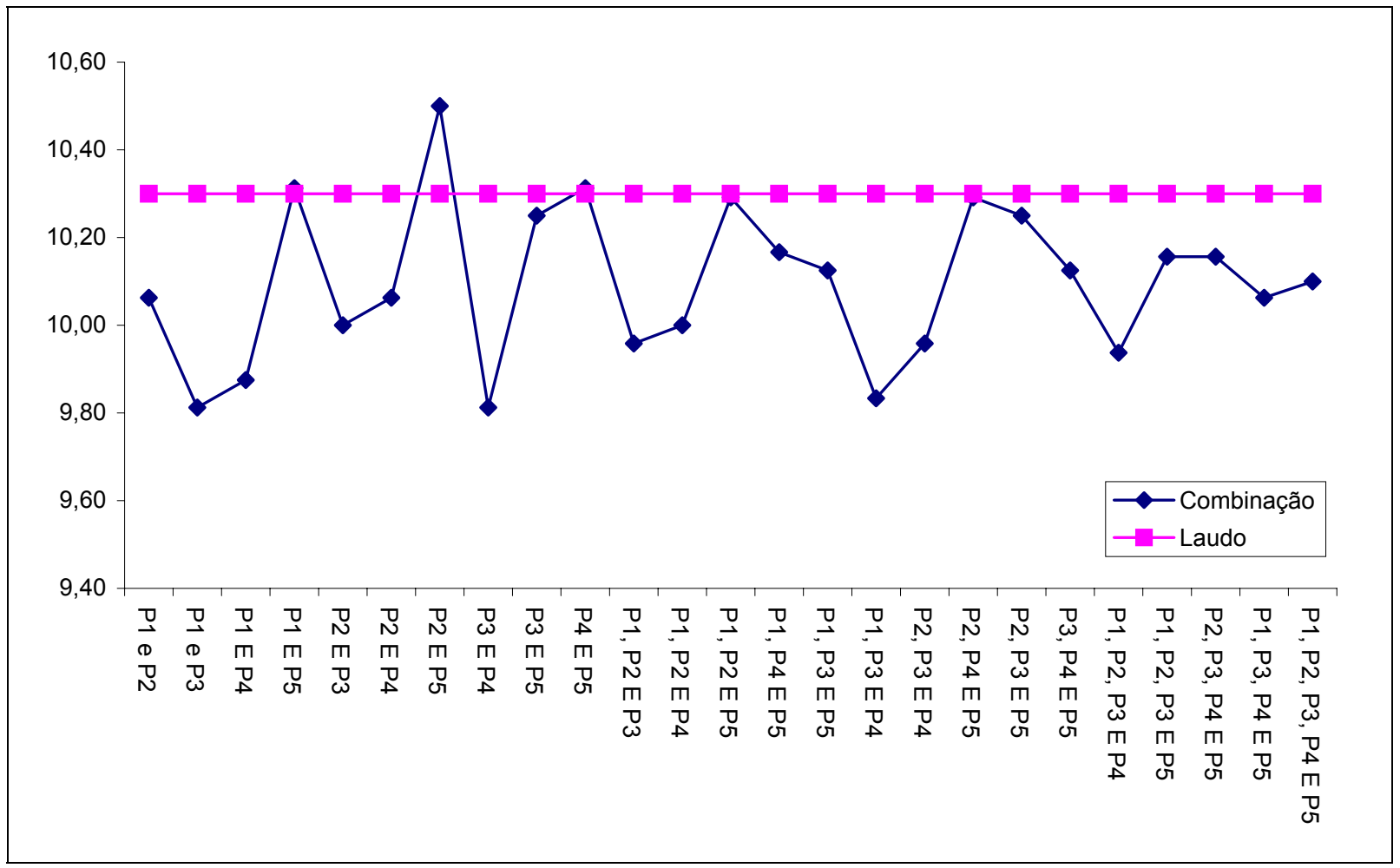

Figura 45 - Resultados obtidos por todas as combinações entre os centros de ossificação para a primeira imagem do sexo feminino 
Analisando o gráfico da Figura 45, nota-se que as combinações que mais se aproximaram do valor do laudo foram: (P1 e P5), (P3 e P5), (P1, P2 e P5) e (P2, P4 e P5).

No gráfico da Figura 46, temos os resultados das combinações para a segunda imagem do sexo feminino.

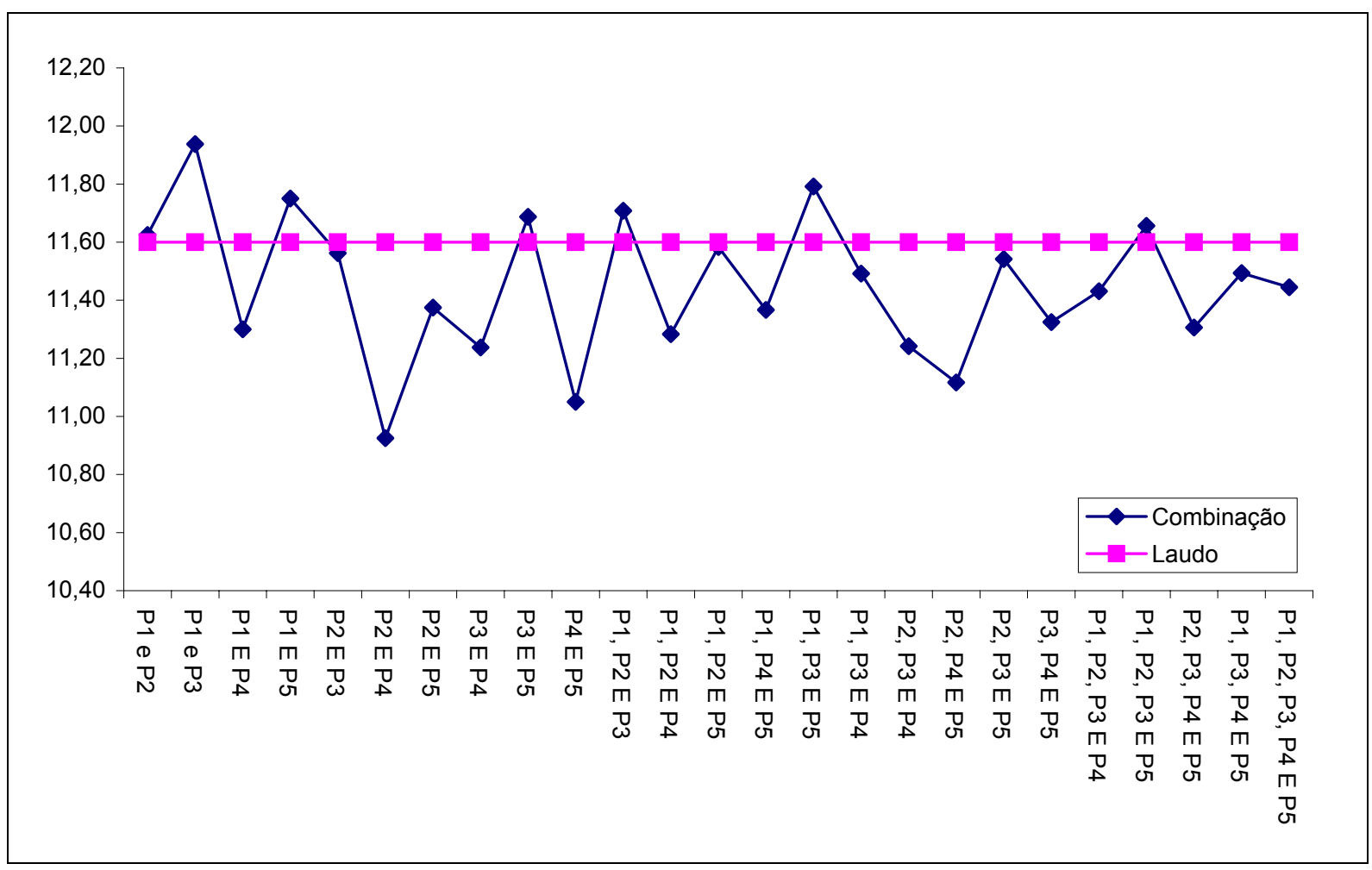

Figura 46 - Resultados obtidos por todas as combinações entre os centros de ossificação para a segunda imagem do sexo feminino

Observando o gráfico da Figura 46, escolheu-se as combinações (P1 e P2), (P2 e P3), (P1, P2 e P5) como as que se mais se aproximaram do valor do laudo.

No gráfico da Figura 47, são apresentados os resultados das combinações para a terceira imagem do sexo feminino. 


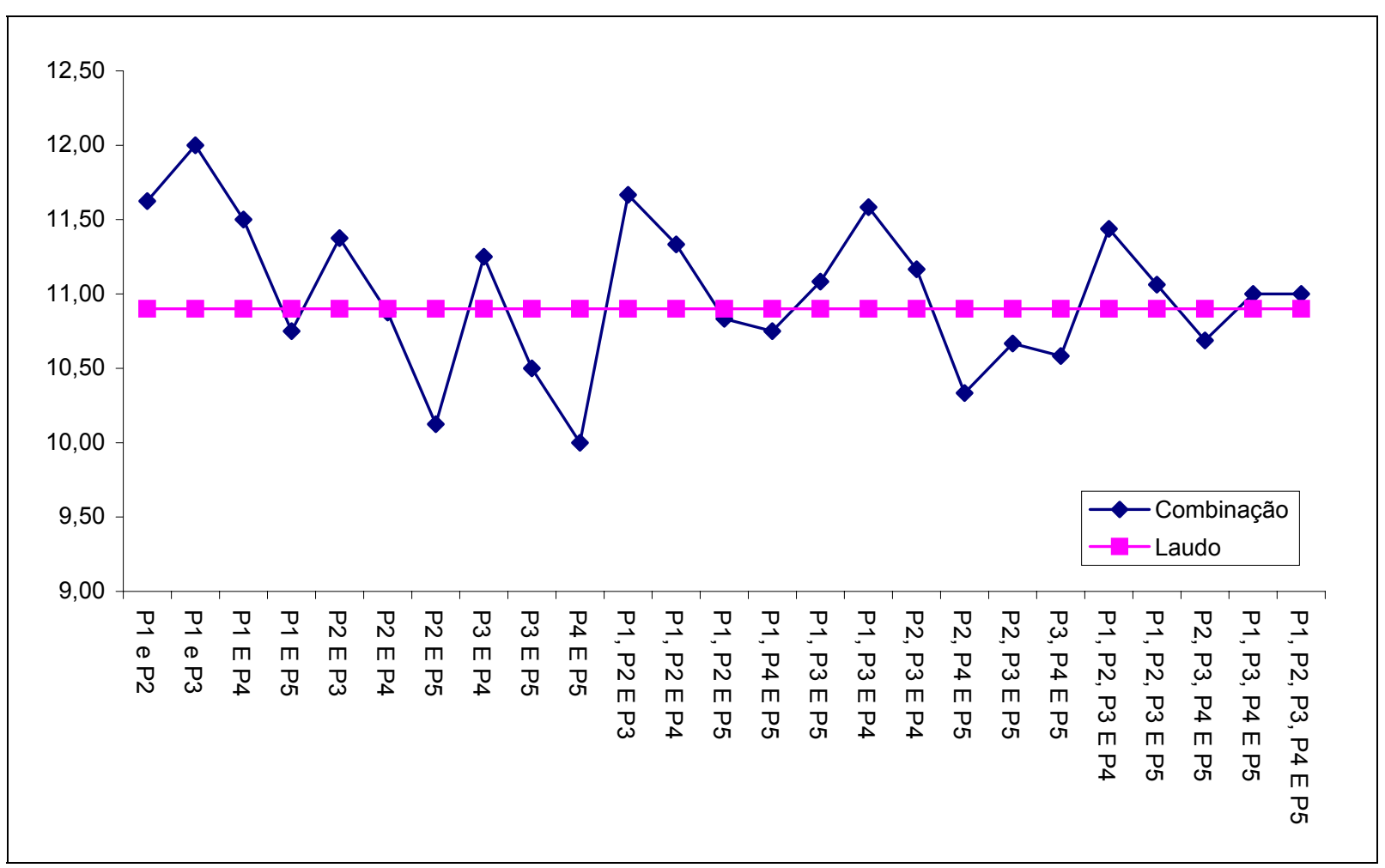

Figura 47 - Resultados obtidos por todas as combinações entre os centros de ossificação para a terceira imagem do sexo feminino

Analisando o gráfico da Figura 47, as combinações (P2 e P4), (P1, P2 e $\mathrm{P} 5)$, (P1, P3, P4 e P5) e (P1, P2, P3, P4 e P5) foram as que mais se aproximaram do valor do laudo.

No gráfico da Figura 48, são apresentados os resultados das combinações entre os 5 centros de ossificação para a última imagem do sexo feminino. 


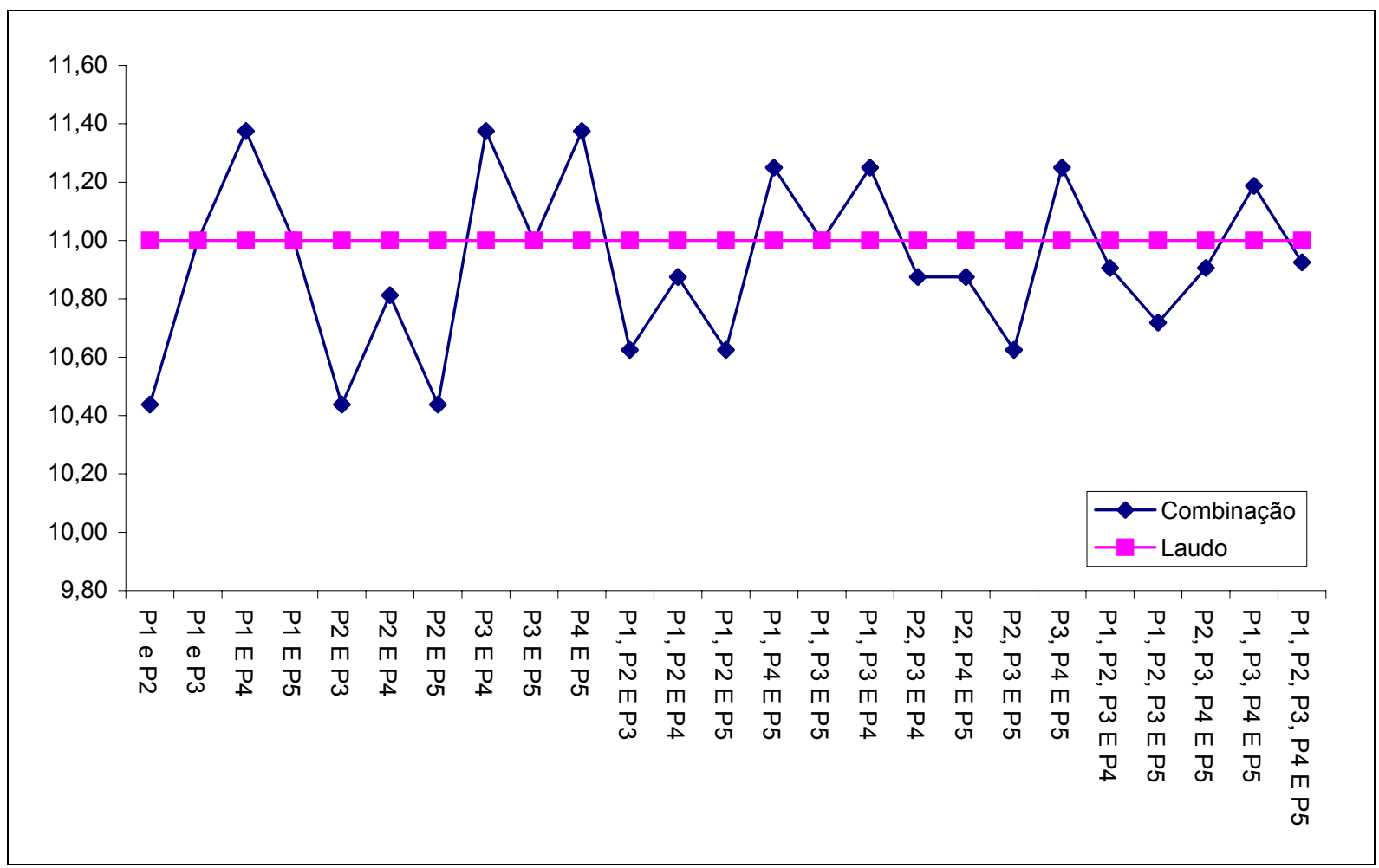

Figura 48 - Resultados obtidos por todas as combinações entre os centros de ossificação para a quarta imagem do sexo feminino

As combinações escolhidas para esta imagem, apresentadas na Figura 48, foram: (P1 e P5), (P3 e P5) e (P1, P3 e P5), finalizando a análise do conjunto de imagens do sexo feminino.

No apêndice C, são apresentados os gráficos para todas as imagens do sexo masculino. 


\section{APÊNDICE C - Gráficos gerados a partir das combinações para as imagens do sexo masculino}

Neste apêndice são apresentados os gráficos gerados através das combinações para o sexo masculino, representados pelas imagens de número 5 , 6, 7 e 8 respectivamente, do apêndice $A$.

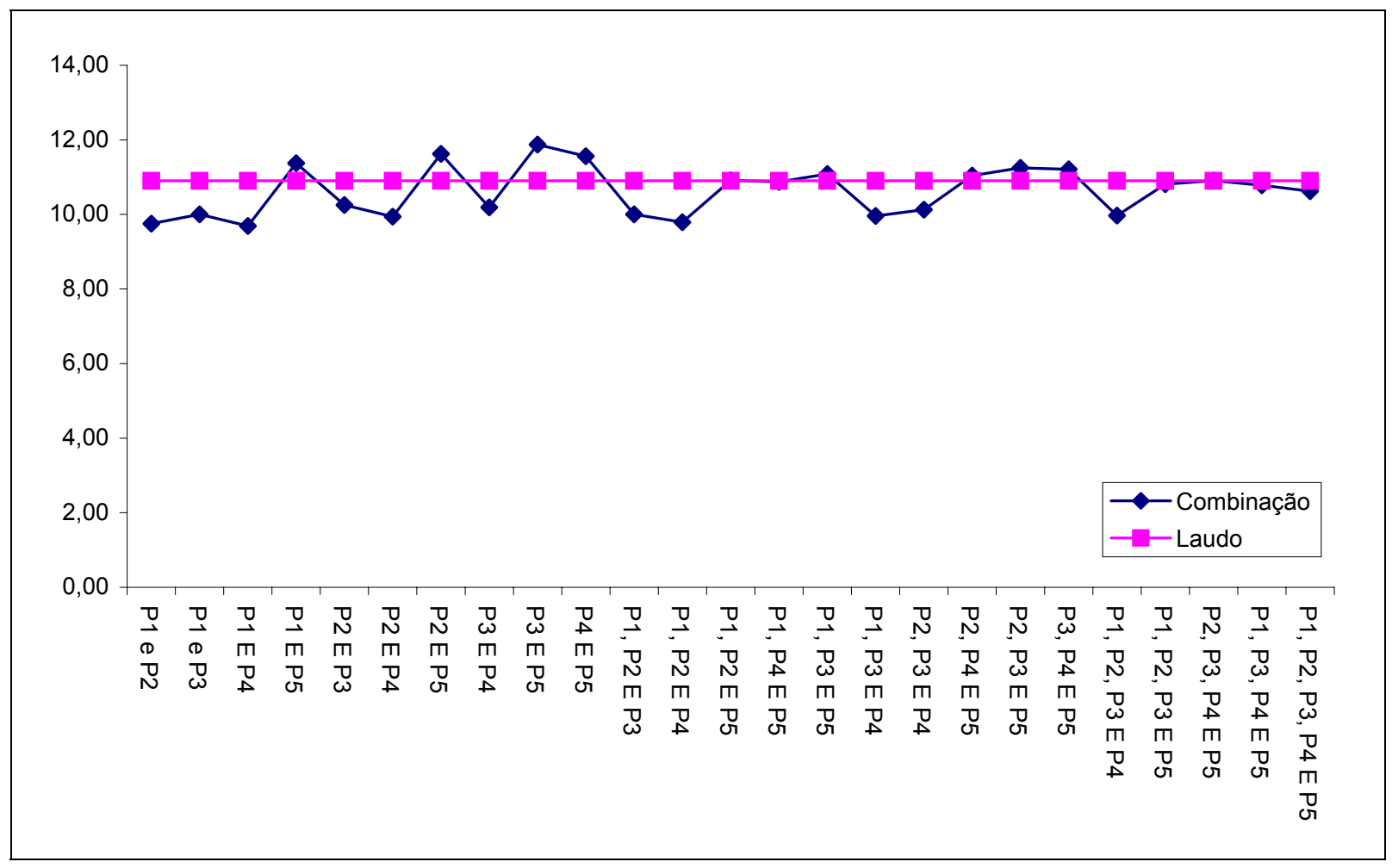

Figura 49 - Resultados obtidos por todas as combinações entre os centros de ossificação para a primeira imagem do sexo masculino 
Analisando o gráfico da Figura 49, nota-se que as combinações que mais se aproximaram do resultado do laudo médico foram: (P1, P2 e P5), (P1, P4 e P5), (P1, P3 e P5), (P2, P4 e P5), (P1, P2, P3 e P5), (P2, P3, P4 e P5), (P1, P3, P4 e P5) e (P1, P2, P3, P4 e P5).

No gráfico da Figura 50, temos os resultados das combinações para a segunda imagem do sexo masculino.

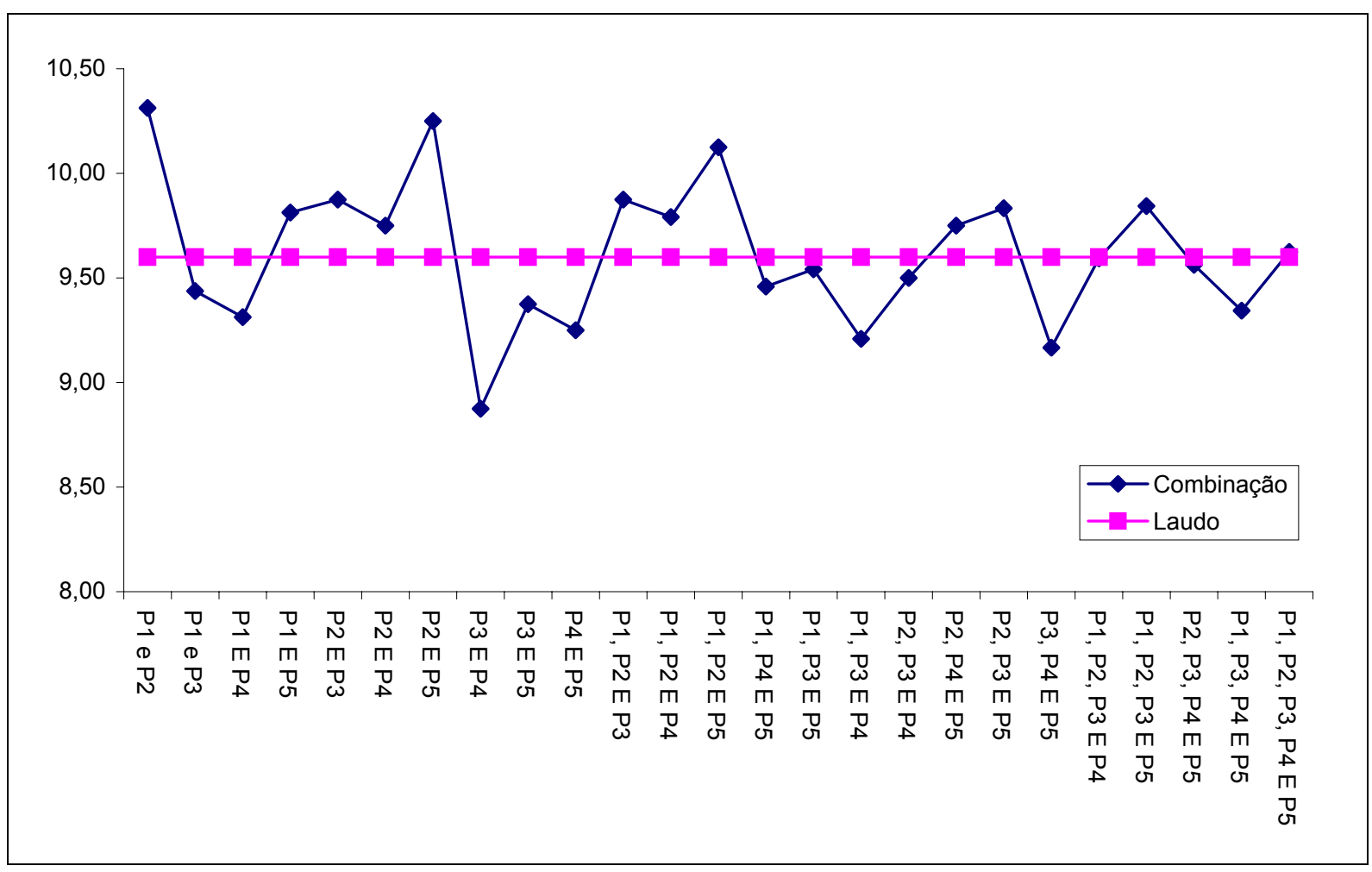

Figura 50 - Resultados obtidos por todas as combinações entre os centros de ossificação para a segunda imagem do sexo masculino

Observando o gráfico da Figura 50, foram selecionadas as combinações (P1, P3 e P5), (P1, P2, P3 e P4), (P2, P3, P4 e P5) e (P1, P2, P3, P4 e P5) como as que se mais se aproximaram do resultado do laudo médico.

No gráfico da Figura 51, são apresentados os resultados das combinações para a terceira imagem do sexo masculino. 


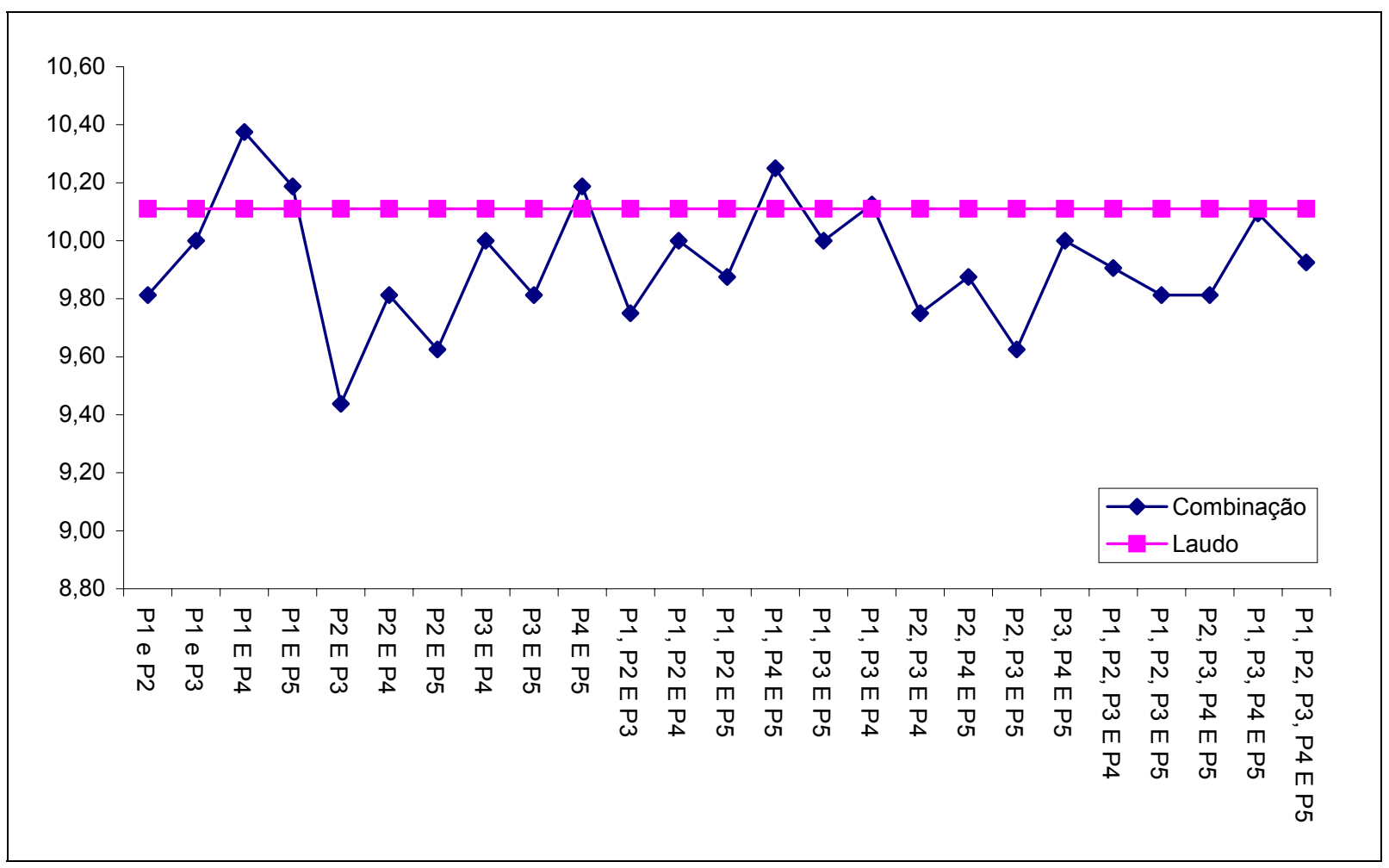

Figura 51 - Resultados obtidos por todas as combinações entre os centros de ossificação para a terceira imagem do sexo masculino

Analisando o gráfico da Figura 51, as combinações (P1, P3 e P4), (P1, P3, P4 e P5) foram as que mais se aproximaram do resultado do laudo médico.

No gráfico da Figura 52, são mostrados os resultados das combinações entre os 5 centros de ossificação para a última imagem do sexo masculino. 


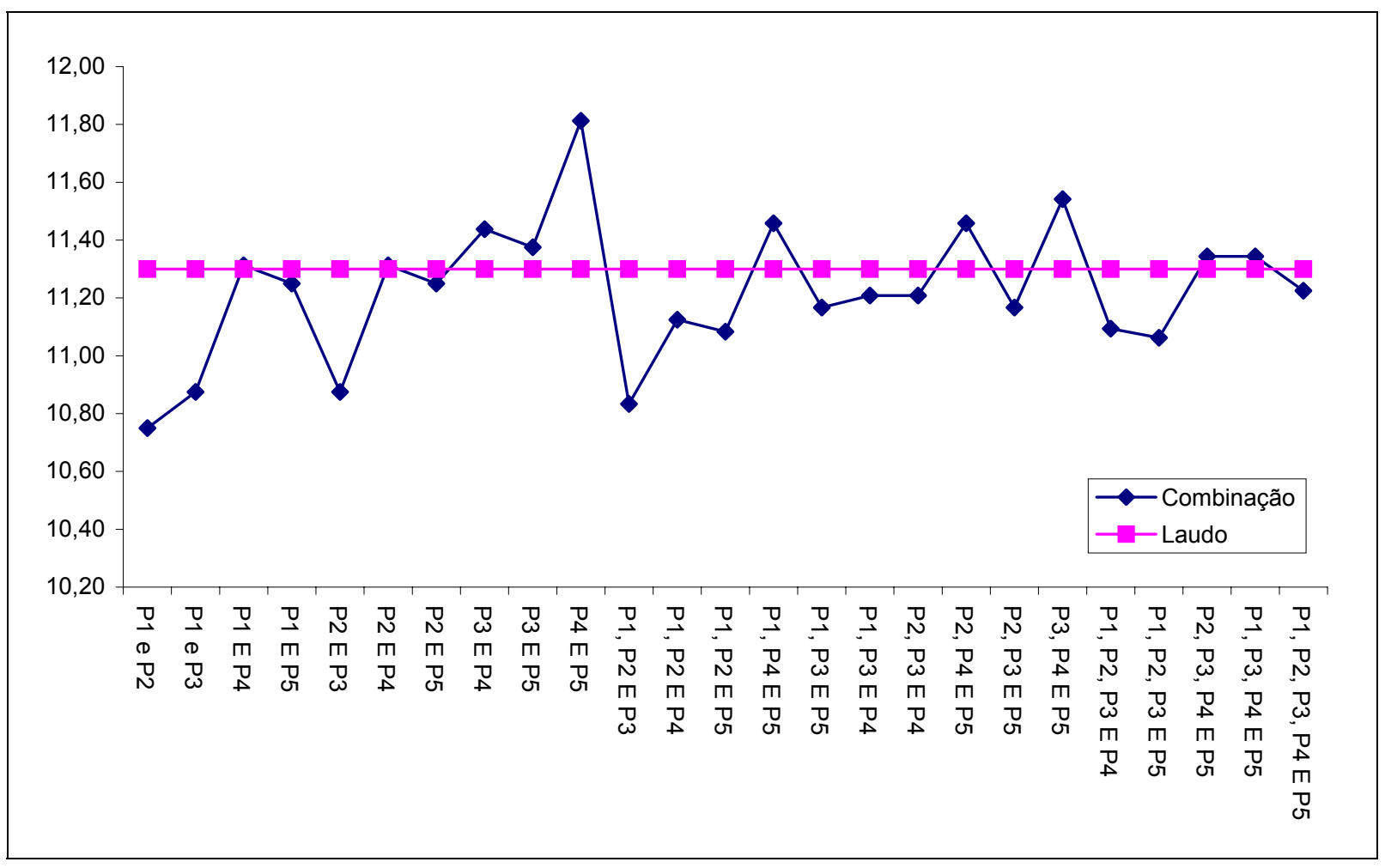

Figura 52 - Resultados obtidos por todas as combinações entre os centros de ossificação para a quarta imagem do sexo masculino

Utilizando o gráfico da Figura 52, escolheu-se as combinações representadas por: ( $\mathrm{P} 1$ e $\mathrm{P} 4)$, ( $\mathrm{P} 2$ e $\mathrm{P} 4)$, finalizando assim a análise do conjunto de imagens do sexo masculino.

Nos apêndices A e B foram mostrados os comportamentos, em relação ao laudo médico, de todas as combinações geradas a partir dos 5 centros de ossificação em análise (P1, P2, P3, P4 e P5). Para exemplificar, foram mostradas apenas 5 imagens do sexo feminino (apêndice A) e 5 do sexo masculino (apêndice B), mas esta análise foi feita em todas as imagens do banco de dados. Tomando estes 5 centros em 2 a 2, 3 a 3, 4 a 4 e, a média dos 5 centros, totalizou-se 26 combinações, ilustradas pelo eixo $X$ da Figura 52. Estas combinações serviram para verificar se era possível encontrar uma nova simplificação, ou seja, estimar a idade óssea analisando-se um número inferior a 5 ossos. Os resultados encontrados a partir desta análise estão descritos no item "Análise da simplificação proposta" do capítulo 8. 


\section{ANEXO A - Índices de Eklof \& Ringertz}

Tabela 8 - Índice de Eklof \& Ringertz para o sexo feminino

\begin{tabular}{|c|c|c|c|c|c|c|c|c|c|c|c|c|c|c|c|c|c|c|c|c|}
\hline \multirow{4}{*}{ Idade } & \multirow{2}{*}{\multicolumn{2}{|c|}{ Radio }} & \multicolumn{4}{|c|}{ Capitato } & \multicolumn{4}{|c|}{ Hamato } & \multicolumn{6}{|c|}{ Metacárpico } & \multicolumn{4}{|c|}{ Falange } \\
\hline & & & \multirow{2}{*}{\multicolumn{2}{|c|}{ Comp. }} & & & & & & & & & & & & & & & \\
\hline & & & & & & & & & & & & & & & & & & & & \\
\hline & & & & & & Max & & & & & & & & & & & & & & Max \\
\hline 00 & & & & & & & & & & & & & & & & & & & & \\
\hline 1,25 & & & & & & & & 9 & & 8 & & & & & & & & & & \\
\hline 1,50 & & & & & & & & & & & & & & & & & & & & \\
\hline 75 & 4,8 & & & & & & & & & & & & & & & 33 & 16 & 24 & 18 & \\
\hline 00 & 5 & & 5,7 & 13 & & 9 & & 9,8 & & & & & & & 21 & & 16,4 & & & 27,2 \\
\hline 2,25 & & & 6 & & & & & 10 & & 8,8 & & & & & & & 17 & & & 27,6 \\
\hline & & & & & & & & & & 9 & & & & & & & 17,2 & & 9,1 & \\
\hline 2 & & & & & & & & & & & & 41,4 & & & & & & & 19,5 & 28,5 \\
\hline & & & ,9 & & & & & & & & & & & 40 & 23,4 & & 7,9 & & 20 & 8,9 \\
\hline & 7,5 & & & & 5 & & & & & & & & & & 24 & & 8,3 & 26,6 & & 9,4 \\
\hline & 8 & & & & & & & 1 & & 9,8 & & & & 1,4 & & & 8,7 & 27 & & 9,8 \\
\hline & 8,5 & & & & & & 5,7 & & & 10 & 0,7 & 44,4 & & & 5,1 & & 9,1 & 27,4 & 1,3 & 0,3 \\
\hline & & & & & & & 6 & & & & 4 & 45,1 & & & 5,8 & & 9,5 & & & 0,7 \\
\hline 4 & & & 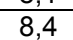 & 5,7 & & & & 1 & & & 2 &, 9 & & & 26,4 & & 9,9 & 8,2 & 2,2 & 1,1 \\
\hline & & & 8,7 & 11 & & & & & & & & 6,6 & & & 27 & & 0,3 & & 22,6 & 31,6 \\
\hline & & & 9 & & & & 6,8 & 12 & & 1 & & 47,3 & & 4,9 & 27,6 & & 0,7 & 29 & 23 & 32 \\
\hline & & & & & & & 7 & 12, & & & 34,4 & 48,1 & & & 8,2 & & 1,1 & & & 32,4 \\
\hline & & & & & & & & & & & & 8,8 & & 46,3 & 8,8 & 4 & & & 3,9 & 2,9 \\
\hline & & & & & & & & & & & & & & 47 & 29,4 & & & & 4,4 & 3,3 \\
\hline & & & & & & & & 13,7 & & & & 50,3 & & 47,7 & 30 & & 2,3 & & 4,8 & 3,8 \\
\hline & & & & & 7 & & & & & & 37,4 & & & & & & & 31 & 5,2 & 4,2 \\
\hline & & & & & & & & & & & & & & 4 & & & & & 5,7 & 4,6 \\
\hline & & & & & & & & & & & & & & & 1,8 & 4 & 3,5 & & 3,1 & 5,1 \\
\hline & & & & & & & & 14,8 & & & & & & & 32,4 & 4 & & & 6,6 & 35,5 \\
\hline & & & & & & & & 15 & & & 0,3 & 54 & & 51,3 & 33 & 2 & 4,3 & 32,6 & 27 & 36 \\
\hline & & & & & & & & & & & 1,1 & 54,8 & & 52 & 33,6 & & 24,7 & 33 & 7,4 & 6,4 \\
\hline & & & & & 8 & & & & & 13 & 1,8 & 5 & & 52,7 & 4,2 & 4 & 25 & & 7,9 & 6,8 \\
\hline & & & & & & & & & & & & 56,3 & & 3,4 & 4,8 & 7,3 & 5,4 & & & 37,3 \\
\hline & & & & & & & & & & & & 57 & & & 35,4 & 4 & 5,8 & & 8,7 & 37,7 \\
\hline & & & & & & & & & & & & & & & & & 6,2 & & & 38,1 \\
\hline & & & & & & &, 7 & & & & , 8 & 58,5 & & & 36,6 & & 26,6 & & 9,6 & 38,6 \\
\hline & & & & & & & & & & & & 59,2 & & & 37,2 & & 27 & & & 39 \\
\hline & & & & & & & & & & & & & & & & & & & & 39,5 \\
\hline & & & & & & & & & & & 47 & 60,7 & & & & & & & & 39,9 \\
\hline & & & & & & & & & & & 47,8 & & & & & & 8,2 & & & 40,3 \\
\hline & & & & & & & & & & & & 62,2 & & & & & & & & 10,8 \\
\hline & & & & & & & & & & & & & & 9,7 & 0,2 & & 29 & & & 41,2 \\
\hline & & & & & & & & & & & & 63,7 & & 0,4 & 0,8 & & 9,4 & 7,7 & 2,7 & 41,7 \\
\hline & & & & & & & & & & & & & & & 41,4 & & & & 3,1 & 42,1 \\
\hline & & & & & & & & & & & & & & & & & & & 33,6 & 42,5 \\
\hline & & & & & & & & & & & 52,2 & & & & 2,6 & & 30,6 & & 34 & 43 \\
\hline & & & & & & & & & & & & & & & & & & & 4,4 & $\overline{43,4}$ \\
\hline & & & & & & & & & & & & 7,4 & & & & & & 39,7 & 4,9 & 43,8 \\
\hline & & & & & & & & & & & & & & & 44,5 & & & & 5,3 & 44,3 \\
\hline & & & & & & & & & & & & & & 65,3 & & & & & 5,8 & 44,7 \\
\hline & & & & & & & & & & & & & & & 45,6 & & & & 6,2 & 45,2 \\
\hline & & & & & & & & & & & 0,7 & 70,4 & & 6,7 & 6,2 & & 9 & 41,2 & 6,6 & 45,6 \\
\hline & & & & & & & & & & & & & & 7,4 & 6,7 & & 3 & 41,6 & 7,1 & 46 \\
\hline & & & & & & & & & & & & 71, & & 8,1 & 47,3 & 9 & 3,7 & 42 & 7,5 & 46,5 \\
\hline & & & & & & & & 21 & & & 8,9 & 72,6 & & 8,8 & 47,9 & 0,5 & 4,1 & 42,4 & 7,9 & 46,9 \\
\hline &, 2 & & & 26,7 & & & & 21 , & & 17,8 & 9,7 & 73,4 & 5,9 & 69,6 & 48,5 & 6 & 4,5 & 2,8 & 8,4 & 47,4 \\
\hline & & & 19,1 & 27 & & & & 22 & & & & 74,1 & & 70,3 & 9,1 & 7 & 4,9 & 3,2 & 8,8 & 47,8 \\
\hline & & & & 27,3 & & & & 22,4 & & 18,2 & & 74,9 & 57,3 & 71 & 9,7 & 62,3 & 5,3 & 43,6 & 9,3 & 48,2 \\
\hline & 27,6 & & & & 12,8 & & 16,7 & 22,6 & & 18,4 & 1,9 & 75,6 & & 71,7 & 0,3 & 62,9 & 5,7 & 44 & 39,7 & 48,7 \\
\hline & 20 & & & & & 17 & & 22 & & & & 76,3 & 3,7 & 72,4 & 9 & 5 & 6,1 & 44,4 & 0,1 & 49,1 \\
\hline & 28,5 & & & 28,2 & & 18 & 17,2 & 23,2 & 14 & 18,8 & 63,4 & 77,1 & 59,4 & 73,1 & 51,5 & 64,1 & 36,5 & 44,5 & 40,6 & 49,6 \\
\hline 15,00 & 29 & 38,2 & 21,2 & 28,5 & 13,3 & 18,2 & 17,5 & 23,4 & 14,5 & 19 & 64,1 & 77,8 & 60,1 & 73,8 & 52,1 & 64,7 & 36,9 & 45,2 & 41 & 50 \\
\hline
\end{tabular}


Tabela 9 - Índice de Eklof \& Ringertz para o sexo masculino

\begin{tabular}{|c|c|c|c|c|c|c|c|c|c|c|c|c|c|c|c|c|c|c|c|c|}
\hline \multirow{4}{*}{ Idade } & \multirow{2}{*}{\multicolumn{2}{|c|}{ Radio }} & \multicolumn{4}{|c|}{ Capitato } & \multicolumn{4}{|c|}{ Hamato } & \multicolumn{6}{|c|}{ Metacárpico } & \multicolumn{4}{|c|}{ Falange } \\
\hline & & & & & $\mathrm{Co}$ & $\mathrm{mp}$. & & & & II & & & & & & & & \\
\hline & & & & & & & & & & & & & & & & & & & & \\
\hline & & & lin. & & Ain. & & & & Min. & & & & & & Min. & Max & Min. & & & Max \\
\hline 1,00 & 5 & & 7 & & & 8 & 2 & & & 7,4 & & & & & & & & & & \\
\hline 1,25 & & & 1 & & & & 2,2 & 8,4 & 3 & & 22 & 37 & & & & 31 & 3,9 & & & 71 \\
\hline & & & 4 & & & 4 & 2,5 & 8,7 & & 7,8 & & & & & 18,4 & & 4,4 & & 16 & 27 \\
\hline & & & 7 & & & 6 & 2,8 & 9 & & & & & & & 19 & & 4,7 & & & 878 \\
\hline 2 , & & & 1 & & & 8,8 & 3, & 9,3 & & & & & & & & & 5,1 & & & 8 \\
\hline & & &, 4 & 6, & & 9 & 3, & 9,6 & & & 25 & & & & & & 5,5 & & & 20 \\
\hline & & & 5 & & & 2 & 3,6 & 9,8 & & & & & & & & ; & & & 7,8 & 29,2 \\
\hline & & & 6,1 &, & & , & 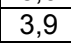 & 10, & & & & 41,4 & & & & & & & 8,2 & 9,6 \\
\hline & & & 6,4 & & & , & , & & & & & 42,1 & & & & & 10,0 & & 18,6 & 30,1 \\
\hline & & & 6,7 & & &,$c$ &, & 10,7 & & 9 & & & & & & & 17 & 27,6 & 19 & 0,5 \\
\hline & & & 7,1 & & & 10 & 4,8 & 11 & & 9,6 & & 43,6 & & 41,1 & 23,4 & & 17,4 & 28 & 19,5 & $\overline{0,9}$ \\
\hline & 7 & & 7,4 & & & & 5 & & & 9,8 & 9,4 & 44,4 & & 42 & 24 & & 7,8 & &, 9 & 1,3 \\
\hline & 7,5 & & 7,7 & & & & & & & 10 & & 5,1 & & 42,5 & 24,6 & & 8,1 & & & 1,8 \\
\hline & 8 & & 8,1 & & & & & & & & & & & 3,2 & & & & & & 32,2 \\
\hline & 8,5 & & 8, & & & & & & 5,8 & & 6 & 6 & & 3,9 & 5,9 & & & & 1,2 & 2,6 \\
\hline & $\mathrm{c}$ & & 8, & & 6 & & & & 6 & & 32,4 & 7,3 & & 4,1 & & &, 3 & & 2,6 & 33 \\
\hline & & & 0 & & & & & & & & & 3,1 & & & 7,1 & & & & 22 & 33,5 \\
\hline & & & & & & & 6,7 & & & & & & & 5,1 & 7,7 & 41 &, 1 & 0,6 & 22,5 & 3,9 \\
\hline & & & 9,7 & & & & 7 & 13 & & & & & 32 & 6,8 & 28,4 & 4 & & 31 & & 4,3 \\
\hline & & &, 1 & & & & & & & & & 50,3 & & 7,5 & 29 & & & & & 4,8 \\
\hline & & & & 17,7 & 7 & & & 13,8 & & 11,7 & & 51 & & 48,3 & 29,6 & 2,9 & 1,2 & & 3,7 & 5,2 \\
\hline & & &, 7 & 1 & & & & 14 & & 12 & & 1,8 & & 49 & & & 21,6 & & 4,2 & 35,6 \\
\hline & & & 11 & & & 12,2 & & 14,3 & & 2,2 & 37,6 & & & & & 1 & 22 & & 24,6 & 36 \\
\hline & & & 1,4 & & & 1 & & 14,6 & 7,8 & & 8,3 & 53,2 & & 0,4 & 1,5 & 4,8 & 22,4 & & 25 & 36,5 \\
\hline & & & 1,7 & & & 12 , & 8,7 & 14 & 8 & & & 54 & 36,3 & 1,1 & 2,1 & 45,4 & 2,7 & & 5,4 & 6,9 \\
\hline & & & & & & 12,8 & 9 & 15,2 & & 12,8 & 9,8 & 4,7 & 37 & 1,8 & 2,7 & 46 & 3,1 & 3,7 & 5,9 & 7,3 \\
\hline & & & & & & & & & & & & & & & & & & & & 7,7 \\
\hline & & & , 7 & 0 & & & & 15,7 & &, 3 & 1,3 & 0,2 & 3,4 & 53,3 & 34 & - & 3,9 & 4,5 & 6,7 & 38,2 \\
\hline & & & & & & & & 16 & & & 42 & & & 54 & 34,6 & & 4,3 & 4,8 & 77,2 & 38,6 \\
\hline & & & & & & & & & & & & & & & & & 4,7 & & 7,6 & 39 \\
\hline & & & & 2 & & & & & & & 3,5 & 3,4 & & & & & 25 & 35,6 & 20 & 39,4 \\
\hline & & & & & & & & & & & 44,2 & & 41,3 & & & & & & 28,4 & 39,9 \\
\hline & & & & & & & & & & & & & & & & & & & & 0,3 \\
\hline & & & & & & & & & & & & & 42,7 & & 7,7 & & & & & 0,7 \\
\hline & & & & & & & & 7,7 & & & & & & & 38,4 & & & 1 & 9,7 & 41,2 \\
\hline & & & & & & & & & & & & & & & & & 27 & & 0,1 & 41,6 \\
\hline & & & & & & & & & & & & & & & & & & & 30,6 & 42 \\
\hline & & & & & & & & & & & & & & & & & 27,7 & & 31 & 42 \\
\hline & & & & & & & & & & & & & 46,3 & & & & & & 31,4 & 42,9 \\
\hline & & & & & & & & & & & & & & & & & & & & 3,1 \\
\hline & & & & & & & & & & & & & & & & & & & 2,3 & 43,7 \\
\hline & & & & & & & & & & & & & & 63,3 & & & $\overline{9,2}$ & & 2,7 & 44,1 \\
\hline & & & & & & & & & & & & & & & 43,4 & & 29,6 & & 3,1 & 44,6 \\
\hline & & & & & & & & & & & & & & & 44 & & & 40,6 & 33,5 & 45 \\
\hline & & & & 25,7 & & & & & & & 3,9 & 68,9 & 0,6 & 5,5 & 44,6 & 9 & 0,4 & 41 & 34 & 45,5 \\
\hline & & & 18,7 & 26 & & & & 20,8 & & & & & & & 5,2 & & 0,8 & 1,4 & 4,4 & 15,9 \\
\hline & & & & & & & & & 12,8 & & & 70,3 & 52,1 & 6,9 & $.5,9$ & 9,1 & 1,2 & 1,7 & 4,8 & 6,3 \\
\hline & & & & 26,7 & & & & 1,3 & & & 6,1 & 71 & 52,8 & 7,6 & 46,5 & 9,8 & 1,5 & 2,1 & 5,3 & 46,7 \\
\hline & & & 19,7 & 27 & & & & & & 17,8 & 6,8 & & & 8,4 & 7,1 & 60,4 & 1,9 & 2,5 & 5,7 & 47,1 \\
\hline & & & & & & & 15,7 & & & & 7,6 & 72,5 & 54,2 & 9,1 & 7,7 & 61 & 2,3 & 2,9 & 6,1 & 47,6 \\
\hline & & &, 3 & 27,7 & & & & 2,2 & & 3,3 & 8,3 & 73,3 & 54,9 & 69,5 & 48,4 & 1,7 & 32,7 & 3,3 & 36,5 & 48 \\
\hline & & & 20,6 & 28 & & 17,8 & & 22,4 & & & 9,1 & 74 & 5,6 & 70,5 & 49 & 2,3 & 3,1 & 43,7 & 37 & 48,4 \\
\hline & & & 21 & 28,3 & & & & 22,7 & & 18,7 & 99,8 & 74,7 & 6,4 & 71,2 & 49,6 & 2,9 & 33,4 & 44 & 37,4 & 48,8 \\
\hline & & & 21,3 & 28,7 & & & & 23 & & & 0,5 & 75,5 & 57,1 & 72 & 0,2 & 3,5 & 33,8 & 4,4 & 77,8 & 9,3 \\
\hline & & & 21,6 & 29 & & & & 23,3 & & & 61,3 & 76,2 & 57,8 & 72,7 & 50,9 & 64,2 & 34,2 & 4,8 & 38,2 & 49,7 \\
\hline & 28,9 & & 22 & 29,3 & & & & 23,6 & 14,7 & 19 & 62 & 77 & 58,5 & 73,4 & 51,5 & 64,8 & 34,6 & 45,2 & 38,7 & 50,1 \\
\hline 15,00 & 29,4 & 40,1 & 22,3 & 29,6 & 13,9 & 18,8 & 17,7 & 23,9 & 4,9 & $y, 0$ & 52,7 & 77,7 & 59,2 & 74,1 & $\overline{52,1}$ & 55, & 35 & 45,6 & 39,1 & 50,6 \\
\hline
\end{tabular}


Tabela 10 - Pontos médios (medidas em $\mathrm{mm}$ ) e suas idades ósseas correspondentes para as medidas do índice de Eklof \& Ringertz, no sexo feminino

\begin{tabular}{|c|c|c|c|c|c|c|c|c|c|c|}
\hline \multirow{2}{*}{ Idade } & \multirow{2}{*}{ Radio } & \multicolumn{2}{|c|}{ Capitato } & \multicolumn{2}{|c|}{ Hamato } & \multicolumn{3}{|c|}{ Metacárpico } & \multicolumn{2}{|c|}{ Falange } \\
\hline & & Comp. & Larg. & Comp. & Larg. & II & III & IV & II & III \\
\hline & 1 & 2 & 3 & 4 & 5 & 6 & 7 & 8 & 9 & 10 \\
\hline 1,00 & 8,05 & 8,15 & 5,85 & 5,75 & 5,55 & 29,35 & 27,55 & 24,9 & 18,95 & 20,95 \\
\hline 1,25 & 8,55 & 8,45 & 6,05 & 6,05 & 5,75 & 30,05 & 28,25 & 25,5 & 19,35 & 21,4 \\
\hline 1,50 & 9 & 8,75 & 6,25 & 6,3 & 5,95 & 30,85 & 28,95 & 26,1 & 19,75 & 21,8 \\
\hline 1,75 & 9,45 & 9,05 & 6,35 & 6,55 & 6,15 & 31,55 & 29,65 & 26,7 & 20 & 22,45 \\
\hline 2,00 & 9,75 & 9,35 & 6,55 & 6,85 & 6,35 & 32,35 & 30,35 & 27,3 & 20,55 & 22,7 \\
\hline 2,25 & 10,35 & 9,65 & 6,75 & 7,05 & 6,55 & 33,05 & 31,05 & 27,9 & 21,05 & 23,15 \\
\hline 2,50 & 10,8 & 9,85 & 6,95 & 7,35 & 6,75 & 33,8 & 31,75 & 28,5 & 21,35 & 23,6 \\
\hline 2,75 & 11,25 & 10,25 & 7,1 & 7,6 & 6,95 & 34,55 & 32,45 & 29,1 & 21,7 & 24 \\
\hline 3,00 & 11,75 & 10,55 & 7,25 & 7,85 & 7,15 & 35,25 & 33,15 & 29,65 & 22,1 & 24,45 \\
\hline 3,25 & 12,25 & 10,85 & 7,45 & 8,15 & 7,35 & 36,05 & 33,85 & 30,25 & 22,45 & 24,9 \\
\hline 3,50 & 12,65 & 11,15 & 7,65 & 8,4 & 7,55 & 36,75 & 34,55 & 30,85 & 22,85 & 25,35 \\
\hline 3,75 & 13,1 & 11,45 & 7,8 & 8,65 & 7,75 & 37,55 & 35,25 & 31,4 & 23,25 & 25,8 \\
\hline 4,00 & 13,55 & 11,75 & 7,95 & 8,95 & 7,95 & 38,25 & 35,95 & 32,05 & 23,65 & 26,2 \\
\hline 4,25 & 14 & 12,05 & 8,15 & 9,15 & 8,15 & 39,05 & 36,65 & 32,65 & 24,05 & 26,65 \\
\hline 4,50 & 14,45 & 12,35 & 8,35 & 9,45 & 8,35 & 39,75 & 37,4 & 33,25 & 24,45 & 27,1 \\
\hline 4,75 & 14,9 & 12,65 & 8,5 & 9,75 & 8,55 & 40,45 & 38,1 & 33,85 & 24,85 & 27,5 \\
\hline 5,00 & 15,35 & 12,95 & 8,7 & 9,95 & 8,75 & 41,25 & 38,8 & 34,45 & 25,25 & 27,95 \\
\hline 5,25 & 15,8 & 13,25 & 8,85 & 10,25 & 8,95 & 41,95 & 39,5 & 35,05 & 25,65 & 28,4 \\
\hline 5,50 & 16,3 & 13,55 & 9,05 & 10,5 & 9,15 & 42,75 & 40,2 & 35,65 & 26,05 & 28,85 \\
\hline 5,75 & 16,75 & 13,8 & 9,25 & 10,75 & 9,35 & 43,45 & 40,9 & 36,25 & 26,45 & 29,3 \\
\hline 6,00 & 17,2 & 14,1 & 9,4 & 11,05 & 9,55 & 44,25 & 41,65 & 36,85 & 26,85 & 29,7 \\
\hline 6,25 & 17,65 & 14,4 & 9,55 & 11,25 & 9,75 & 44,95 & 42,35 & 37,45 & 27,25 & 30,15 \\
\hline 6,50 & 18,1 & 14,7 & 9,75 & 11,55 & 9,95 & 45,7 & 43,05 & 38,05 & 27,65 & 30,6 \\
\hline 6,75 & 18,55 & 15 & 9,95 & 11,85 & 10,15 & 46,45 & 43,75 & 38,65 & 28,05 & 31,05 \\
\hline 7,00 & 19 & 15,3 & 10,1 & 12,05 & 10,35 & 47,15 & 44,45 & 39,25 & 28,45 & 31,5 \\
\hline 7,25 & 19,45 & 15,6 & 10,25 & 12,35 & 10,55 & 47,95 & 45,15 & 39,85 & 28,85 & 31,9 \\
\hline 7,50 & 19,9 & 15,9 & 10,45 & 12,6 & 10,75 & 48,65 & 45,85 & 40,45 & 29,15 & 32,35 \\
\hline 7,75 & 20,4 & 16,2 & 10,65 & 12,85 & 10,95 & 49,45 & 46,55 & 41,05 & 29,55 & 32,8 \\
\hline 8,00 & 20,85 & 16,5 & 10,8 & 13,15 & 11,15 & 50,15 & 47,25 & 41,65 & 29,95 & 33,2 \\
\hline 8,25 & 21,3 & 16,8 & 11 & 13,3 & 11,35 & 50,9 & 47,95 & 42,25 & 30,35 & 33,65 \\
\hline 8,50 & 21,75 & 17,1 & 11,15 & 13,65 & 11,55 & 51,65 & 48,65 & 42,85 & 30,75 & 34,1 \\
\hline 8,75 & 22,2 & 17,4 & 11,35 & 13,95 & 11,75 & 52,35 & 49,35 & 43,45 & 31,15 & 34,55 \\
\hline 9,00 & 22,65 & 17,7 & 11,5 & 14,15 & 11,95 & 53,15 & 50,05 & 44,05 & 31,55 & 35 \\
\hline 9,25 & 23,1 & 18 & 11,7 & 14,45 & 12,15 & 53,85 & 50,75 & 44,65 & 31,95 & 35,4 \\
\hline 9,50 & 23,55 & 18,3 & 11,85 & 14,7 & 12,35 & 54,65 & 51,45 & 45,25 & 32,35 & 35,85 \\
\hline 9,75 & 24 & 18,6 & 12,05 & 14,95 & 12,55 & 55,35 & 52,15 & 45,85 & 32,75 & 36,3 \\
\hline 10,00 & 24,5 & 18,9 & 12,25 & 15,25 & 12,75 & 56,15 & 52,85 & 46,45 & 33,15 & 36,75 \\
\hline 10,25 & 24,95 & 19,2 & 12,4 & 15,45 & 12,95 & 56,85 & 53,55 & 47,05 & 33,55 & 37,2 \\
\hline 10,50 & 25,4 & 19,5 & 12,55 & 15,75 & 13,15 & 57,55 & 54,25 & 47,65 & 33,95 & 37,6 \\
\hline 10,75 & 25,85 & 19,8 & 12,75 & 16,05 & 13,35 & 58,35 & 54,95 & 48,25 & 34,35 & 38,05 \\
\hline 11,00 & 26,3 & 20,1 & 12,95 & 16,25 & 13,55 & 59,05 & 55,65 & 48,85 & 34,75 & 38,5 \\
\hline 11,25 & 26,75 & 20,4 & 13,1 & 16,55 & 13,75 & 59,85 & 56,35 & 49,45 & 35,15 & 38,9 \\
\hline 11,50 & 27,2 & 20,7 & 13,25 & 16,8 & 13,95 & 60,55 & 57,05 & 50,05 & 35,55 & 39,35 \\
\hline 11,75 & 27,65 & 21 & 13,45 & 17,05 & 14,15 & 61,35 & 57,7 & 50,7 & 35,85 & 39,8 \\
\hline 12,00 & 28,1 & 21,3 & 13,65 & 17,35 & 14,35 & 62,05 & 58,45 & 51,25 & 36,25 & 40,25 \\
\hline 12,25 & 28,55 & 21,55 & 13,8 & 17,55 & 14,55 & 62,75 & 59,15 & 51,85 & 36,65 & 40,7 \\
\hline 12,50 & 29,05 & 21,85 & 14 & 17,85 & 14,75 & 63,55 & 59,85 & 52,45 & 37,05 & 41,1 \\
\hline 12,75 & 29,55 & 22,15 & 14,15 & 18,1 & 14,95 & 64,25 & 60,55 & 53 & 37,45 & 41,55 \\
\hline 13,00 & 29,95 & 22,45 & 14,35 & 18,35 & 15,15 & 65,05 & 61,25 & 53,6 & 37,85 & 42 \\
\hline 13,25 & 30,4 & 22,75 & 14,55 & 18,65 & 15,35 & 65,75 & 62 & 54,2 & 38,25 & 42,4 \\
\hline 13,50 & 30,85 & 23,05 & 14,7 & 18,9 & 15,55 & 66,55 & 62,75 & 54,8 & 38,65 & 42,9 \\
\hline 13,75 & 31,2 & 23,35 & 14,85 & 19,15 & 15,75 & 67,25 & 63,45 & 55,4 & 39,05 & 43,3 \\
\hline 14,00 & 31,75 & 23,65 & 15,05 & 19,45 & 15,95 & 68 & 64,15 & 56 & 39,45 & 43,75 \\
\hline 14,25 & 32,25 & 23,95 & 15,25 & 19,65 & 16,15 & 68,75 & 64,85 & 56,6 & 39,85 & 44,2 \\
\hline 14,50 & 32,65 & 24,25 & 15,4 & 19,95 & 16,35 & 69,45 & 65,55 & 57,2 & 40,25 & 44,6 \\
\hline 14,75 & 33,15 & 24,55 & 15,55 & 20,2 & 16,55 & 70,25 & 66,25 & 57,8 & 40,5 & 45,1 \\
\hline 15,00 & 33,6 & 24,85 & 15,75 & 20,45 & 16,75 & 70,95 & 66,95 & 58,4 & 41,05 & 45,5 \\
\hline
\end{tabular}


Tabela 11 - Pontos médios (medidas em $\mathrm{mm}$ ) e suas idades ósseas correspondentes para as medidas do índice de Eklof \& Ringertz, no sexo masculino

\begin{tabular}{|c|c|c|c|c|c|c|c|c|c|c|}
\hline \multirow{2}{*}{ Idade } & \multirow{2}{*}{ Radio } & \multicolumn{2}{|c|}{ Capitato } & \multicolumn{2}{|c|}{ Hamato } & \multicolumn{3}{|c|}{ Metacárpico } & \multicolumn{2}{|c|}{ Falange } \\
\hline & & Comp. & Larg. & Comp. & Larg. & II & III & IV & II & III \\
\hline & 1 & 2 & 3 & 4 & 5 & 6 & 7 & 8 & 9 & 10 \\
\hline 1,00 & 6,85 & 7,4 & 5,55 & 5,1 & 5,1 & 28,75 & 26,45 & 23,75 & 18,8 & 20,95 \\
\hline 1,25 & 7,35 & 7,75 & 5,75 & 5,3 & 5,3 & 29,5 & 27,15 & 24,35 & 19,2 & 21,35 \\
\hline 1,50 & 7,85 & 8,1 & 5,95 & 5,6 & 5,5 & 30,2 & 27,9 & 25 & 19,65 & 21,75 \\
\hline 1,75 & 8,35 & 8,4 & 6,15 & 5,9 & 5,75 & 30,95 & 28,65 & 25,45 & 20 & 22,2 \\
\hline 2,00 & 8,85 & 8,75 & 6,35 & 6,2 & 5,95 & 31,7 & 29,35 & 25,95 & 20,4 & 22,65 \\
\hline 2,25 & 9,35 & 9,1 & 6,55 & 6,5 & 6,15 & 32,45 & 30,05 & 26,85 & 20,8 & 23,05 \\
\hline 2,50 & 9,9 & 9,4 & 6,75 & 6,7 & 6,4 & 33,2 & 30,75 & 27,5 & 21,1 & 23,5 \\
\hline 2,75 & 10,35 & 9,75 & 6,95 & 7 & 6,6 & 33,9 & 31,5 & 28,25 & 21,5 & 23,9 \\
\hline 3,00 & 10,85 & 10,05 & 7,15 & 7,3 & 6,8 & 34,65 & 32,2 & 28,75 & 21,9 & 24,35 \\
\hline 3,25 & 11,35 & 10,4 & 7,35 & 7,6 & 7,05 & 35,4 & 32,95 & 29,35 & 22,3 & 24,75 \\
\hline 3,50 & 11,85 & 10,75 & 7,5 & 7,9 & 7,25 & 36,15 & 33,85 & 30 & 22,7 & 25,2 \\
\hline 3,75 & 12,35 & 11,05 & 7,65 & 8,1 & 7,5 & 36,9 & 34,45 & 30,65 & 23,05 & 25,6 \\
\hline 4,00 & 12,85 & 11,4 & 7,85 & 8,4 & 7,7 & 37,65 & 34,85 & 31,25 & 23,4 & 26,05 \\
\hline 4,25 & 13,35 & 11,75 & 8,05 & 8,7 & 7,9 & 38,35 & 35,8 & 31,85 & 23,8 & 26,45 \\
\hline 4,50 & 13,85 & 12,05 & 8,25 & 9 & 8,1 & 39,1 & 36,35 & 32,5 & 24,2 & 26,9 \\
\hline 4,75 & 14,35 & 12,4 & 8,45 & 9,3 & 8,35 & 39,85 & 36,6 & 33,15 & 24,6 & 27,8 \\
\hline 5,00 & 14,85 & 12,75 & 8,65 & 9,55 & 8,55 & 40,6 & 37,95 & 33,75 & 25 & 27,75 \\
\hline 5,25 & 15,35 & 13,05 & 8,85 & 9,8 & 8,8 & 41,35 & 38,65 & 34,35 & 25,35 & 28,2 \\
\hline 5,50 & 15,85 & 13,4 & 9,05 & 10,1 & 9 & 42,05 & 39,4 & 35 & 25,7 & 28,6 \\
\hline 5,75 & 16,35 & 13,75 & 9,25 & 10,4 & 9,2 & 42,8 & 40,1 & 35,65 & 26,1 & 29,05 \\
\hline 6,00 & 16,85 & 14,05 & 9,45 & 10,7 & 9,4 & 43,55 & 40,85 & 36,25 & 26,5 & 29,45 \\
\hline 6,25 & 17,35 & 14,35 & 9,65 & 10,95 & 9,65 & 44,3 & 41,55 & 36,85 & 26,9 & 29,9 \\
\hline 6,50 & 17,85 & 14,7 & 9,75 & 11,2 & 9,85 & 45,05 & 42,25 & 37,5 & 27,25 & 30,3 \\
\hline 6,75 & 18,35 & 15,05 & 9,95 & 11,5 & 10,1 & 45,75 & 43 & 38,15 & 27,65 & 30,75 \\
\hline 7,00 & 18,8 & 15,35 & 10,15 & 11,8 & 10,3 & 46,55 & 43,7 & 38,75 & 28 & 31,15 \\
\hline 7,25 & 19,3 & 15,7 & 10,35 & 12,1 & 10,5 & 47,25 & 44,4 & 39,35 & 28,4 & 31,6 \\
\hline 7,50 & 19,8 & 16,05 & 10,55 & 12,35 & 10,7 & 48 & 45,15 & 40 & 28,8 & 32 \\
\hline 7,75 & 20,3 & 16,35 & 10,75 & 12,6 & 10,95 & 48,75 & 45,85 & 40,65 & 29,2 & 32,45 \\
\hline 8,00 & 20,8 & 16,7 & 10,95 & 12,9 & 11,15 & 49,45 & 46,55 & 41,25 & 29,55 & 32,9 \\
\hline 8,25 & 21,3 & 17,05 & 11,15 & 13,2 & 11,4 & 50,25 & 47,3 & 41,85 & 29,95 & 33,3 \\
\hline 8,50 & 21,8 & 17,35 & 11,35 & 13,5 & 11,6 & 50,95 & 48 & 42,5 & 30,3 & 33,7 \\
\hline 8,75 & 22,3 & 17,7 & 11,55 & 13,75 & 11,8 & 51,7 & 48,7 & 43,15 & 30,7 & 34,15 \\
\hline 9,00 & 22,8 & 18,05 & 11,75 & 14 & 12 & 52,45 & 49,45 & 43,75 & 31,1 & 34,6 \\
\hline 9,25 & 23,3 & 18,35 & 11,95 & 14,3 & 12,25 & 53,2 & 50,15 & 44,35 & 31,3 & 35 \\
\hline 9,50 & 23,8 & 18,7 & 12,1 & 14,6 & 12,5 & 53,95 & 50,85 & 45 & 31,85 & 35,45 \\
\hline 9,75 & 24,3 & 19,05 & 12,25 & 14,9 & 12,75 & 54,65 & 51,6 & 45,65 & 32,3 & 35,85 \\
\hline 10,00 & 24,8 & 19,35 & 12,45 & 15,15 & 12,9 & 55,4 & 52,3 & 45,9 & 32,9 & 36,3 \\
\hline 10,25 & 25,3 & 19,65 & 12,65 & 15,4 & 13,1 & 56,15 & 53,05 & 46,85 & 33 & 36,5 \\
\hline 10,50 & 25,8 & 20 & 12,85 & 15,7 & 13,3 & 56,9 & 53,75 & 47,5 & 33,4 & 37,15 \\
\hline 10,75 & 26,3 & 20,35 & 13,05 & 16 & 13,55 & 57,65 & 54,45 & 48,15 & 33,8 & 37,45 \\
\hline 11,00 & 26,8 & 20,65 & 13,25 & 16,3 & 13,8 & 58,35 & 55,2 & 48,75 & 34,15 & 38 \\
\hline 11,25 & 27,25 & 21 & 13,45 & 16,55 & 14 & 59,1 & 55,9 & 49,35 & 34,5 & 38,4 \\
\hline 11,50 & 27,75 & 21,35 & 13,65 & 16,8 & 14,2 & 59,85 & 56,6 & 50 & 34,9 & 38,85 \\
\hline 11,75 & 28,25 & 21,65 & 13,85 & 17,1 & 14,4 & 60,6 & 57,35 & 50,65 & 35,3 & 39,25 \\
\hline 12,00 & 28,75 & 22 & 14,05 & 17,4 & 14,65 & 61,4 & 58,05 & 51,25 & 35,7 & 39,75 \\
\hline 12,25 & 29,25 & 22,35 & 14,25 & 17,7 & 14,85 & 62,1 & 58,75 & 51,85 & 36,1 & 40,15 \\
\hline 12,50 & 29,75 & 22,65 & 14,4 & 17,95 & 15,1 & 62,85 & 59,5 & 52,5 & 36,45 & 40,55 \\
\hline 12,75 & 30,25 & 23 & 14,55 & 18,2 & 15,3 & 63,55 & 60,2 & 53,15 & 36,8 & 41 \\
\hline 13,00 & 30,75 & 23,35 & 14,75 & 18,5 & 15,5 & 64,3 & 60,9 & 53,75 & 37,2 & 41,4 \\
\hline 13,25 & 31,25 & 23,65 & 14,95 & 18,8 & 15,7 & 65,05 & 61,65 & 54,35 & 37,6 & 41,85 \\
\hline 13,50 & 31,75 & 24 & 15,15 & 19,1 & 15,95 & 65,8 & 62,2 & 55,05 & 38 & 42,25 \\
\hline 13,75 & 32,25 & 24,3 & 15,35 & 19,35 & 16,15 & 66,55 & 63,05 & 55,65 & 38,4 & 42,7 \\
\hline 14,00 & 32,75 & 24,65 & 15,55 & 19,6 & 16,4 & 67,25 & 63,8 & 56,25 & 38,7 & 43,1 \\
\hline 14,25 & 33,25 & 25 & 15,75 & 19,9 & 16,6 & 68 & 64,55 & 56,85 & 39,1 & 43,55 \\
\hline 14,50 & 33,75 & 25,3 & 15,95 & 20,2 & 16,8 & 68,75 & 65,25 & 57,55 & 39,5 & 43,95 \\
\hline 14,75 & 34,25 & 25,65 & 16,15 & 20,5 & 17 & 69,5 & 65,95 & 58,15 & 39,9 & 44,4 \\
\hline 15,00 & 34,75 & 25,95 & 16,35 & 20,8 & 17,25 & 70,2 & 66,65 & 58,75 & 40,3 & 44,85 \\
\hline
\end{tabular}

Fonte: Tavano (2001) 